\title{
General-Purpose Heat Source Safety Verification Test Series: SVT-1 Through SVT-6
}

D. Pavone

T. G. George

C. E. Frantz

This report was prepared as an account of work sponsored by an agency of the United States Government. Neither the United States Government nor any agency thereof, nor any of their employees, makes any warranty, express or implied, or assunes any legal liability or responsibility for the accuracy, completeness, or usefulness of any information, apparatus, product, or process disclosed, or represents that its use would not infringe privately owned rights. Reference herein to any specific commercial product, process, or service by trade name, trademark. manufacturer, or otherwise does not necessarily constitute or imply its endorsement, recommendation, or favoring by the United States Government or any agency thereof. The views and opinions of authors expressed herein do not necessarily state or reflect those of the United States Government or any agency thereof. 


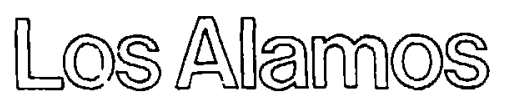

Los Alamos National Laboratory

ro Holders of LA-10353-MS

DATE July 26, 1985

FROM IS- 11

MAIL STOP/TELEPHONE D418/7-5469

STMBOL

SUBJECT Addendum

Addendum, p. 37.

Fig. A-1. Particle-size distributions of selected impected plutonia pellets. 


\title{
GENERAL-PLIRPOSE HEAT SOURCE SAFETY VERIFICATION TEST SERIES: SVT-1 THROUGH SVT-6
}

\author{
by
}

\author{
D. Pavone, T. G. George, and C. E. Frantz
}

\begin{abstract}
ABSTRICT
The General-Purpose Heat Source (GPHS) is a modular heat source that will supply energy for Radioisotope Thermoelectric Generators (RTGs) in space missions. The Safety Verification Tests (SVTs) are performed to assess the plutonia containment capahility of heat source modules subjected to certain accident environments. This interim report describes the GPISS module configuration, the test environment, and the response of the module components following simulated reentry and solid Eath impact. The specific test environment of these initial six tests results from failure of the booster rocket to place the spacecraft in a proper trajectory and subsequent reentry of the GPHS modules from Farith orbit.
\end{abstract}

\section{INTRODLCTION}

The General-Purpose Heat Souree ( (iPHS) is a modular radioisotopic heal source that produces heal from the a-decay of the 238 isotope of plutonium. The heatsource modules have been designed so that they ma! be used as individual heat sources in Radioisotope Thermoelectric G(nerators (RTGs) of various final power outpuls and as a heat source for turbine-type generators if such equipment were developed. The initial applicaiion of the GPHS will be ir. RTGs 10 furnish electric power for the NASA Galileo mission and the Ulysses mission (formerly the Internationa! Solar-Polar mission). The RTGs for these missions each use eighteen 250-W(L: ،10dules.

The GPHS module was primarily designed at the Los Alamos National Laboratory: however. that design was modified by the General Electric Company. system contractor for the RTG. te reduce the weight for the above-mentioned missions. A short series of Design Ileration Tests (DITs) was conducted in the modified design configuration and then the design was accepted for use in the Galileo and Ulysses missions. An $\mathrm{cx}$ tensive series of lests is being conducled io assess the capability of the system to contain piutonium in the event of an aborted mission from orbit with subsequent reentry and Earth impact. This interim report describes the planned Safet! Verification Test (SVT) series and the results of the initial sie impact tests.

The GPHS module contains four right circular cylindrical pellets of 238 -plutonia nominall! $27.7-\mathrm{mm}$ diam $\times 27.7-\mathrm{mm}$ height. which weigh approximately $150 \mathrm{~g}$ and generate 62.5 $W(t)$. Each plutonia pellet is clad in a welded DOP-26 iridiun-alloy capsule $29-\mathrm{mm}$ diam $x$ 29.4-mm height $\times 0.64-\mathrm{mm}$ wall thickness. One end of the iridium capsule is fitted with a vent of sintered iridium powder through which the decay product helium is released. This assembly. referred to as a fueled clad (FC) is the basic unt of plutonia containment. Two fucled clads are loaded into a cylindrical. Fineweave-Pierced Fabric* (FWPF) composite graphile inpact shell (GIS). 39.4-num diam $\times 78.7-\mathrm{mm}$ length. To complete the GPHS module. wo (ilSs, each surrounded by a cylinder and two disks of carbon-bonded carbon-fiber (CBCF) insulation. are contained within cavinies of a reclangular parallelepiped FWPF acroshell (A/S) $98 \mathrm{~mm} \times 94 \mathrm{~mm} \times 54 \mathrm{~mm}$. A schematic vew of the module is shown in Fig. 1 .

Reentry analysis indicaled that if an RTCi reentered the atmosphere, the RTG case and thermoelectric modules would be stripped from the heat source and the heat

\footnotetext{
*Fineweave-Pierced Fabric 3-D carbon/crrbon compositc. a product of $A V C O$ Sysiems Division. 201 Lowell St.. Wilmington. MA 01887 .
} 
source modules would reenter as single entities. Thus, individual modules were selected for testing in the test program.

\section{TEST OBJECTS}

Objects to be tested in this phase of the program were complete GPHS modules assembled from flight-quality components excepl as noted below. The source and fabrication responsibilities of the somponents were as follows:

\section{A. Iridium Clad}

Iridium-alios sheet for the cladding wals produced by Oak Ridge National Laboratory. Circular blanks and foil were supplied to Monsanto Research Corporation Mound Plant (MRC'-Mound).

MRC Mound formed cups from the blanks: formed vent assemblies. decontamination covers. and weld shields from the foil: and assembled these pieces 10 constitute the pellet cladding.

\section{B. Plutonia}

Piutonia pellets were tubricated at the Savannah River Planı (SRP) and were encapsulated in the iridium clad at that site. A process change during the product run resulted in two classes of plutonia pellets, on which had been fired in an argon atmosphere and other in an $A r / O_{2}$ atmosphere. Both pellet groups considered to be of flight quality. Table I lisı production history of the pellets.

Because weld cracking occurred in some test we SRP developed an ultrasonic. nondestructive $v$ evaluation procedure (NDE). An arbitrary sc calibrated against standard defects. was established. those FCs with ultrasonic reflections $<8$ were de nated as tlight quality.

\section{CBCF Insulation}

Carbon-based carbun-fiter insulation compon were manufactured tw final configuration at Oak $R$ National Laboratory and were supplicd directly MRC-Mound.

\section{Aeroshell and Impact Shell}

Fineweave-Pierced Fabric composite graphite ponents were machined at two locations. Los Ala National Laboratory and Teledyne Isotopes Timonium. Maryland. Items produced by Teien carty an identification code of PAT or PGT followe a four-digit nuniber. PAT-XXXX or PGT-XX

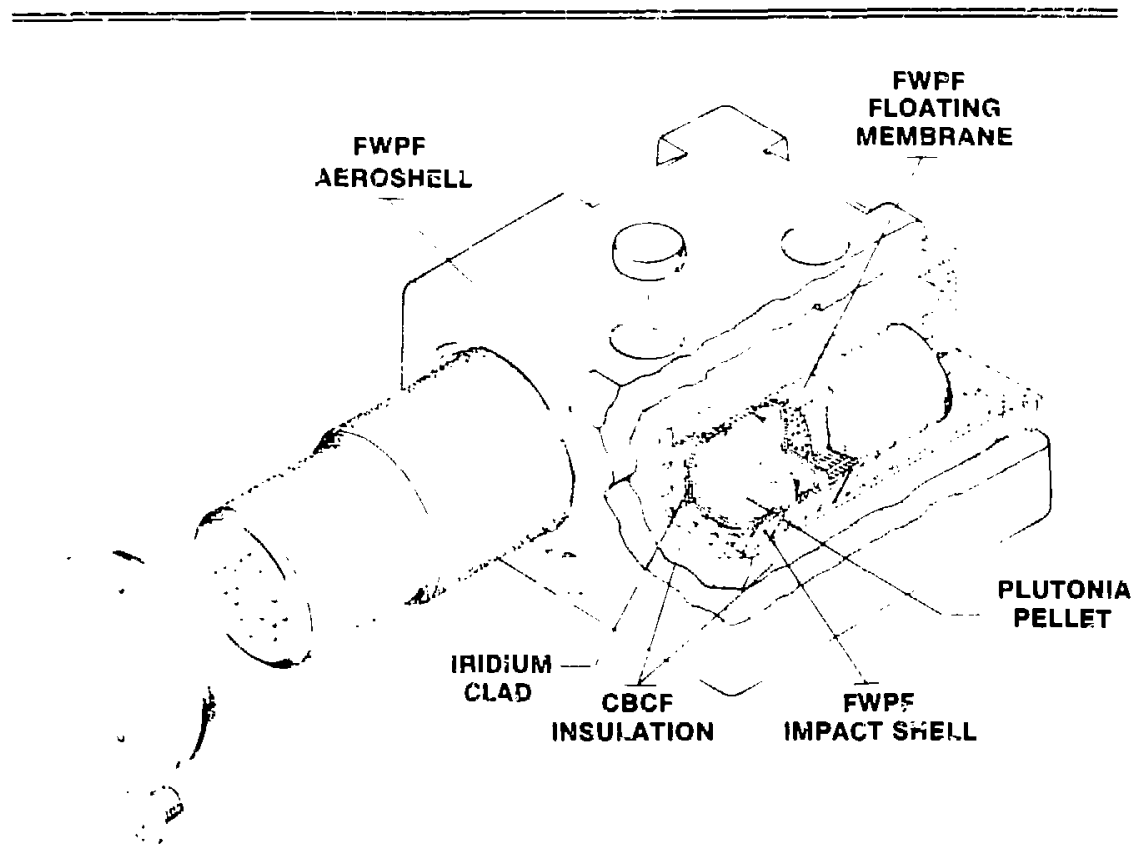

Fig. 1. Schematic thagram of a GPIS module. 


\begin{tabular}{|c|c|c|}
\hline \multicolumn{3}{|c|}{$\begin{array}{l}\text { TABLE I. Production History of the SVT } \\
\text { Fuel Pellets }\end{array}$} \\
\hline Pellet Yo. & Firing Atmosphere & Test \\
\hline $\begin{array}{l}H F-232 \\
H F-238 \\
H F-261 \\
H F-410\end{array}$ & $\begin{array}{l}\mathrm{Ar} / \mathrm{O}_{2} \\
\mathrm{Ar} / \mathrm{O}_{2} \\
\mathrm{Ar} / \mathrm{O}_{2} \\
\text { Argon }\end{array}$ & $\begin{array}{l}\text { SVT-1 } \\
\text { SVT-1 } \\
\text { SVT-1 } \\
\text { SVT-1 }\end{array}$ \\
\hline $\begin{array}{l}H F-273 \\
H F-355 \\
H F-369 \\
H F-449\end{array}$ & $\begin{array}{l}\mathrm{Ar} / \mathrm{O}_{2} \\
\mathrm{Argon} \\
\text { Argon } \\
\text { Argon }\end{array}$ & $\begin{array}{l}\text { SVT-2 } \\
\text { SVT-2 } \\
\text { SVT -2 } \\
\text { SVT-2 }\end{array}$ \\
\hline $\begin{array}{l}H F-343 \\
H F-350 \\
H F-454 \\
\text { IIF-457 }\end{array}$ & $\begin{array}{l}\text { Argon } \\
\text { Argon } \\
\text { Argon } \\
\text { Argon }\end{array}$ & $\begin{array}{l}\text { SVT }-3 \\
\text { SVT-3 } \\
\text { SVT-3 } \\
\text { SVT-3 }\end{array}$ \\
\hline $\begin{array}{l}\text { HF-139 } \\
\text { HF-162 } \\
\text { HF-348 } \\
\text { HF-354 }\end{array}$ & $\begin{array}{l}\mathrm{Ar} / \mathrm{O}_{2} \\
\mathrm{Ar} / \mathrm{O}_{2} \\
\text { Argon } \\
\text { Argon }\end{array}$ & $\begin{array}{l}\text { SVT }-4 \\
\text { SVT-A } \\
\text { SVT-A } \\
\text { SVT-4 }\end{array}$ \\
\hline $\begin{array}{l}\text { HF-260 } \\
\text { HF-267 } \\
\text { HF-415 } \\
\text { HF-426 }\end{array}$ & $\begin{array}{l}\operatorname{Ar} / \mathrm{O}_{2} \\
\mathrm{Ar} / \mathrm{O}_{2} \\
\mathrm{Ar} / \mathrm{O}_{2} \\
\text { Argon }\end{array}$ & $\begin{array}{l}\text { SVT-5 } \\
\text { SVT-5 } \\
\text { SVT-5 } \\
\text { SVT-5 }\end{array}$ \\
\hline $\begin{array}{l}H F-189 \\
H F-225 \\
H F-361 \\
H F-373\end{array}$ & $\begin{array}{l}\mathrm{Ar} / \mathrm{O}_{2} \\
\mathrm{Ar} / \mathrm{O}_{2} \\
\operatorname{Arggon} \\
\text { Argon }\end{array}$ & $\begin{array}{l}\text { SVT-6 } \\
\text { SVT-6 } \\
\text { SVT-6 } \\
\text { SVT-6 }\end{array}$ \\
\hline
\end{tabular}

Those produced at Los Alamos are identitied with a code of P.AL or PGL followed by a three-digit number. PAL-XXX or PGT-XXX. Acroshelis used in the test modules of this series were machined at Los Alamos to remove twice the thickness of expected ablation for the reentry mode of the test. The RTG contractor. General Electric Company. described two recntry configurations: a minimum-gamma and an orbitaldecay reentry mode.

\section{E. Module Assembly}

Componen,s of the test modules were asembled at MRC-Mound. After the vents of the fueled clads were activated and the nodule was assembled. the assembled module was treated in the Mound Reduction and Monitoring Facility (MRMF). Then the module was subjected to two cycles of flight-acceptance vibration spectra and transient accelerations, radiographed, and shipped to Los Alamos in welded stainless steel containers. Table II identifies the components of the modules SVT-1 through SVT-6.

\section{TEST PROGRAM}

The tesi program was designed to simulate the sequence of environments and events that a module would experience during an aborted mission.

Thirteen modules were allocated for testing in the SVT series. Each module was fueled with two GISs: one GIS, designated the primary impact assembly (PIA). contained flight-quality FCs, and the other GIS. oi secondary impact assembly (SI.A), contained non-tlightquality FCs. The FCs in the SIA are not flight-quality because weld-inspection NDE indications excerded \& (arbitrary units). No FC with an NDE indication $>14$ was used in the SVT series.

In addition to the reentry mode and the fuel processing variables, various impact orientations of the module were included. Schematic representation of possible orientations is depicted in Fig. 2. and the Impact Test Plan is depicted in Fig. 3. Orientations of tests following the initial five (SVT-1 through 5) were determined by a Technical Review Board consisting of R. W. Zocher (Los Alamos National Laboratory). C. T. Bradshaw (General Electric Company), and R.W. Englehart (NUS).

\section{EXPERINIENTAL PROCEDURES}

\section{A. Receiving and Inspection}

Assembled modules were received from MRCMound in welded stainless steel containers. Three of the modules had been disassembled at MRC-Mound and the impact assemblies shipped in stainless steel containers separate from the aeroshell/insulation components.

The test articles were radiographed to establish the condition of the fuel pellet before further test operations. Test modules were removed from the shipping can in an argon-atmosphere glove box $1 \mathrm{O}_{2}=<150$ ppm). were disassembled to the exient of removal of the impact assemblies from the acroshell. and were visually examined.

\section{B. Aging}

A 1/16-in.-diam optical pyrometer sight hole was drilled through the cap of the primary impact assembly. and both GISs were loaded into an ATJ graphite fur nace fixture. The aging assembly was transported to the furnace in a covered can and loaded into the furnace with minimum exposure to air.

Aging treatments were performed in high-vacuum furnaces with tungsten mesh heating elements and tantalum radiation shields. Most of the GISs were aged in Brew Model 424C furnaces, which have a 4-in.-diam hot 


\begin{tabular}{|c|c|c|c|c|c|c|}
\hline Component & SVT-1 & SVT-2 & SVI-3 & SVI-4 & SVT-5 & SVT-6 \\
\hline teroshell & PAL-1012 & PAL-015 & PAI,-(1)14 & PAT-1007 & PAT- 1008 & PAT-1009 \\
\hline
\end{tabular}




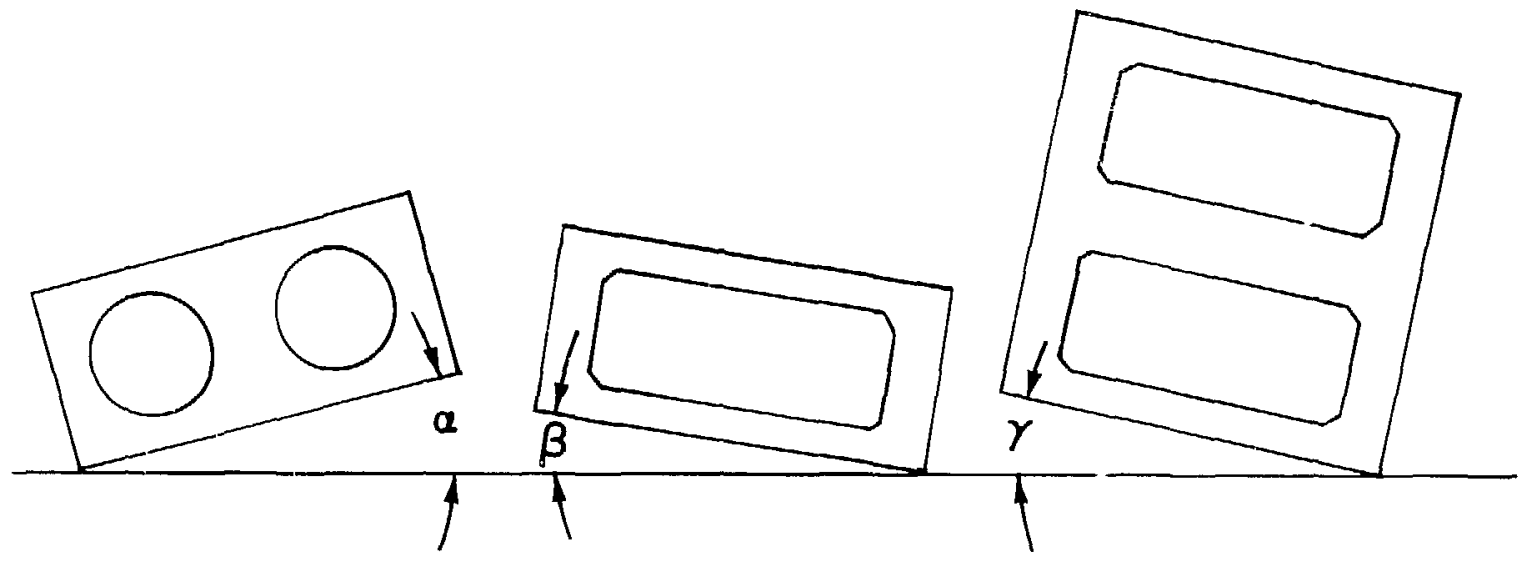

Fig. 2. Three angles describe the orentation sensillvits of the (illis module to impact

zone and accommodate the two GISs from a single module. A 6-in.-diam Brew Model 426C. which could accommodate four GISs from two modules, was used for the aging heat treatment of some test pieces.

Two of the 4-in.-diam furnaces were equipped to monitor the helium released from the FCs during the aging treatment. Those modules treated in these furnaces were continuously monitored. but modules to be handled in this manner were not preselected.

tging treatments were conducted at a pressure of $<1 \times 10^{-h}$ torr and a clad temperature of $1287^{\circ} \mathrm{C}$ as measured with a calibrated optical pyrometer sighted on the end of one of the GIS fueled clads. This temperature represented a weighted average of the iridium-clad temperature at the operating conditions of the heat source in the Galileo and Ulysses RTGs. Aging time was $200 \mathrm{~h}$ for GISs from modules to be tested in the minimumgamma reentry mode, and 90 davs for GISs from modules to be tested in the orbital-decay reentry mode. The 90-day aging reflects the expected elapsed time for an aborted Galileo mission:2 however. the data obtained are considered applicable to the Ulysses mission as well. which would have a 38 -day operational period before an orbital-decay reentry.

\section{Reentry Simulation}

When the aging treatment was completed. the GISs were returned to the inert-atmosphere glove box. and two additional holes were drilled in the cap of the impact shells to accommodate the legs of a split-junction thermocouple. The appropriate reentry temperature profile was applied in an electron-beam furnace. Figure 4 illustrates the temperature profiles for the minimum-gamma and orbital-decay reentry conditions.

\section{Preimpact Inspection}

Before the GISs were reassembled into the aeroshell. they were again radiographed to document the preimpact condition of the plutonia pellet.

\section{E. Impact Test}

Holes were drilled in the aeroshell and the primary GIS for thermocouples used to monitor the temperature of the impact assembly. A split-junction. ChromelAlumel thermocouple was installed with its lcgs contacting a primary FC. and two beaded-junction thermocouples were placed in contact with the outer surface of the primary GIS. The instrumented module was transported to the test site in a helium-filled container that was cooled by forced air.

Test modules in these reported tests were impacted at the Los Alamos Isotope Fucls Impact Test Facility (IFIT) against a hardened steel target at the designated temperature and velocity corresponding to the reentry mode of the test. The impact test conditions, specified by General Electric Company, were a velocity of $54 \mathrm{~m} / \mathrm{s}$ and a clad impact temperature of $919^{\circ} \mathrm{C}$ for minimumgamma reentries and $975^{\circ} \mathrm{C}$ for orbital-decay entrics.

The IFIT. a 178-mm-diam gas gun with provision for containment of the impacted test article in a catch tube. is described in detail in Los Alamos Scientific Laboratory report LA-6013 (January 1976), entitled "Isotope Fuels Impaci Tester." Tests of GPHS SVT modules differed from that shown for the Multihundred-Watt Fuel Sphere Assemblies (MHW FSAs): The modules were not enclosed in an impact can, iridium-clad temperatures were measured directly, and the desired impact temperatures and thermal inventory of a module 


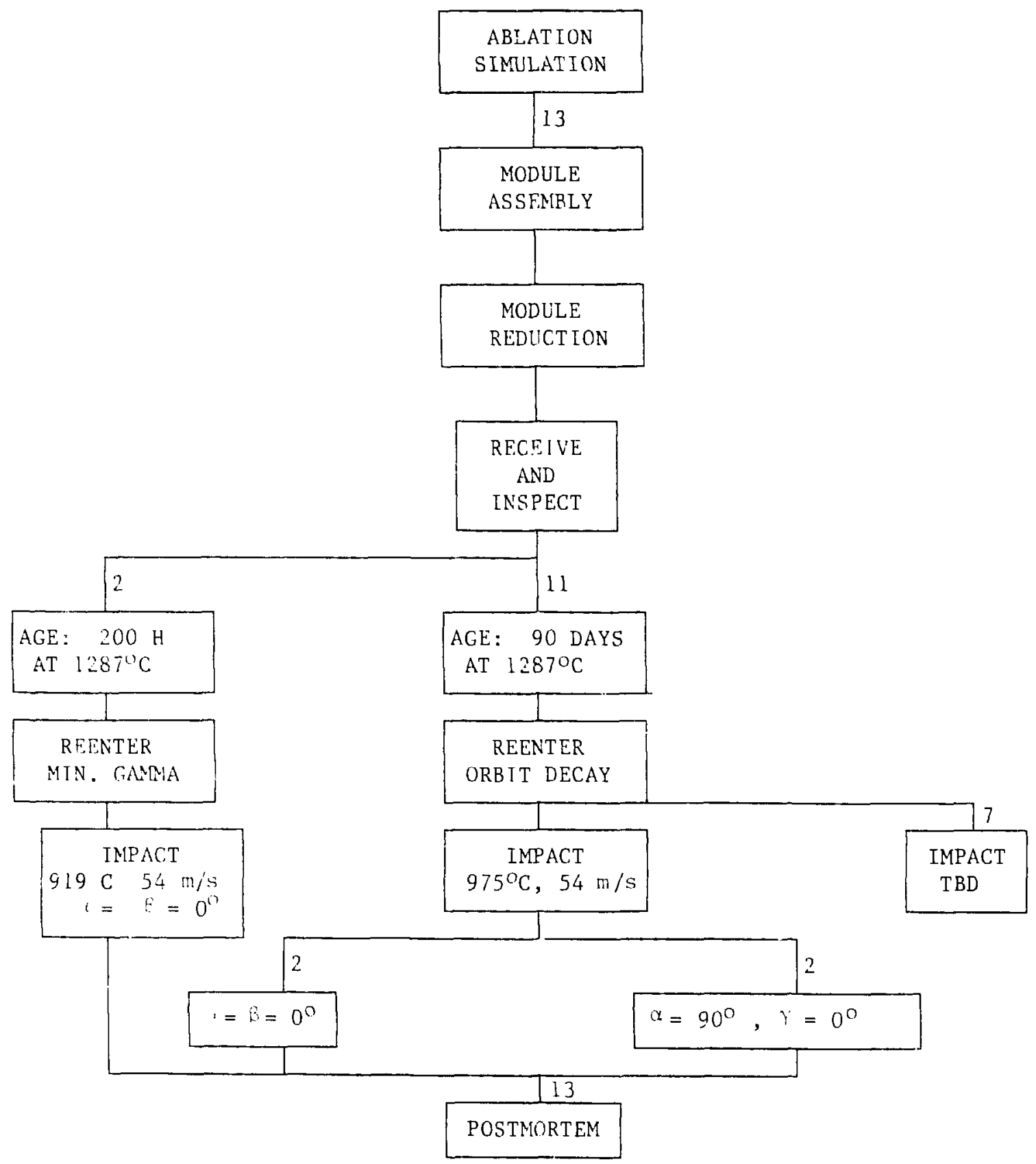

Fig. 3. Test scheme for aging reentry-impact portion of (iPHS SVT stress. 

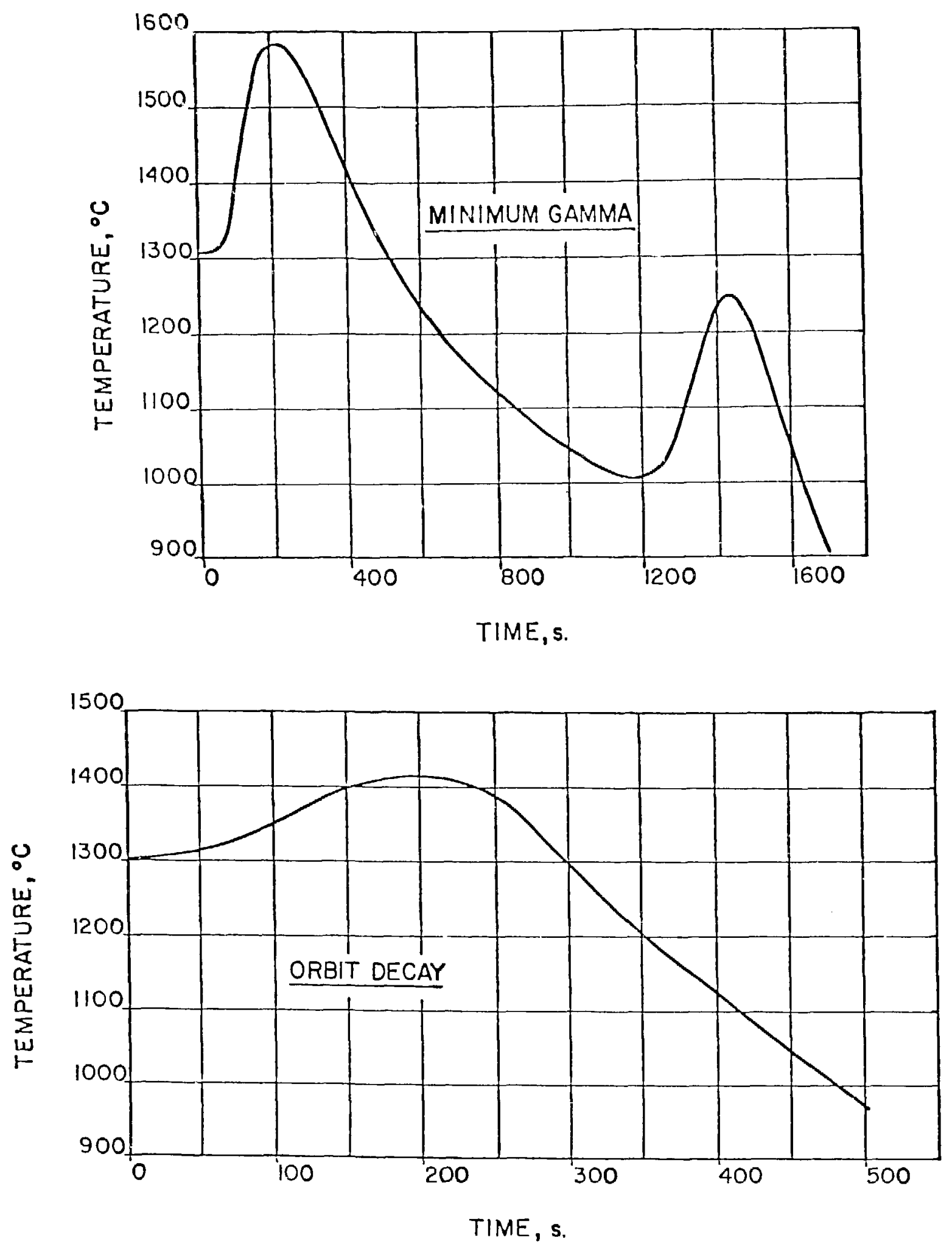

Fig. 4. Clad temperature histories during reentry of a GPHS module. 
were such that the impact temperatures were reached by self-heating.

For modules in the $\alpha=\beta=0^{\circ}$ (broad-face) impact orientation. geometric considerations prevented the direct use of split-junction thermocouple measurement of the clad temperature. In these cases. a temperature calibration was made in the gun, in which the surface temperature of the impact shell was determined to correspond to the iridiunt-clad temperature measured wh the split-junction thermocouple. The split-junction thernocouple was removed. and the test was conducted at the callbrated inpact-shell surface temperature.

\section{F. Postmortem Examination}

Because the schedule for Safey Analysis Reriews allowed only a limited time to complete the impact tests and postmortem examinations. we adopted the protocol of performing complete postmortem examinations only (1) the promars $F($ s. This protece) was later amended io include investigation of failures of the secondary FCs. and since the fuel pellet would be processed for plutonia recovery, chemical analyses of the secondary fuel pellets were obtained.

The principal objectives of the postmortem examination were to determine the quantity of plutonium released if any. and the fraction in the $<111-\mu \mathrm{m}$ particlesize range: to document the damage sustained by all components: and to characterize the iridium and plutonia with respect to chemical composition ard microstructure. The following nine steps summarize the postmortem cxamination.

(1) Obtain documentary photographs of the postimpact condition of the aeroshell. the impact shells and the flieled clads.

(2) Recoser all graphitic components, including the watch-tuhe debris, and determine the total plutonium content and the fraction in the particle-size range $<1(1)-\mu \mathrm{m}$.

(3) Measure the principal dimensions of the inpacted FC's.

(4) Estimate the area of fractures from suitably orented photographs.

15 ) Defuel the $F($ s. obtain documentary photographs of the nlutonia fracture pattern. and perform seve analysis of the impacted plutonia pellets of selected unfailed FC's.

(4) Select a sample of each cup of the iridium elad for emission specorographic analysis and select two samples for tuger electron spectroscopy (AES) analycis.

17) Select metallographic cross sections through any falures or severe localized deformation of the iridium clad, select an axial cross section through the weld. and select other cross sections so that both transverse and axial microstructure and the grain size of each cup may be determined.

(8) Cross section the vent assembly and metallographically examine the vent-assembly weld microstructures. vent deposits, and vent effusates.

(9) Select samples of the plutonia fuel pellet for emission spectrographic analysis, colorimetric phosphorus analysis, and ceramographic microstructural examination.

The experimental procedures for conducting most of the postmortem operations involve generally well known equipment and techniques and need not be described in any further detail. However, the procedure for obtaining the total plutonium and the $<1()_{-} \mu \mathrm{m}$ fraction contained in the graphitic materials warrants further discussion.

In previous test programs involving the MHW FSAs, the FSAs were impacted with the FSA contained within a welded tantalum can. All graphite debris was recovered after sawing the can open, and the debris was burned in air al about $850-900^{\circ} \mathrm{C}$. The resulting ash was dissolved in acid. and the solution was analyzed for plutonium by radiochenical techniques.

For most of the initial tests (SVT-1 through 5) described here, the debris remaining in the catch tube was recovered by washing with ethyl alcohol, then was dried and combined with the aeroshell and impact shells. Processing of this material then followed the technique used previously, except that the ash resulting from the combustion was sieved into fractions greater than and less than $10 \mu \mathrm{m}$. and cach fraction was analyzed separately.

To investigate possible agglomeration of plutonia particles into larger aggregates by sintering at the combustion temperature of graphite, an extracion replica was made of a sample from the $<20-\mu \mathrm{m}$. $>10-\mu \mathrm{m}$ fraction of the ash. and this replica was examined by elertron microscopy. Figure 5 shows that very small particles, a few tenths of a micron in diameter, did indecd form aggregates larger than $10 \mu \mathrm{m}$. To circumvent this problem. the procedure for handling 'ht. graphitic materials was modified according to a scher:: suggested by $E$. W. Johnson (MRC). In this procedure. large pieces of aeroshell. impact shells, and insulation were cleaned ultrasonically in ethyl alcohol before conbustion in the usual manner. Material recovered from the washing operation was combined with the catchtube debris and burned in oxygen in a plasma-assisted combustion furnace. The rate of oxidation is very slow in this apparatus, but the temperature remains low $\left(\sim 50^{\circ} \mathrm{C}\right)$ so that particle sintering is not a problem. The ash is sieved into $<10-\mu \mathrm{m}$ and $>10-\mu \mathrm{m}$ fractions and analyzed as before. The plutonium remaining on the 


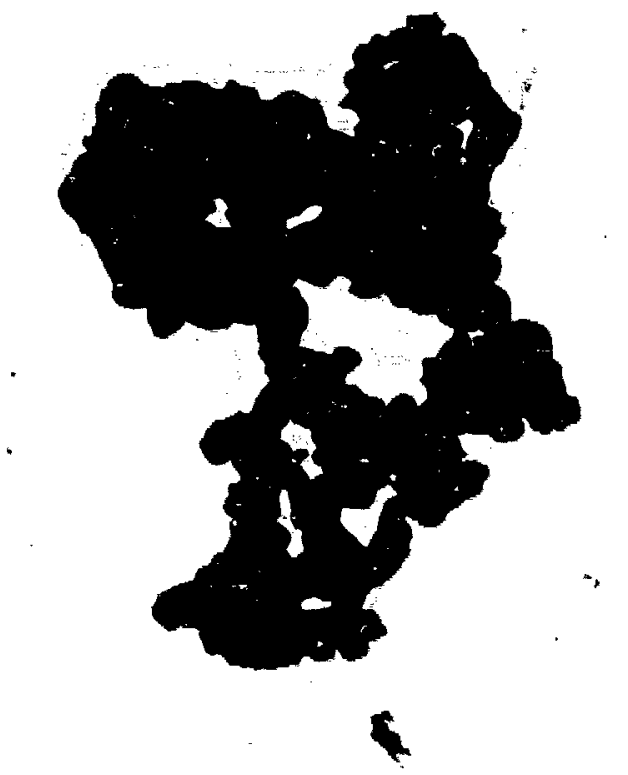

Fig. 5. Agglomerates of plutonia particles and ash were formed during combustion of the graphitic materials. $1010(100 \mathrm{x}$

aeroshell and impace shells is considered to be $<10_{-\mu} \mathrm{m}$ material.

\section{TEST RESLLTS}

Results will be presented narratively as a description of observations, with illustration of significant features. For ease of comparison and ready reference, analytical results are tabulated as follows in the Appendix:

Table .4-I. Impact TeSt Summary-GPHS SIT

Series

This table lists the NDE valuc, the gross deformation of each FC, the number of failures, and the estimated area of the fractures.

Table A-II. GPHS SIT Fud Release

This table lists the total plutonium released in the test and the distribution between the $<10-\mu \mathrm{m}$ and $>10-\mu \mathrm{m}$ size range.

Tahle -1-III. Particla Size Distrihution of the $<101-\mu m$ Fruction of Selected Impacteci Pellets

The size distribution of the $<10-\mu \mathrm{m}$ fraction of the plutonia pellets from selected unfailed fuel clads is shown in this table. Figure A-1 graphically shows the results of the sieve analysis of these pellets.

Table A-IV. Iridium Grain Size-GPHS SIT Series This table lists the grain size of the iridium cups in axial and transverse cross section expressed as grains $/ 640 \mu \mathrm{m}$ thickness.
Table t-1: Summary of AES thalyses of ciPHS SIT Iridium

This table summarizes the results of AES analysis of the primary iridium clads and a few of the secondary clads. The $T h_{65} / / r_{2: 4}$ intensity ratios are given for the interior, center, exterior, and for the average. The average intensity ratios are given for other elements.

Table A-I\%. Results of Spectrograpinic thalisis at GPHS SIT Iridium!

The concentrations are tabulated fo: :-minti:. alc-

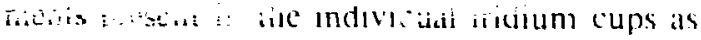
determined by emission spectroscopy.

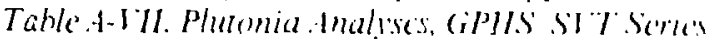

This table summarizes the results of emission spectrographic analysis of the plutonia pellets and gives the phosphorus coritent as determined ty a colorimetri: procedure.

\section{A. SIT-1}

This assembly was tested to simulate minimumgamma reentry conditions in a broad-ficc $\left.(a=\beta=1)^{\prime \prime}\right)$ orientation. The impact temperature was $4 y^{\circ}{ }^{\circ}$ (clad) and the impact velocity was $54.4 \mathrm{~m} / \mathrm{s}$. The target was hardened 4340 stecl.

Figure 6 sliows the module as recovered from the catch tube. There were nearly full length cracks on both nonclosure narrow faces of the aeroshell and two cracks parallel to the axes of the impact assemblies on the impact face. The back face was dented and eracked. Although forces exerted on the back face during impact may account for the deformation and cracking of the aeroshell back face, the observed deformation and cracking might also result when the module rebounds against thermocouple extension wires that are fed through ihe center of the inner projectile cylinder. The condition of the PIA impact shell is shown in Fig. 7 Both of the GISs had slightly bowed profiles and irregular cracks on the impact face extenditig about $85 \%$ of the length from the closure end. These postimpact features are typical of the FWPF components of a module impacted in the $\alpha=\beta=0^{\circ}$ orientation.

No failures were observed in either of the FC's of the PIA, FC-232 and FC-238. The crerail deformation was symmetrical and only modest localized iridium deformation was observed, principally on the impact face.

Failures occurred in both fucled clads of the SI:. Figure 8 illustrates a major failure located on the back side in both cups of the iridium clad of $F(-26)$ and shows a small failure on the impact face of the shicld cup about $180^{\circ}$ from the back-side fracture. The vent-end profile view shows the overall distnition of the iridium clad caused by plutonia fragments siiding along a planc oriented at an angle near $45^{\circ}$ to the impact plane. The failure in FC-410 apparently originated at the corner of the shield-cup back side and extended axlally through 


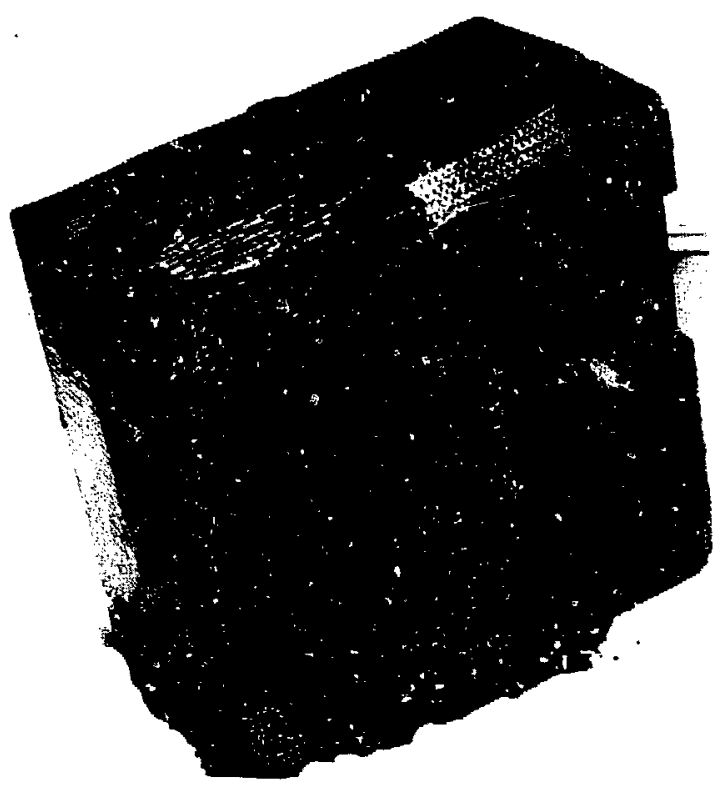

(a)

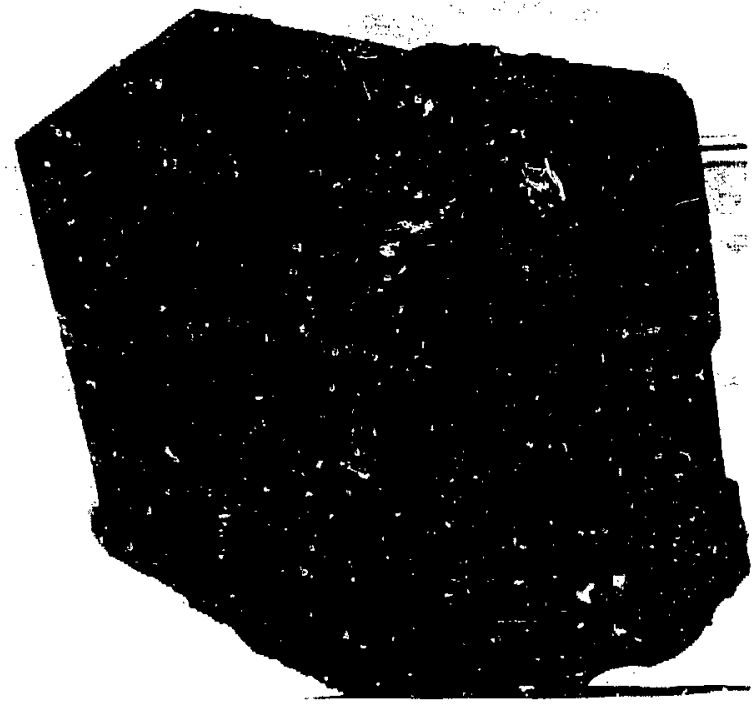

(b)

Fig. 6. The aeroshell of SVT-1. There were cracks on the impact face, on both nonclosure narrow faces, and on the back. (a) Impact face forward, (b) back forward.

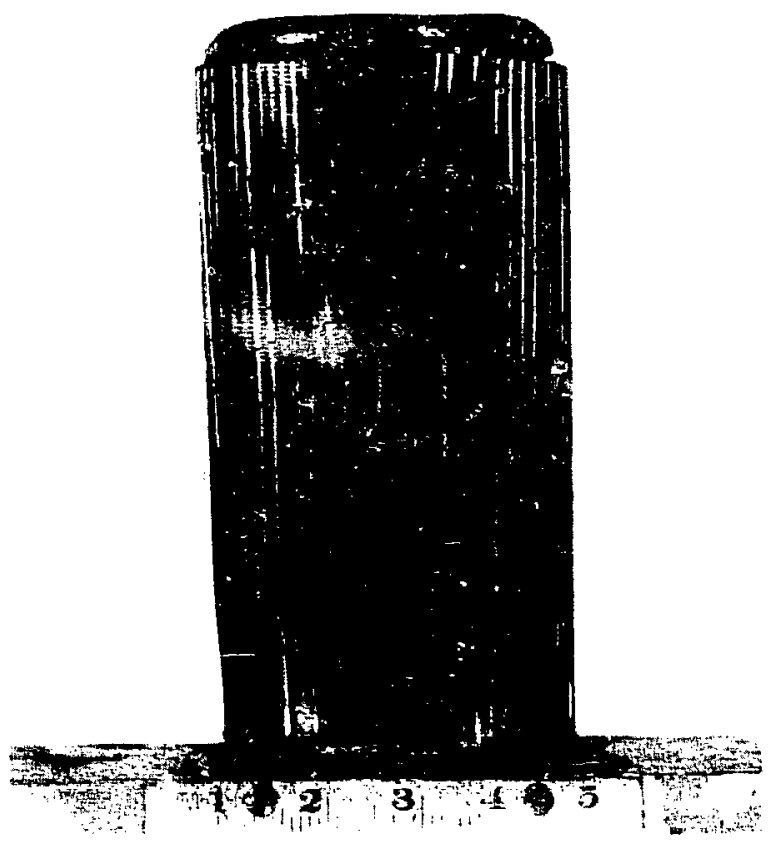

(a)

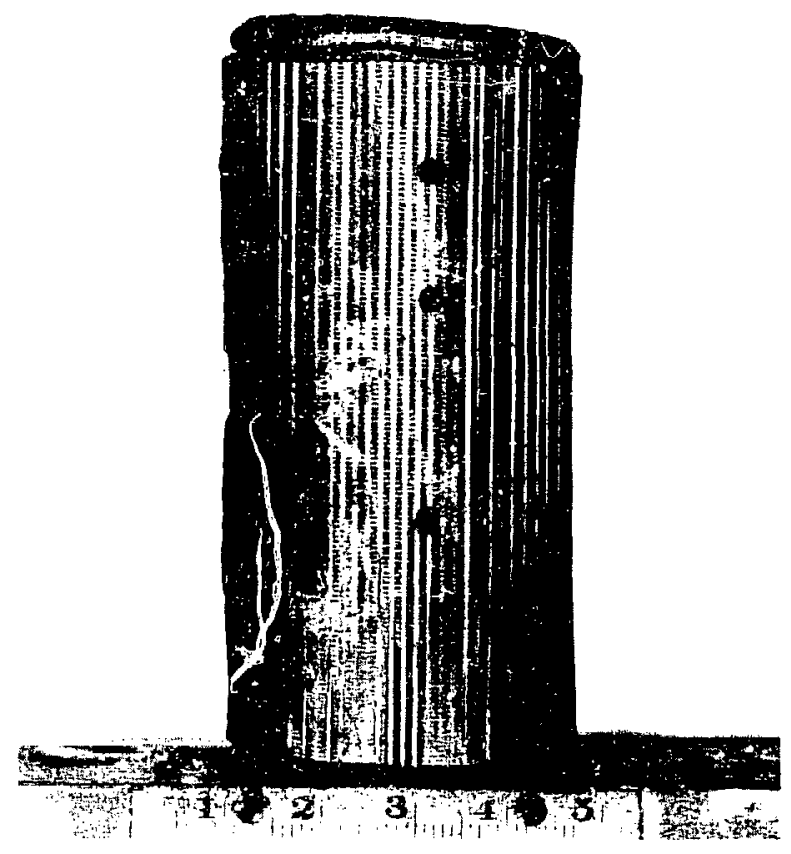

(b)

Fig. 7. The graphite impact shell of the PIA of SVT-1 was cracked on the impact face and had a slightly bowed profile. (a) Impact face. (b) profile view. 


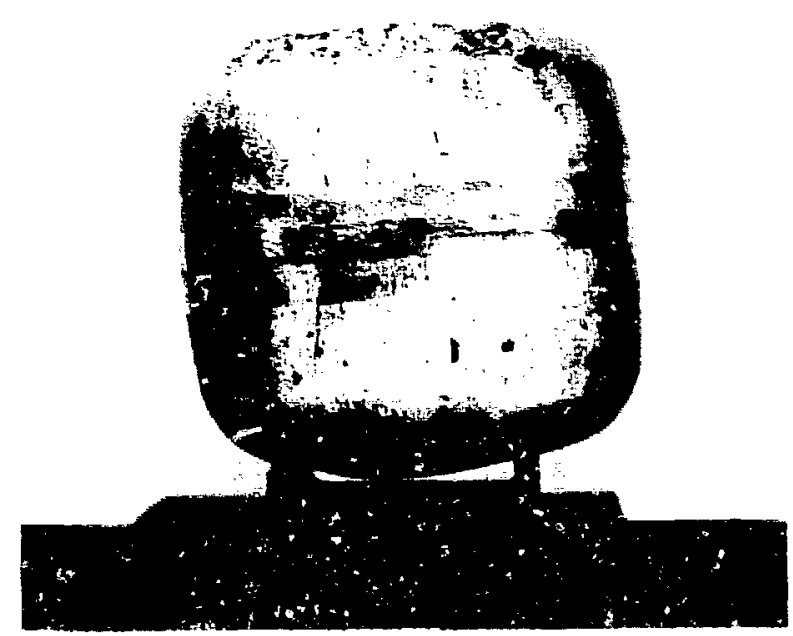

(a)

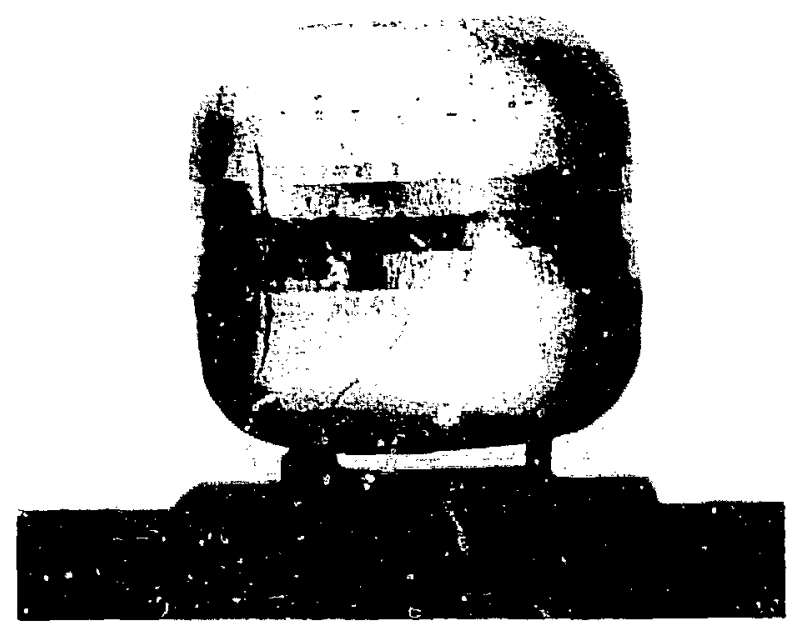

(b)

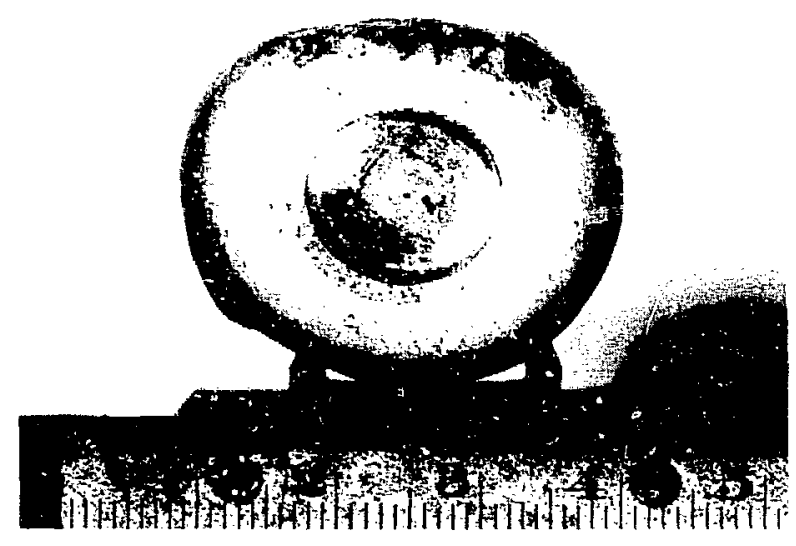

(c)

Fig. 8. Fuel push-through failures occurred on the impact face of FC-26! and on the back side of FC-261. (a) !mpact face, (b) back side, and $(c)$ vent-end view.

the weld into the vent-cup wall, as well as into the edge of the shield-cup bottom. Figure 9 illustrates the location and the extent of the iailure.

Metallographic transverse cross sections through the failures in FC-261 are shown in Figs. 10 and 11. The fracture mode at the fracture site on the vent-cup back side (Fig. 10) was intergranular, although a small reduction in thickness, about $4 \%$, indicates limited ductility. The radial displacemen 1 of opposite sides of the fracture indicates the effect of fuel-fragment push-through. The photomacrograph of the cross section through the impact-face fracture of the shield cup (Fig. 11) shows a sharp bend at the point of the fuel-fragment pushthrough and the fracture nearby in the reverse-bend repi.n. The etched microstructure indicates that the feilure occurred where some relatively large, columnar grains normal to the surface were present. This microstructure is similar to that observed in some ventassembly welds and is probably the location at which the weld-shield tab was wided to the cup interior.

Transverse metallographic cross sections through the shield-cup failure of FC-410 are shown in Fig. 12. Again, the effect of fuel-fragment push-through is evident. The fraciure mode was intergranular, but the reduction of thickness of about $6 \%$ indicates modest ductility

Auger electron spectroscopy analysis of fracture surfaces indicated that small quantitites of grain-boundary sulfur were present in both samples of the FC-261 vent cup. 


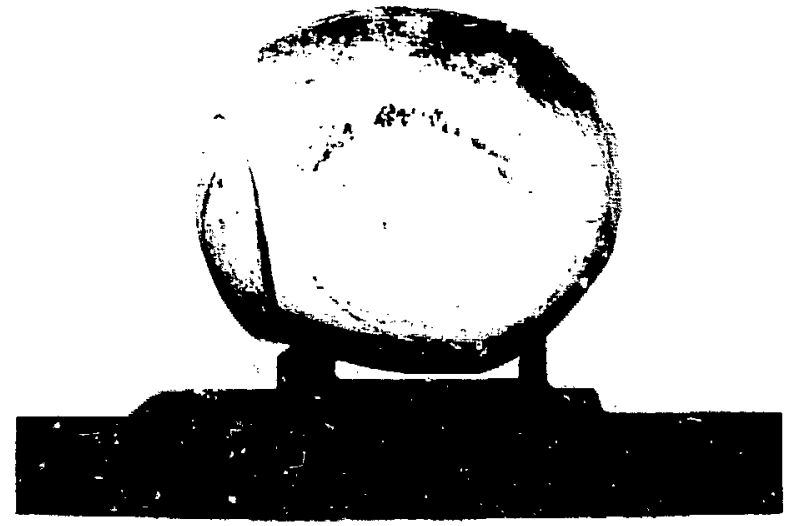

(a)

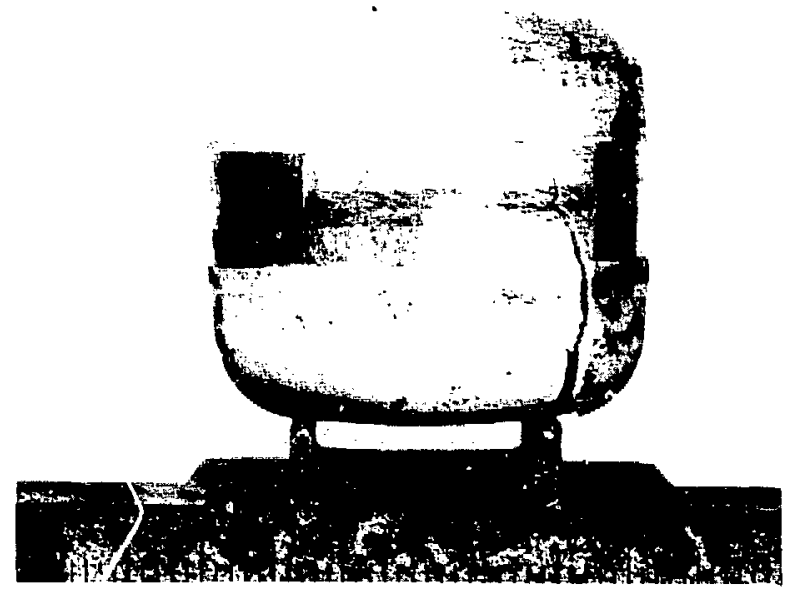

(b)

Fig. 9. The failure in FC-4lo originated al corner on the shield-cup back side. and it extended axially through the wall of the shieid cup into the vent cup as sell as into the edge ol the capsule bottom.

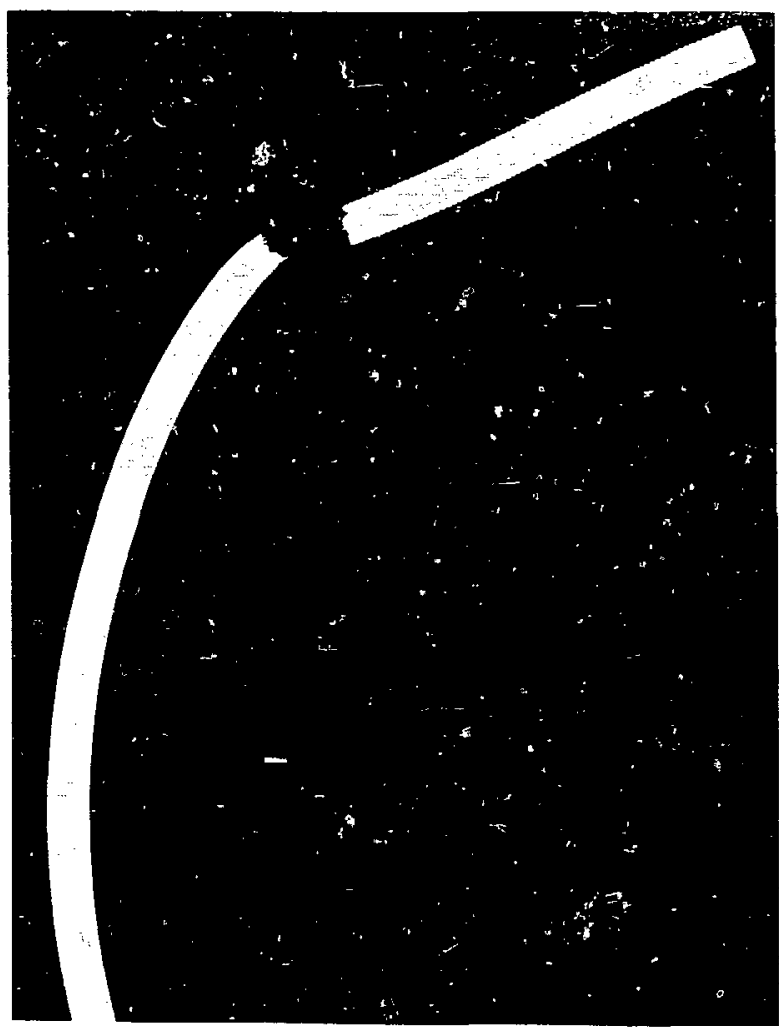

(a)

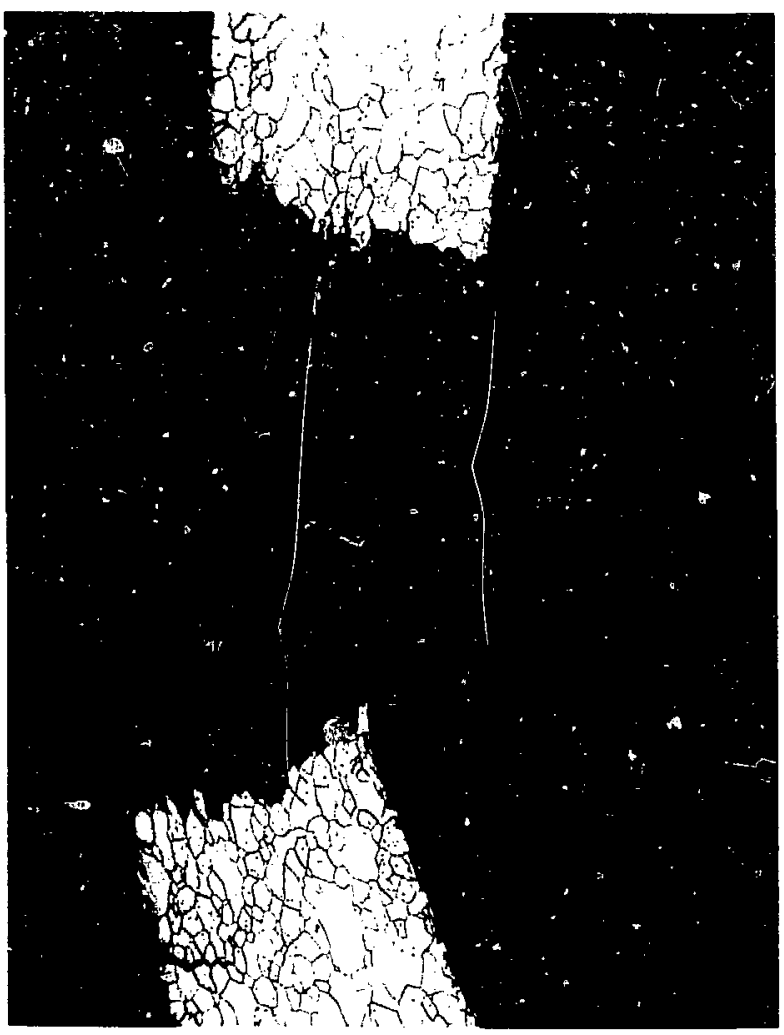

(b)

Fig. 10. Radial displacement of the two sides of the fracture on the back side of the FC-26I vent cup indicates the cffect of fuelfragment push-through. The fracture mode was intergranular. 


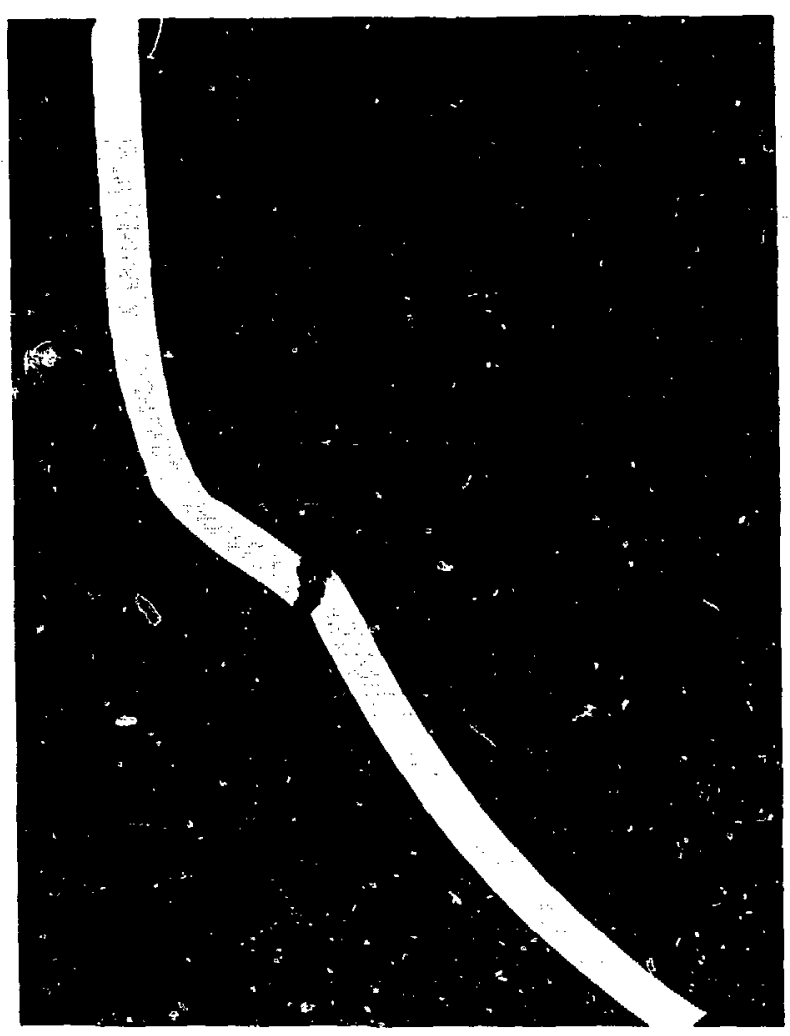

(a)

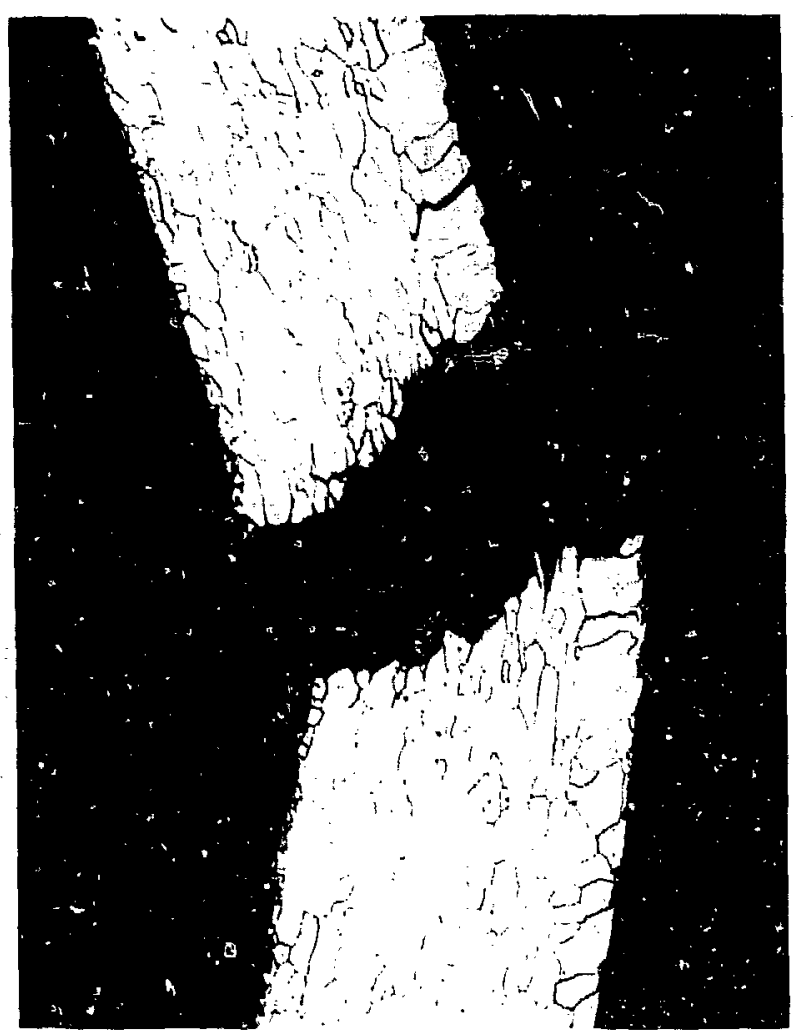

(b)

Fig. 1:. The fracture on the shield-cup impact face occurted in the reverse-bend region natar the point of fucl-fragment indentation. Large grains on the intertor of the wall thickness result from welding of the weld-shield tab to the capsule wall. (a) $7 \times$. (b) $50 \times$.

The calcium content of the plutonia pellets HF-238. HF-261, and HF-410 exceeded the SRP guideline limits. The microstructures of pell is HF-238 and HF-239 were typical of SRP material.

The iridium microstructure was uniform: however, the grain size varied from 20 grains $/ 640 \mu \mathrm{m}$ thickness for cup LR315-2 to 28 grains/ $640 \mu \mathrm{m}$ thickness for cup LR318-6.

Metallographic examination of an axial cross section through the weld bead indicated that the microstructure consisted of randomly oriented. equiaxed grains in the center of the weld bead, that there was no porosity, and that the penetration was complete.

Metallographic examination of the vent-assembly cross sections of FC-232 and FC-238 showed that both vent orifices were free of deposits, that the entrance to the filter element of the vents contained only a small quantity of plutonia, and that the decontamination cover and vent-assembly welds were sound.

\section{B. SVT-2}

This module was also tested in the minimumi-gamma reentry mode at an orientation of $\alpha=\beta=0^{\circ}$. The impact temperature was $919^{\circ} \mathrm{C}$ (clad) and the velocity was 55 $\mathrm{m} / \mathrm{s}$ against a target of hardened steel.

The condition of the graphitic components was similar to that of graphitic components in SVT-1. The aeroshell had impact-face cracks about parallel to the GIS axes, and it was fracturcd on both nonclosure narrow faces. Both impact shells had bowed profiles and irregular impact-face cracks along about $80 \%$ of the length.

There were no failures or severe localized iridium deformation in either FC-355 or FC-369. the fucled clads of the primary impact assembly, or in clad FC -273 of the secondary imipact assembly.

The fueled clad positioned in the closure end of the secondary impact shell, FC-449. suffered three failures: 


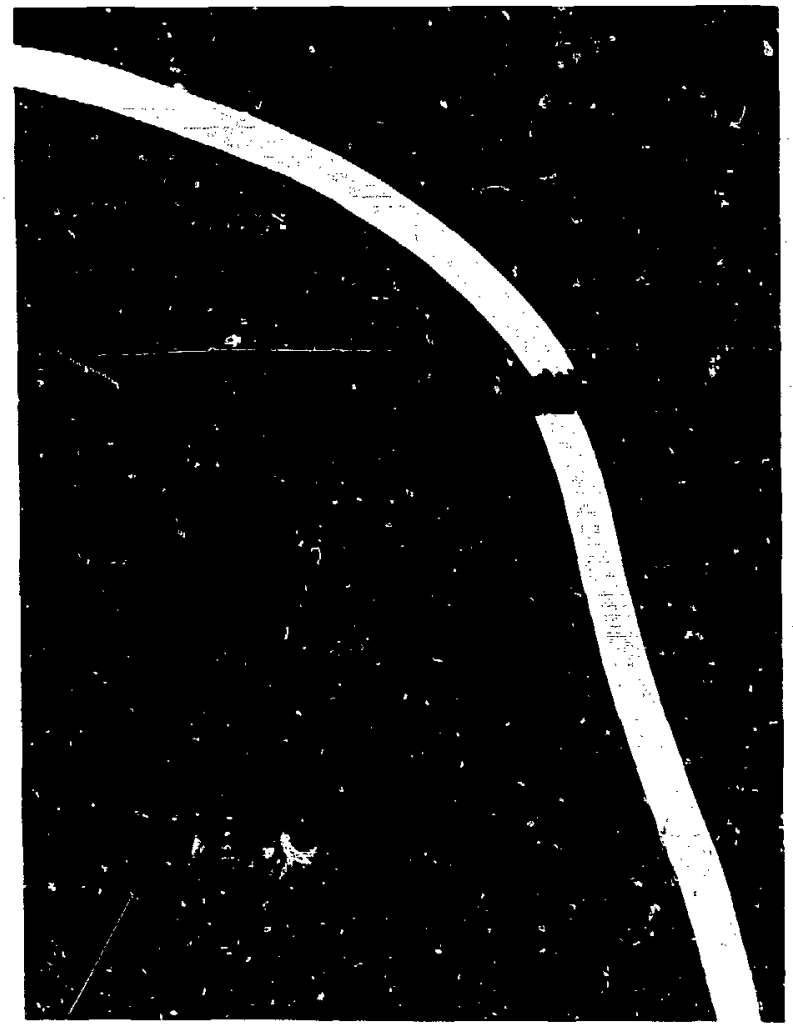

(a)

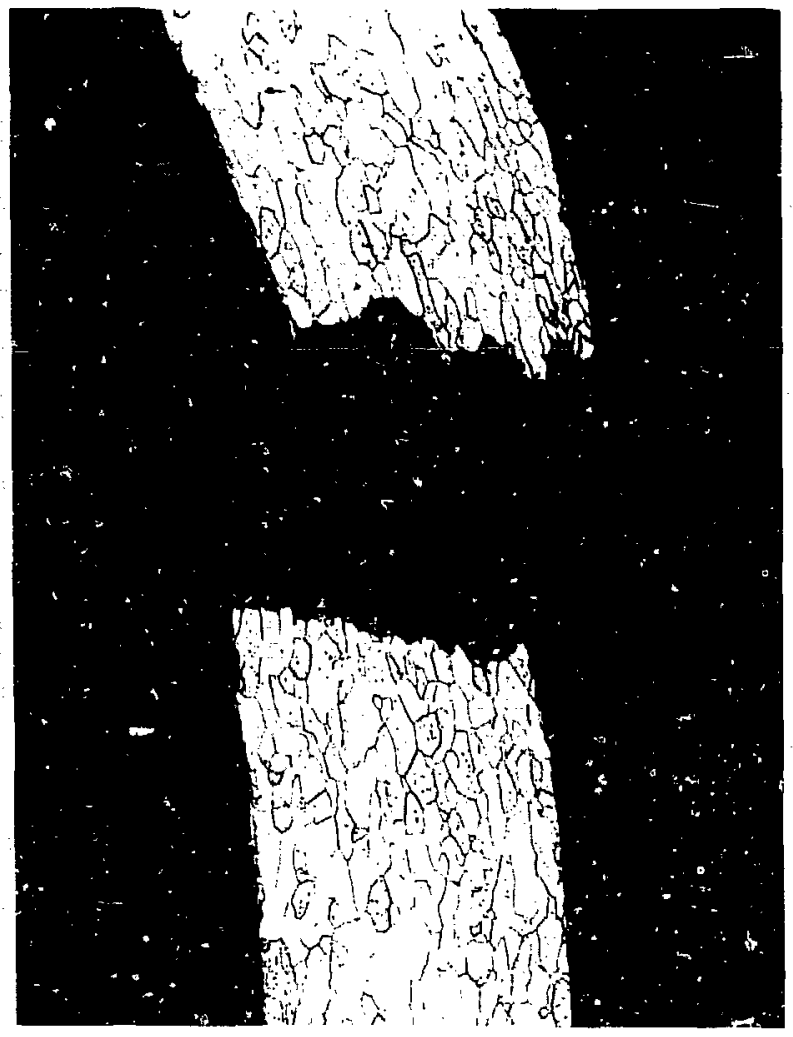

(b)

Fig. 12. The fracture on the back side of the shicld cup of FC-410 was also of the fucl-fragment push-through type. (a) $7 \times$, (b) $50 \times$.

an axial failure on the back side, a failure on the centerline of the weld bead. and a failure on the vent-cup radius on the back side. Figure 13 illustrates the observed failures. The weld-bead failure was in a singlepass region of the weld bead, about $180^{\circ}$ from the weld over!ap and about $90-100^{\circ}$ from the center of the impact face.

Metallographic cross sections through the failures of both cups on the back side of FC-449 (Fig. 14) show that the fracture mode was intergranular with no significant reduction of thickness: however, radial displacement of the sides of the fractures indicates fuel-fragment pushthrough.

Figure 15 shows the metallographic cross section through the fractured weld bead. The microstructure of the weld consists of small, randomly orienied grains that uould not be particularly subject to failures along the centerline of the bead; however, relative displacement of the two sides of the fracture suggests that the failure was caused by fuel push-through effects similar to those seen on the impact face and back side of the cylinder portion of other assemblies. An AES analysis of the weld bead did not show any unusual impurities, though the thorium content on the vent-cup side of the weld was higher than that on the shield-cup side.

The metallographic cross section through the fracture in :he vent-cup corner is shown in Fig. 16. The fracture mode is intergranular with no indication of reduced thickness and no displacement of the two sides of the fracture. This is a low-strain region of the capsule, so the reason for failure at this location is not evident.

Examination of the microstructure of the FC-355 weld bead (Fig. 17) revealed a crack that extended about $25 \%$ of the thickness from the interior surface. The weld sample cross section was located on the side of the impacted fuel clad and by chance included the weld overlap region. The observed crack is doubtlessly a preexisting fabrication defect and not an impact-induced 


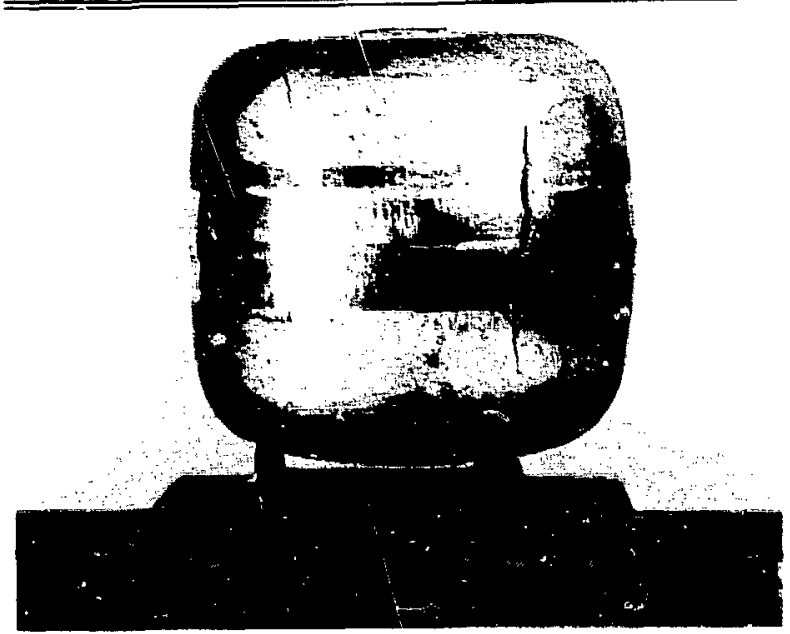

(a)

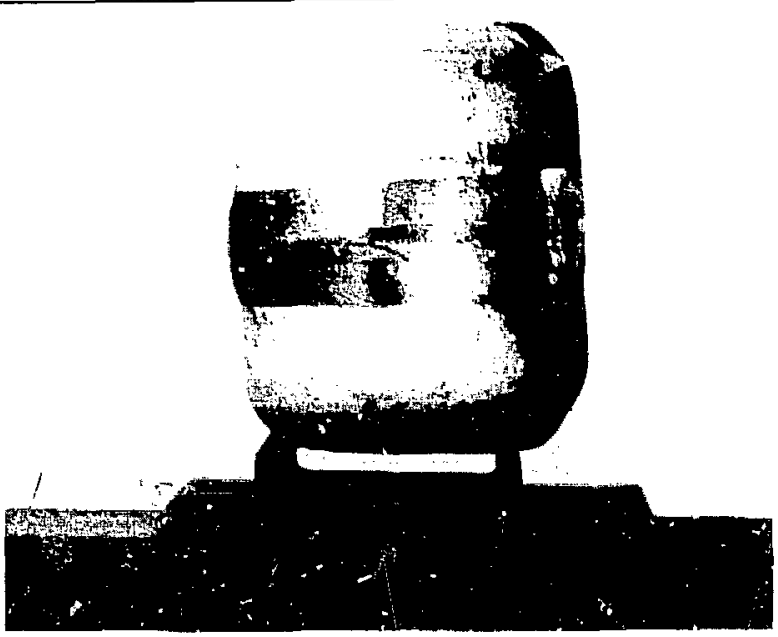

(b)

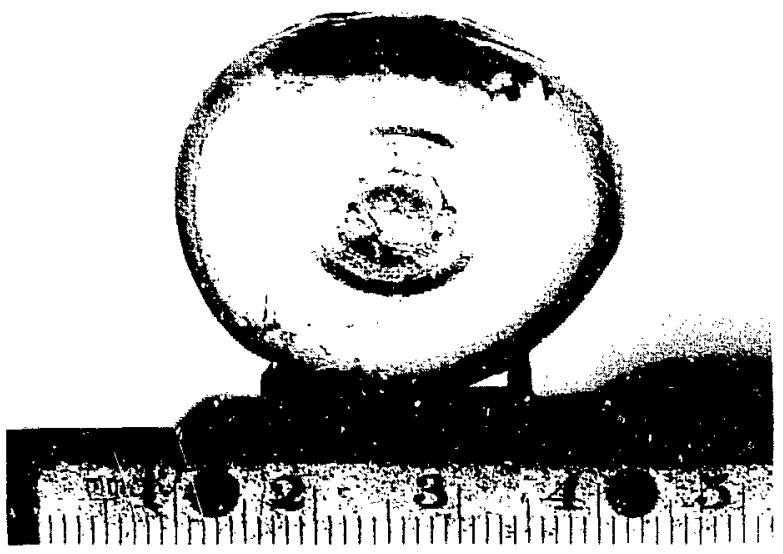

(c)

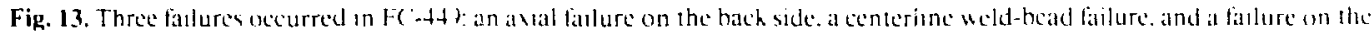
vent-cup radius on the bate side. (a) Back side. (b) side protile. and (c) vent-end view.

failure. The micros:ructure of the center of the weld bead includes undesirable clongated grains oriented approximately normal to the thickness of the capsule wall.

The microstructures of the iridiun clads were uniform. The observed grain sizes ranged from 28 grains $/ 640 \mu \mathrm{m}$ thickness for cup NR528-3 to 21 grains/640 $\mu \mathrm{m}$ thickness for rup Q806-2.

Vent-assembly metallographic examination of FC -355 and FC-369 showed that the vent orifices were free of deposits and that only a small quantity of plutonia was deposited in the entrance to the vent filter element. The decontamination cover and ventassembly welds to the clad were free of defects.

AES analysis of the grain-boundary chemistry of the iridium clad reveaicd expected concentrations of thorium. Small amounts of phosphorus were present in samples from $F(-355$ and $F(-369$ (prime). Iron was 1 lac principal impurity element detected by emission spectroscopy.

The microstructure of the prime plutonia pellets wals normal. and no impurities exceeding the SRP guidelınes were present.

\section{SVT-3}

This assembly was prucessed for simulation of an orbital-decay reentry and was impacted in the $12=\beta=0$ " orientation. The impact temperature was $975^{\circ} \mathrm{C}^{\circ}$ (clad) and the impact velocity was $54.4 \mathrm{~m} / \mathrm{s}$; rainst a stecl target. Continuous monitoring of the $1 . \mathrm{t}: 1 \mathrm{~m}$ released 


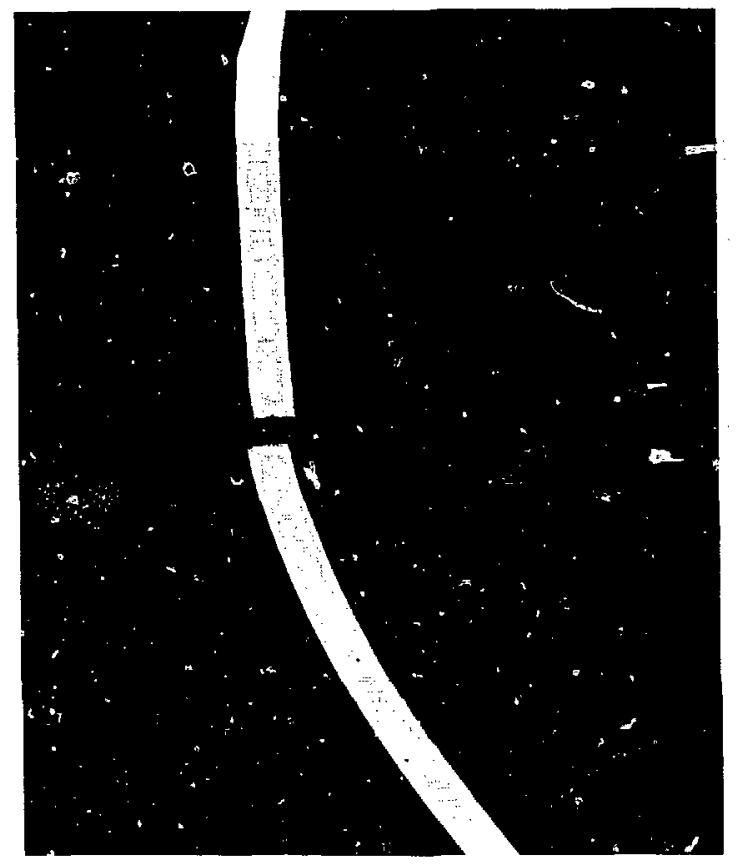

(a)

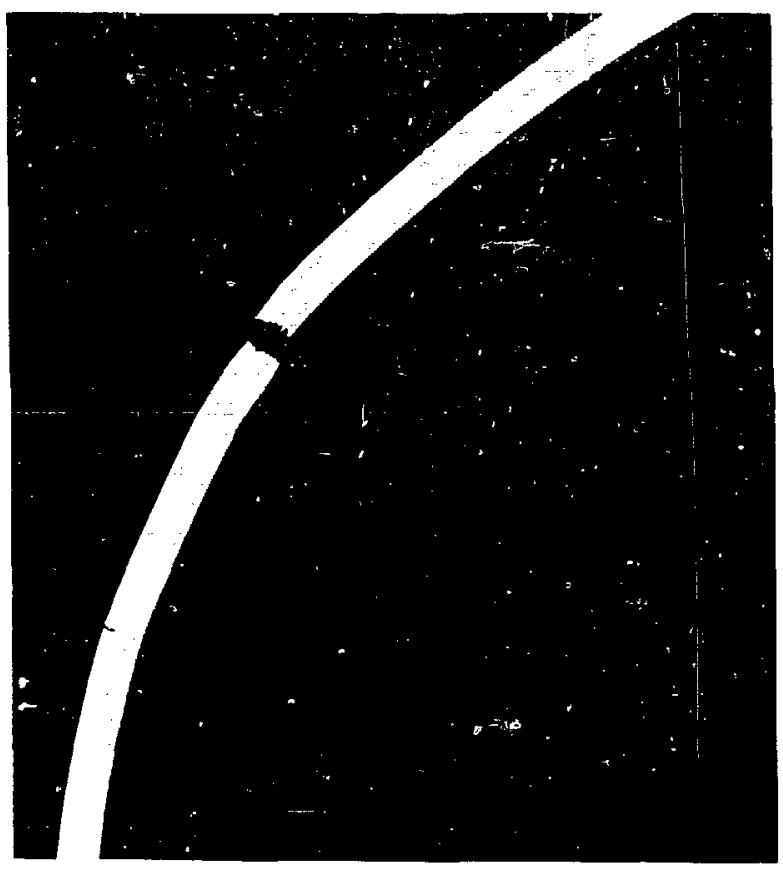

(c)

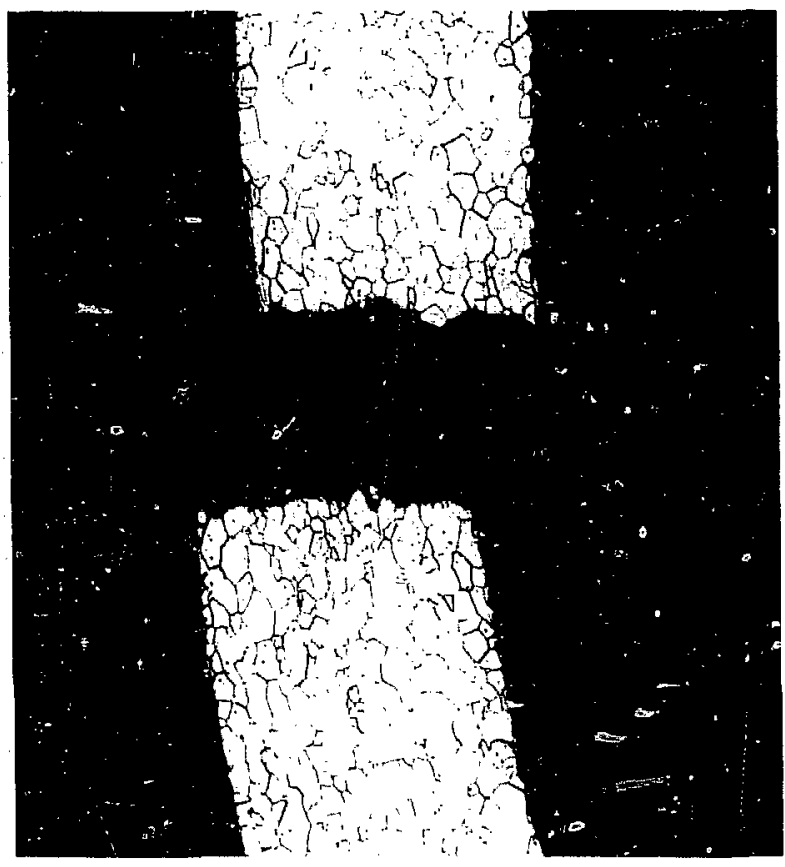

(h)

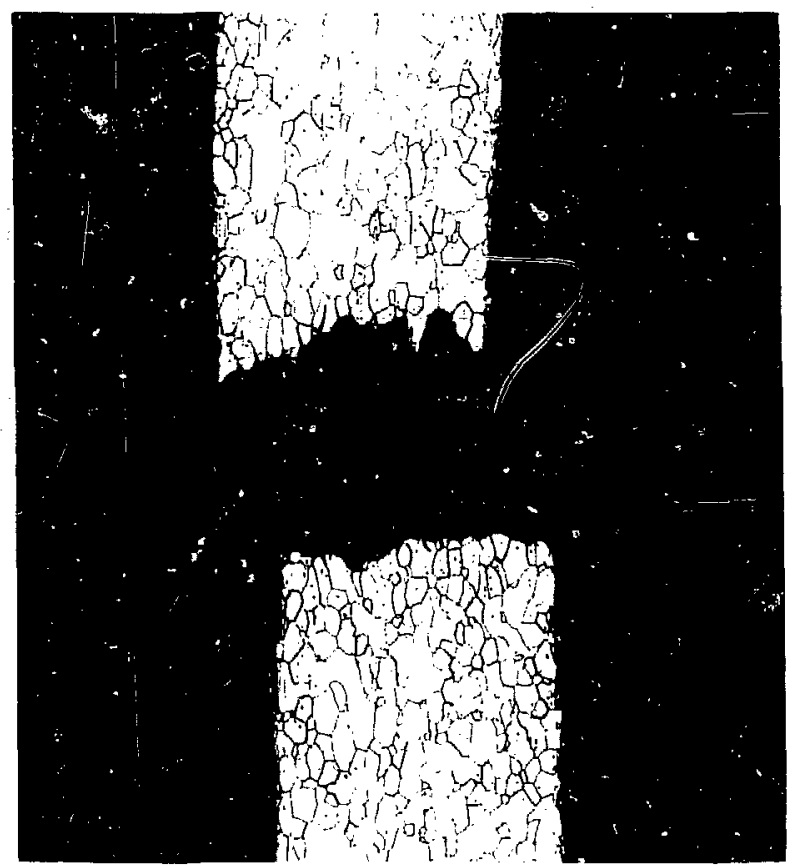

(d)

Fig. 14. Failures on the back side of FC-449 occurred in areas of mild localized iridium deformation. Shield cup (a) $7 \times$ and (b) $50 \times$. Vent cup (c) $7 \times$ and (d) $50 X$. 


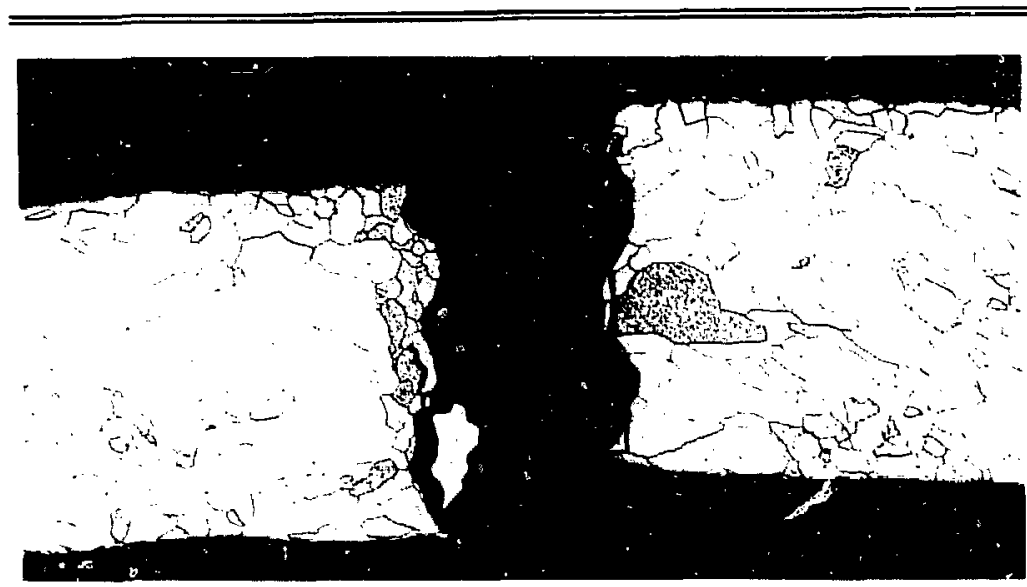

Fig. 15. The microstructure of the center of the FC -449 weld bead consisted of small, randomly oriented grains. Radial displacement oi the two sides of the fracture suggests unequal strain across the weld. $50 \times$

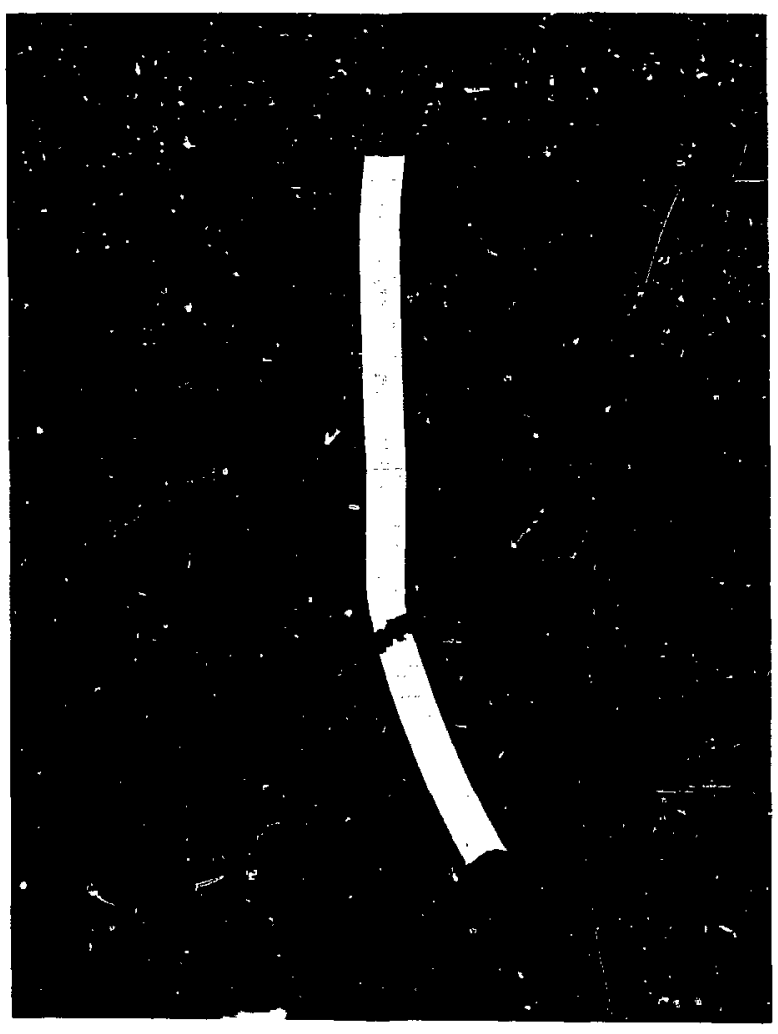

(a)

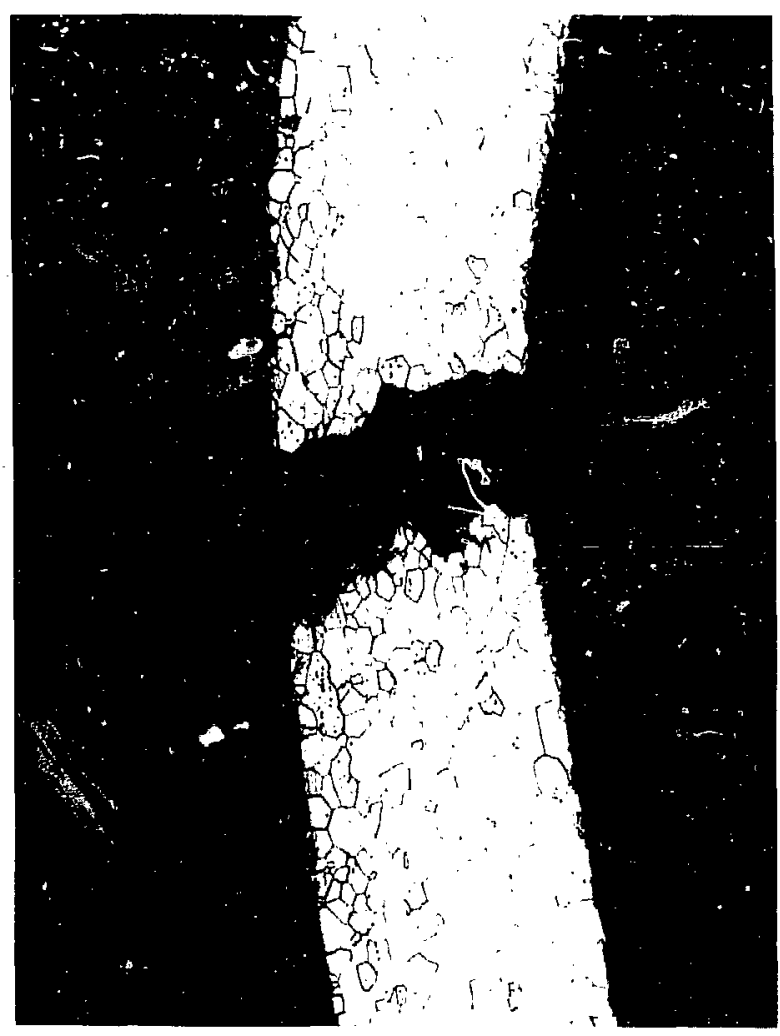

(b)

I. The failure on the vent-cup radius of FC-449 exhibited no evidence of fuel-fragment push-through, and the fracture $u$ urted with no indication of ductitity. (a) Photomacrograph $7 \times$. (b) $50 \times$. 


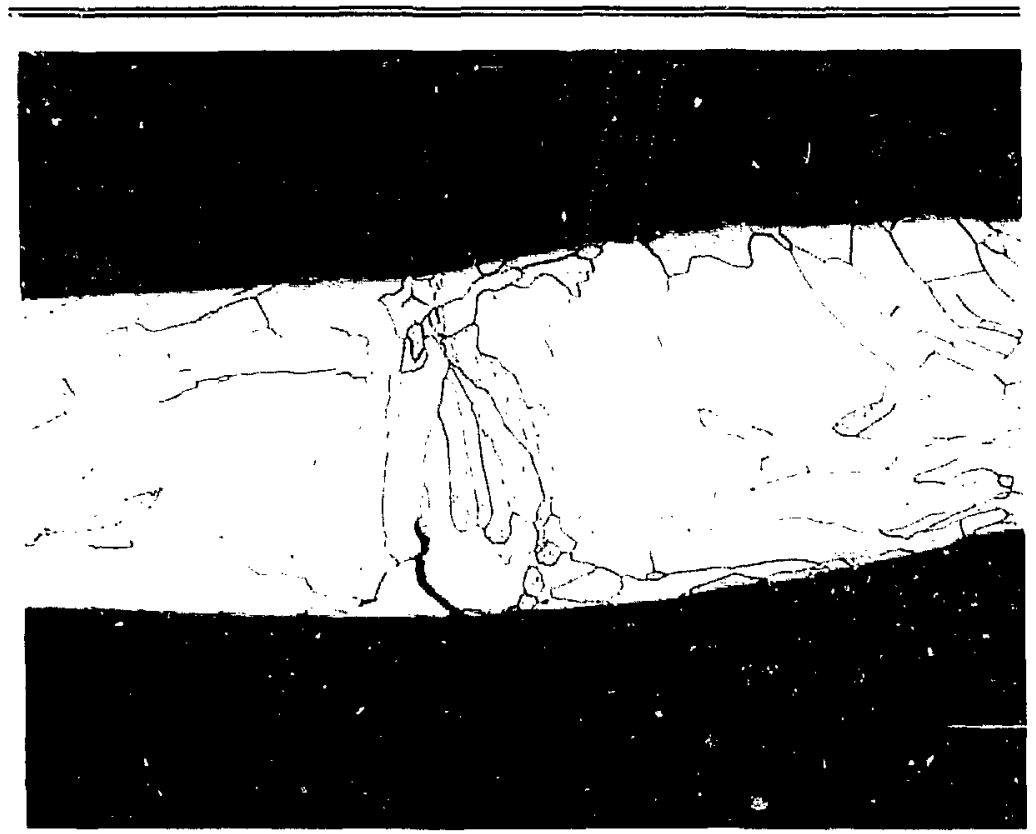

Fin. 17. The microstructure of the weld heid of $\mathrm{FC}-355$ contained clonsated grains uriented normal to the wall thickness; a rack extending about $25^{14}$ of the thickness in the weld overlap was present. $50 \times$.

from the test assembly sinwed that there were several periods during the initial $680 \mathrm{~h}$ of the 90-day aging exposure in which the helium released was equivalent to $75 \%$ of the generation rate, indieating intermittent vent plugging of one fueled clad.

There were no fractures on the impact face or narrow faces of the acroshell. but a diagonal crack was present on the back side. Both impact shells had bowed protiles and impact-face cracks spanning ahout $70 \%$ of the length.

No fractures of the iridium clads of the primary impact assembly. $F(-343$ and $F(-350$, or of the secondary impact assembly clad. $F(-457$, were observed.

Figure 18 a shows a smiall fracture in the center of the back side of the $F(-45+$ shield cup. This capsule also displayed a significant quantity of vent effusate surrounding the vent hole as shown in Fig. 18b.

Metallographic examination of a transverse cross secwon through the back-side fracture of the F(-454 shield cup revealed that the fracture mode was intergranular with a small reduction in thickness of about $4 \%$ near the fracture. The photomicrographs of Fig. 19 show no serere localized deformation of the iridium in this clad area and no radial displacement by fuel fragments to account for the fracture.

tuger electron spectroscopy analysis of the grainhoundan chemistry of samples taken adjacent to the fracture in the $F(-454$ shicld cup revealed high sulfur concentrations. Small quantities of sulfur were also ooserved $a$ some locations in san ples from FC-355 and FC -369. Thorium concentrations at all sample interiors were lower than in the center and exterior locations. The principat impurity element detected by emission spectroscopy was iron.

Figure 2n shows a meiallographic cross section through the vent orifice and the intermetallic reaction products on the exterior surface surrounding the orifice of FC-454. A porous deposit of iridium-tungsten alloy was present on the wall of the orifice. particularly near the interior. The four phases on the clad exterior were identified as (1) iridium, tungsten, and iron; (2) iridium. plutonium, and titanium: (3) iridium and plutonium: and (4) iridium and iron. The vent orifices of the other fueled clads did not show any effused materials, therefore FC-454 probably was responsible for the observed periods of ver.t plugging.

The vent 'srifices of FC -343 and FC-350 were free of vapor-transiported material, and only small quantities of plutonia were deposited at the vent entrance. The decontamination cover and vent-assembly welds of FC-350 were free of defects or abnormal microstructures. The weld areas of FC-454 exhibited a large grain size, and in FC-343 large grains were observed on one side of the sample while normal microstructure exisied on the other. These features are illustrated in Fig. 21. 


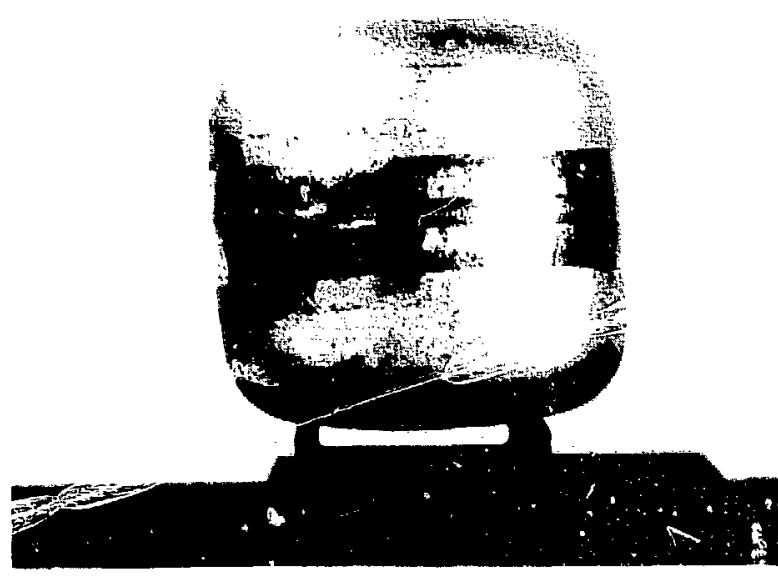

(a)

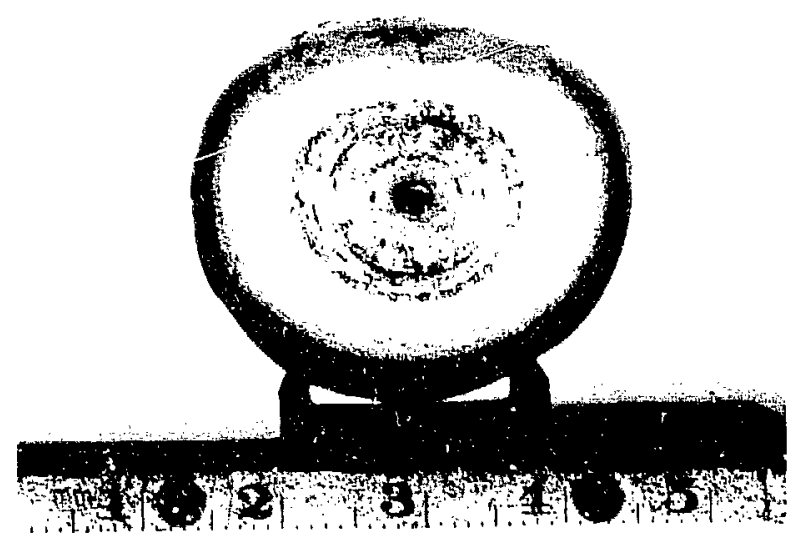

(b)

Fig. 18. A small fracture in the center of the back side of FC -454 was the unly fallure in $S V T-3$ (a). Eflusate surrounding the vent orifice indicates that this vent was plugging during the aging treatment (b).

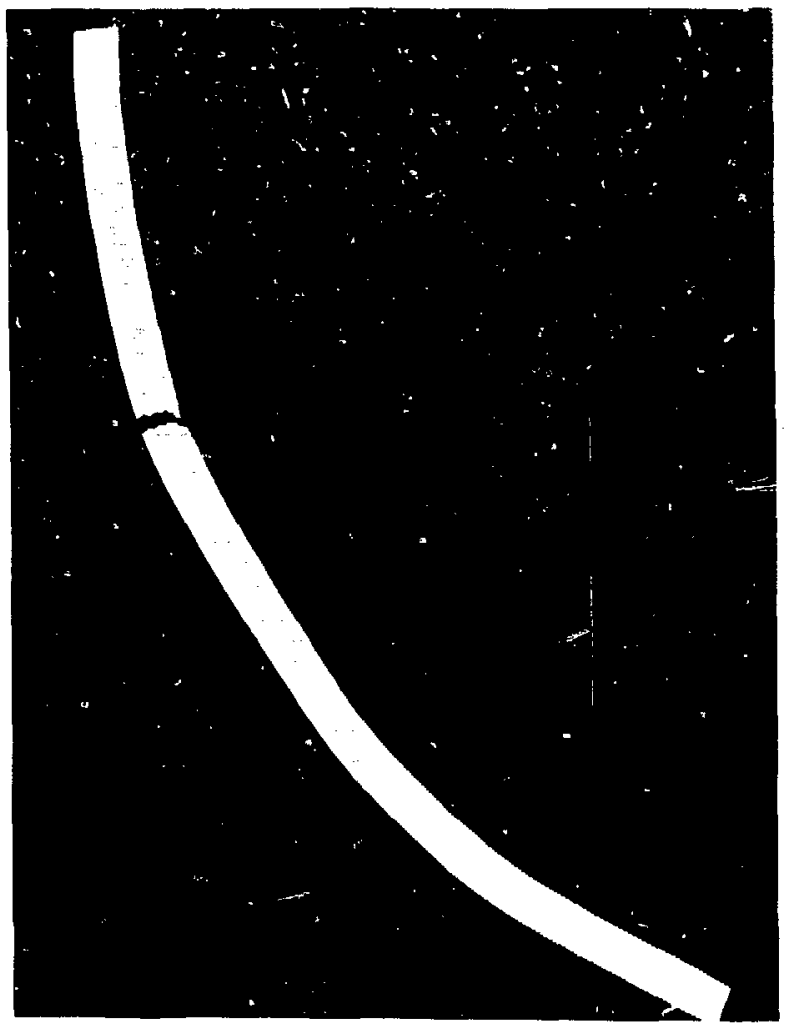

(a)

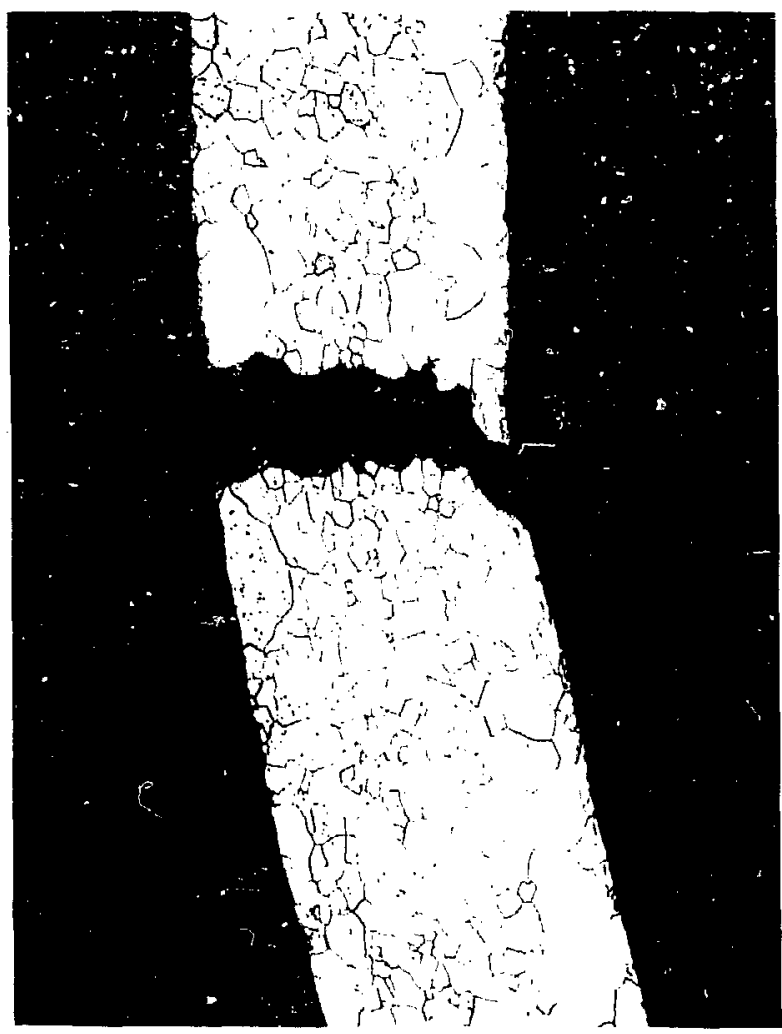

(b)

Fig. 19. Failure in the shicld cup of $\mathrm{FC}-454$ occurred in an area without s:vere localized iridium deformation or indications of fucl-tiagment push-through. (a) $7 \times$. (b) $50 \times$. 


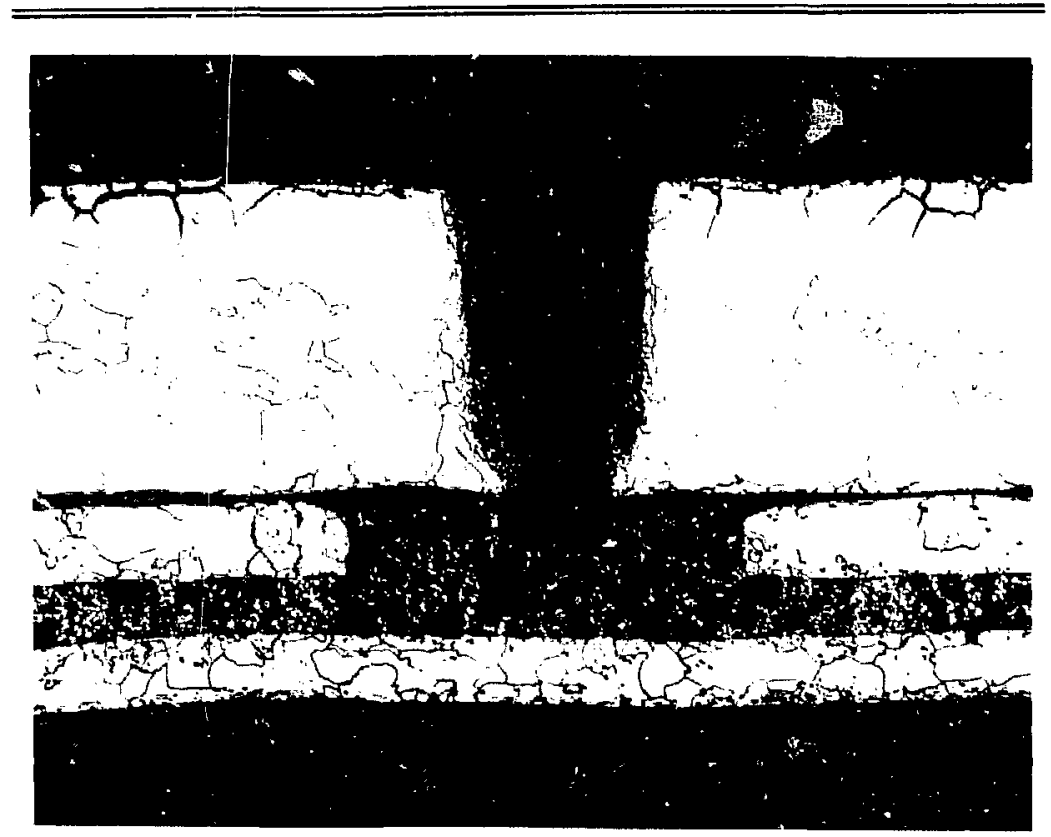

(a)

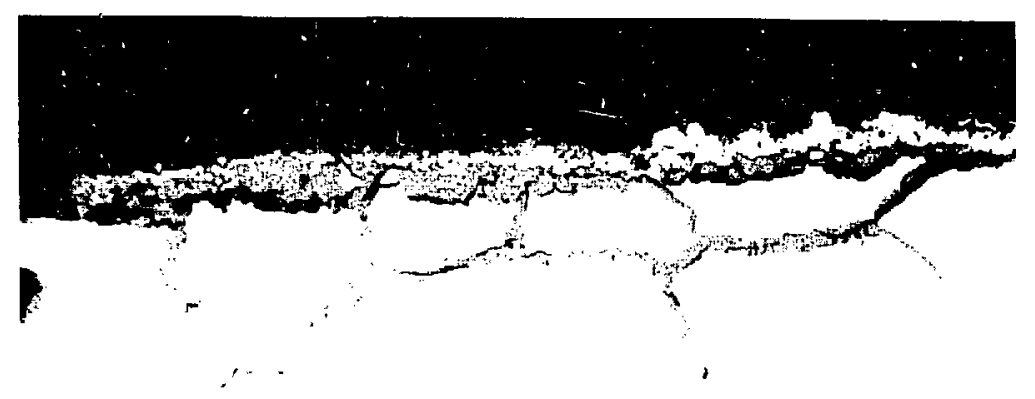

(b)

Fig. 20. The orifice of the $F(-454$ vent had a deposit of iridiumtungsten alloy. Intermetallic reaction products were present on the clad exterior. (a) $50 \times$. (h) $250 \times$. 

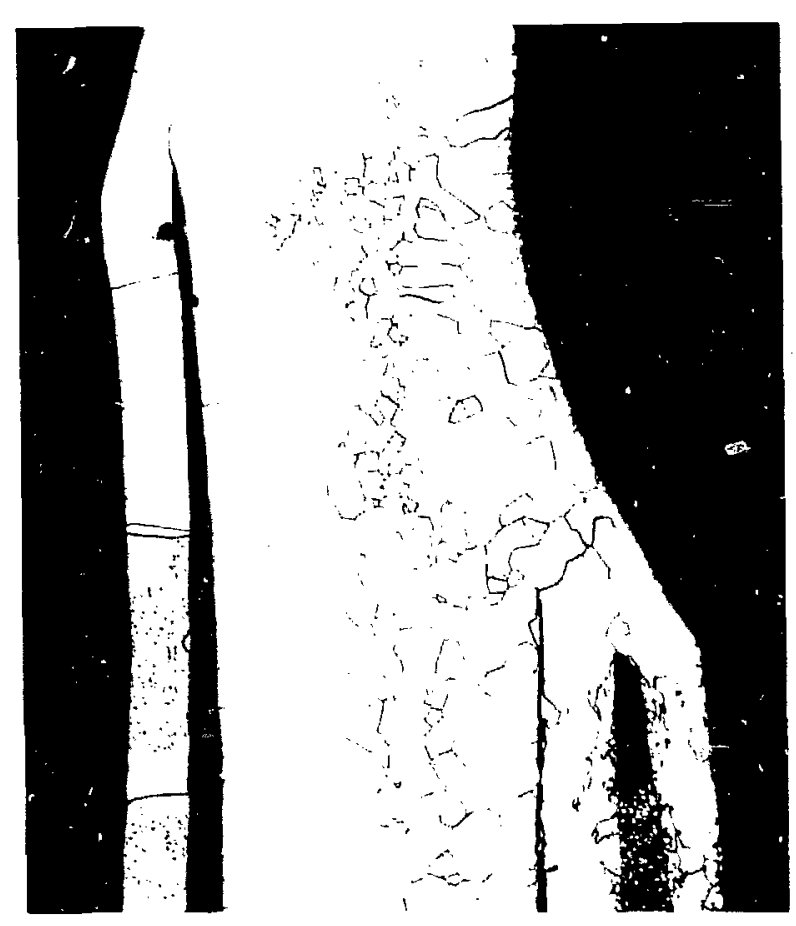

(a)

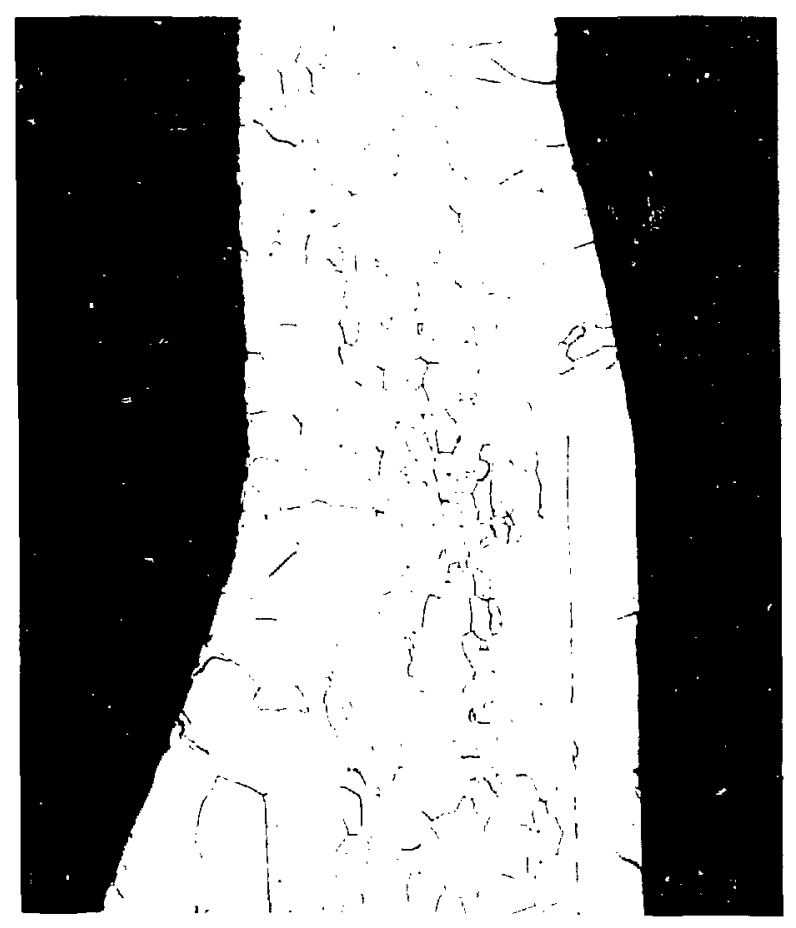

(c)
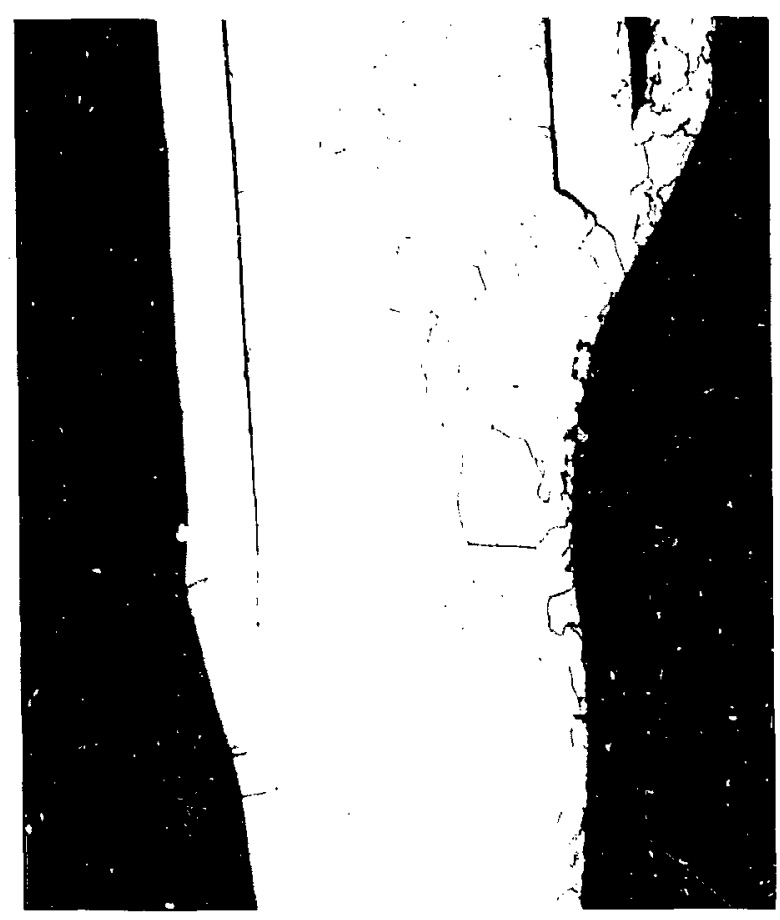

(b)

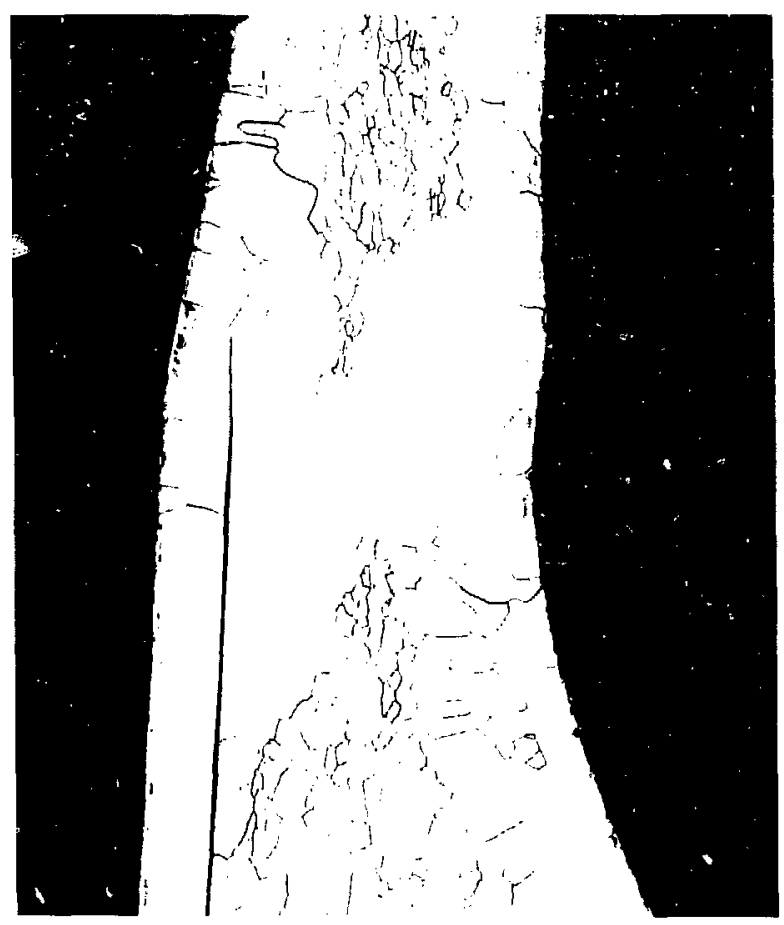

(d)

Fig. 21. Abnormal grain growth occurred in the vent-assembly welds of FC-454 (a,b) and FC-343 (c,d). $50 x$. 


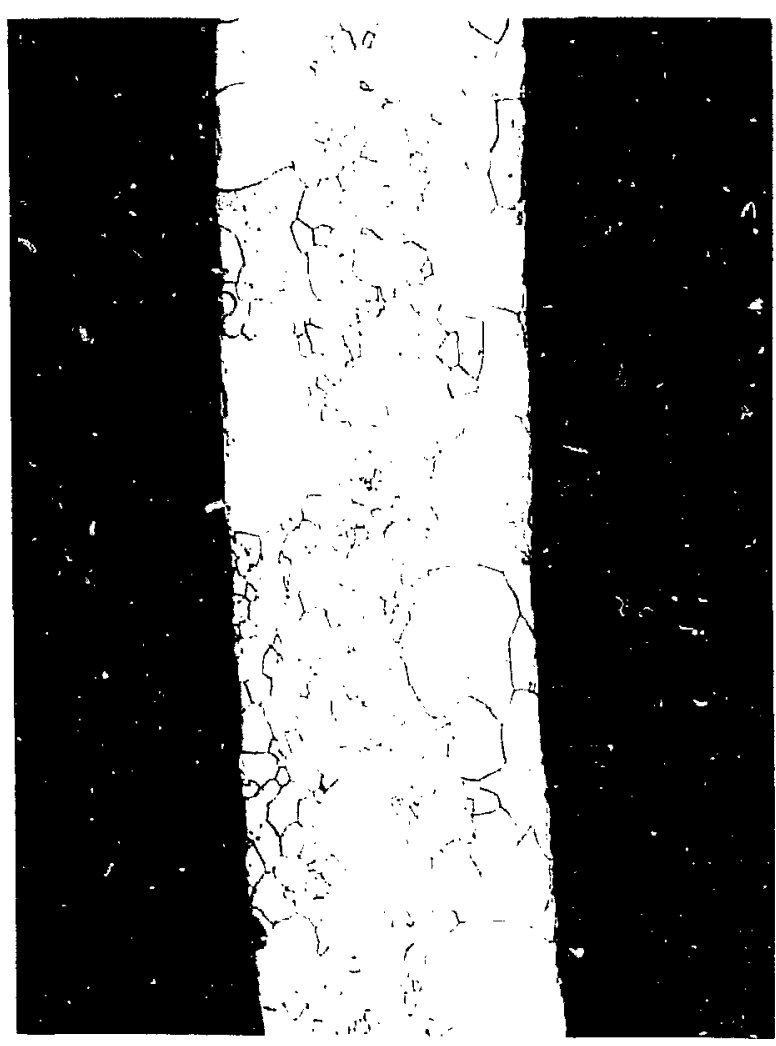

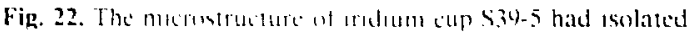

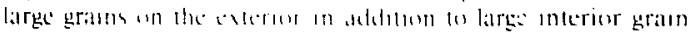
पार्ष

Th: irudium microstructures observed were nonuniform ateross the thickness. Ty pically the interior 20-25\% of the thickness showed a large grain size. Isolated occurrences of large grain size were also observed on the cutcrior of cup $\mathrm{S} 34-5(\mathrm{~F}(-454)$. as illustrated in Fig. 22

Metallographic examination of the cross section through the welds of $F(-343$ and $F(-350)$ indicated that the welds were free of porosity. had penetrated completely, and had microstructures consisting of randomly urented grains in the center of the weid bead.

The microstructure of the primary fueled-clad plutonia pellets was typical. Pellets HF-350 and HF-454 ach had a calcium concentration of $200 \mathrm{ppm}$, which slightly exceeds the SRP guideline.

\section{I). $\$ Y T-4$}

- - 4 : $:$ duplicated SVT-3, that is. with orbital-decay and and an an and $\alpha=\beta=0^{\circ}$ orienta: a - is atecl target. The impact temperature was $\therefore \quad:$ and the impact velocity was $54 \mathrm{~m} / \mathrm{s}$.

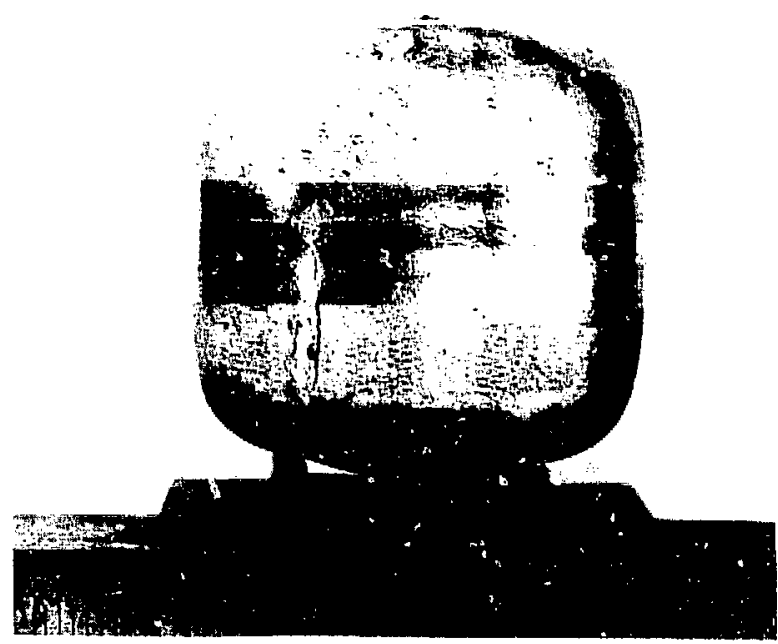

Fig. 23. FC-348 sustained a fucl-fragment push-lhrough crask on the impate face, principally in the shicld cup.

Continuous monitoring of the helium released from the four fueled clads showed no evidence of vent plugging throughout the 90-day aging exposure.

Damage sustained by the aeroshell was similar to that observed in the previous three lests conducted in the $\alpha=$ $\beta=0^{\circ}$ orientation. There were irregular cracks on the impact face near both edges of the aeroshell body and a fracture the full length of the narrow face on the PIA side of the atroshell. The fracture on the other narrow side extended only about $50 \%$ of the length. A dent was present on the back side with cracks radiating to the corners. Several longitudinal cracks distributed over the impact face occurred in the inipact shell of the primary impact assembly. This failure mode differs from the single crack on the center of the impace face usually observed. Both impact shells exhibited the typical bowed profiles.

No failures occurred in the iridium clad of $\mathrm{FC}-354$ of the PIA or in eithes of the fueled clads. FC-139 and FC-162. of the SIA. Only mild to moderate localized iridium deformation was observed in these units.

A longitudinal fuel push-through failure in a reversebend area was present on the impact face of FC -348 . The fracture extended nearly the full length of the shield cLp and a short distance into the vent cup, with a discontinuity at the weld: Fig. 23 illustrates the location and extent of the failure.

Metallographic cross-sections taken transversely through the fractures of the shield cup and the vent cup are shown in Figs. 24 and 25 . respectively. The 


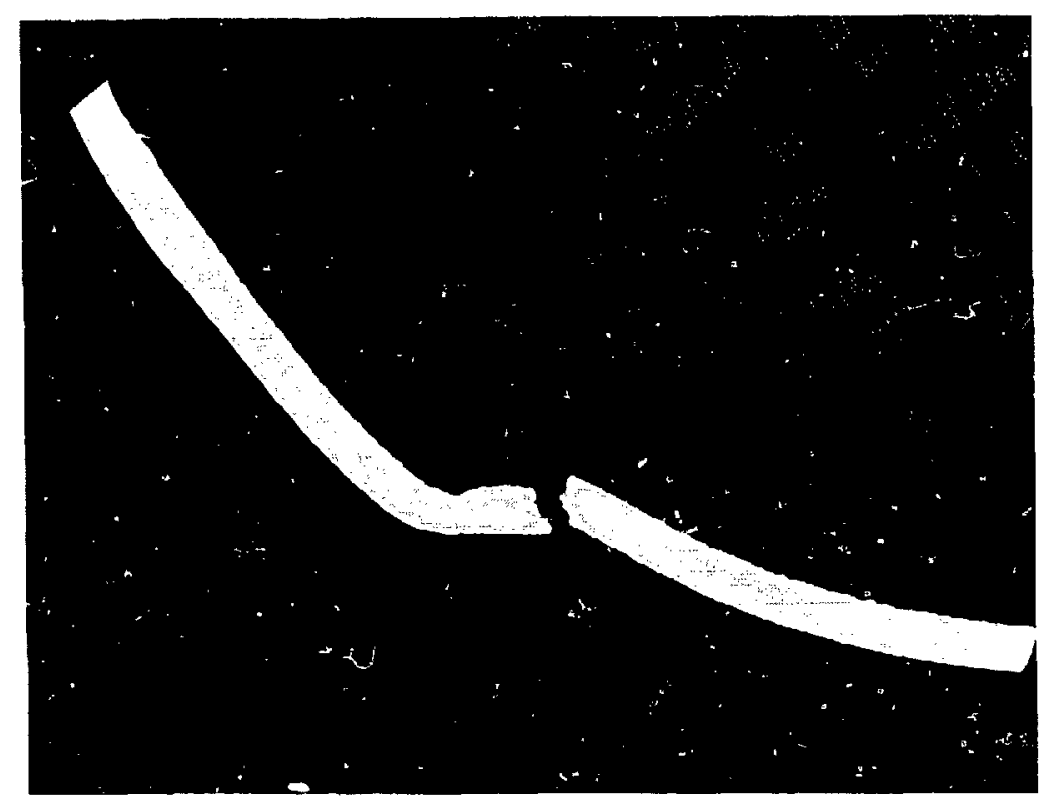

(a)

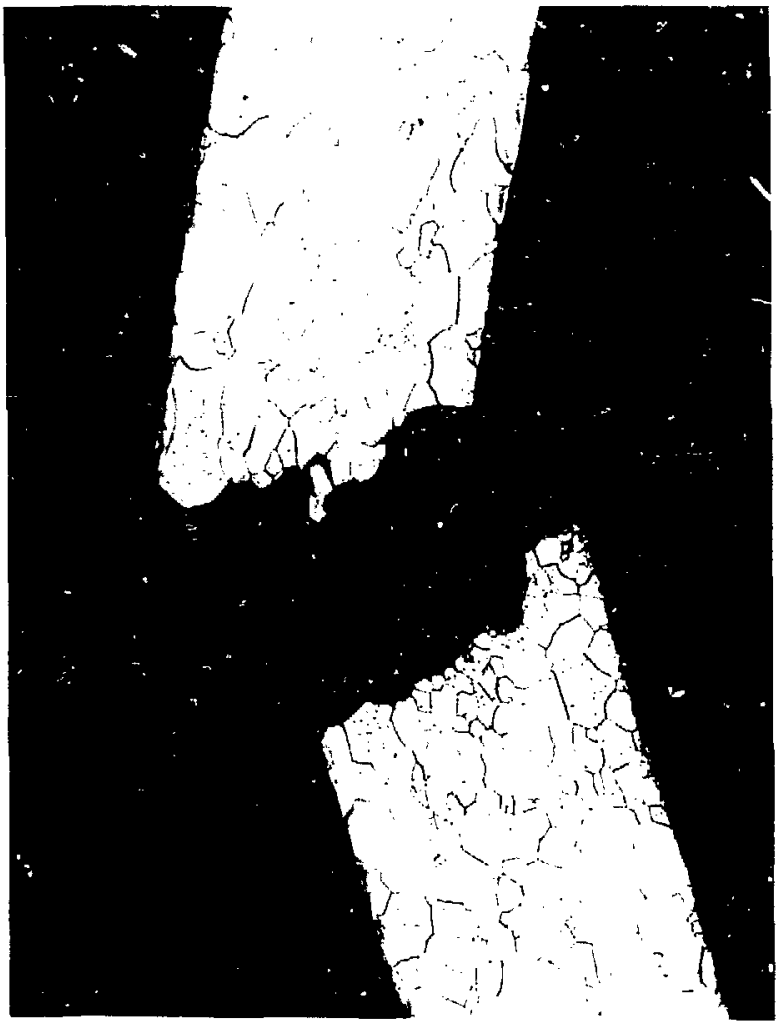

(b)

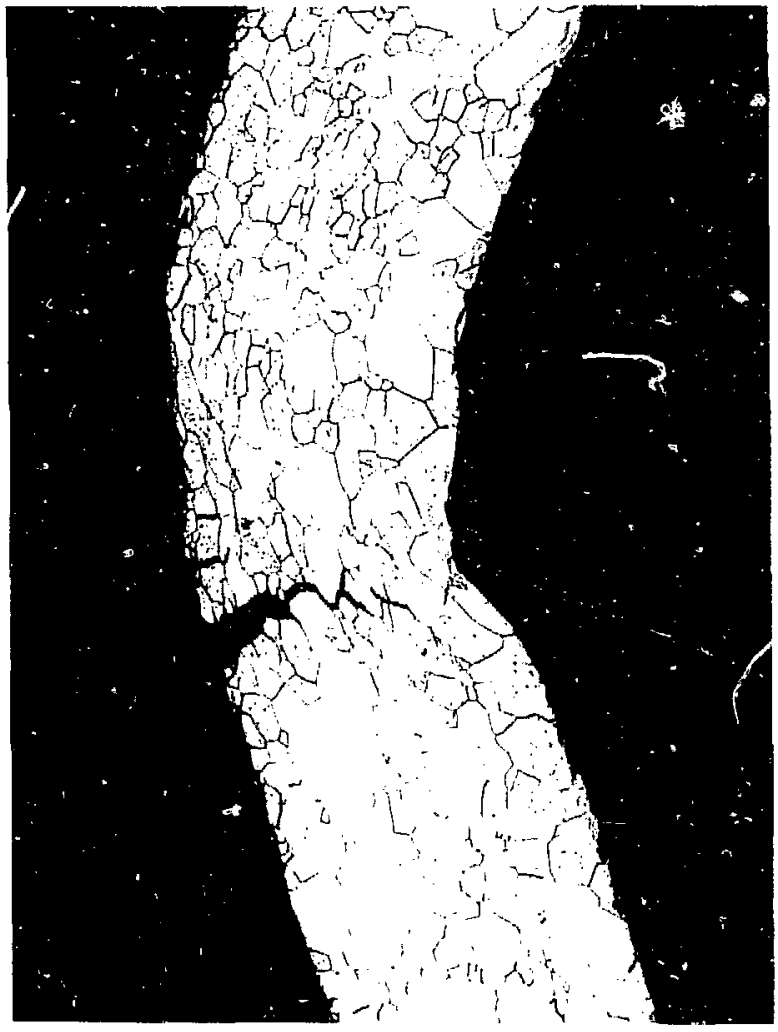

(c)

Fig. 24. The impact-face failure in the shield cup of $F(-348$ oceurted in a region of severe reverse bending near a fuel-fragment indentation. (a) $7 \times$. (b) and (c) $50 \times$. 


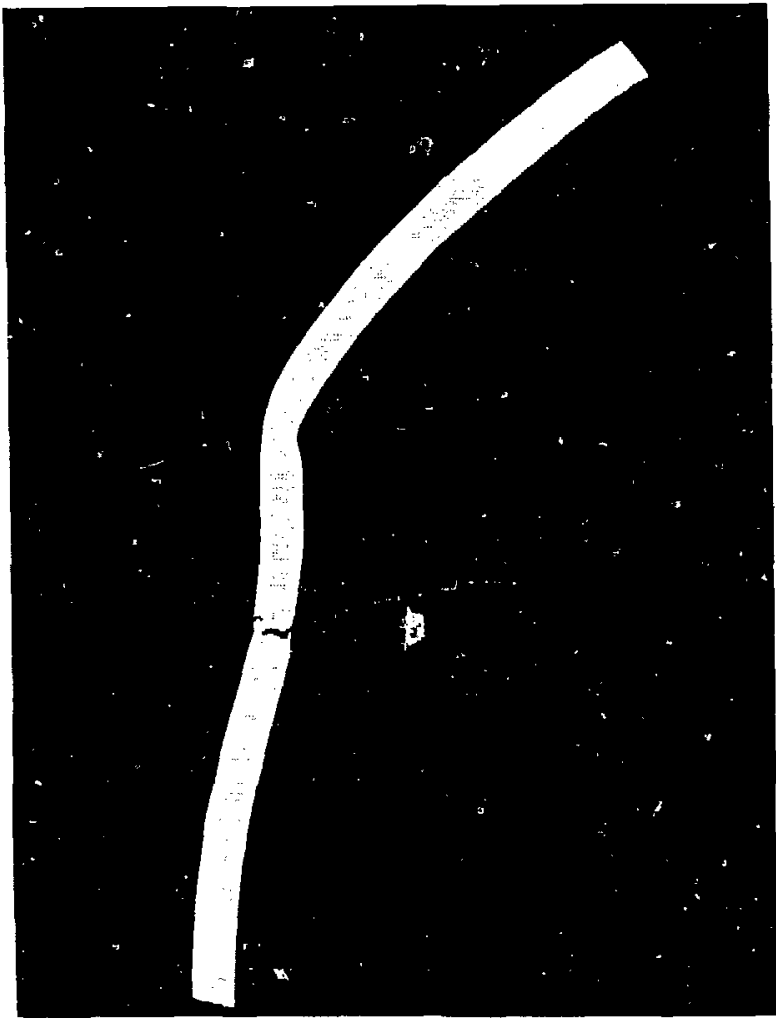

(a)

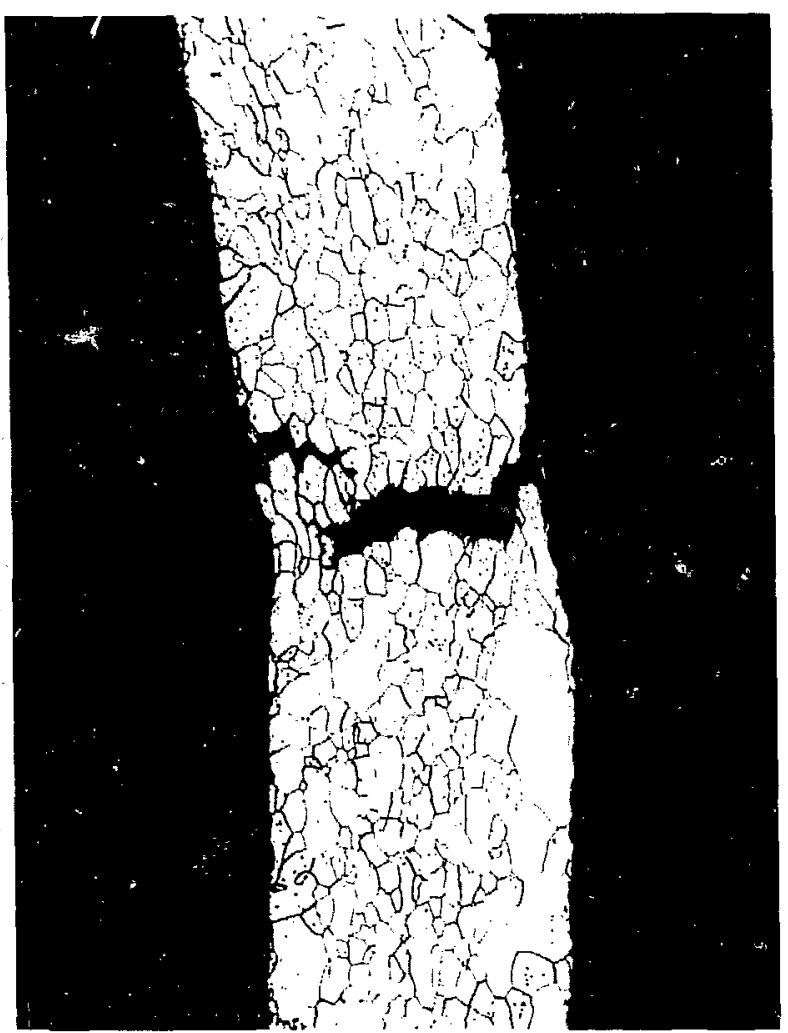

(b)

Fig. 25. Deformation in the vent cup of FC-348 also exhibited the fuel-fragment push-through characteristics. Failure occurred after modest reduction in thickness.

photomacrographs clearly illustrate the point of fuelfragment indentation. with failure occurring in the reverse-bend region nearby. The shield-cup cross section also shows a crack progressing from the exterior surface through about two-thirds of the wall thickness. The primary fracture in the shield cup exhibits negligible reduction of thickness at the fracture site and about $15 \%$ reduction of thickness at the point of fuel-fragment indentation. A reduction of thickness of about $9-10 \%$ at the fracturc site in the vent cup indicates a limited amount of ductility. The fracture appears to lack about one grain thickness of full penetration on this plane, but quite likely penetrated through the thickness somewhere along its length.

Though no failures were observed in FC-354 of the primary impact assembly, a crack progressing through about $40 \%$ of the wall thickness occurred in the reversebend region of the impart face. as illustrated in Fig. 26. The degree of fuel-tragment indentation and reverse bending at this location was comparatively mild.
AES analysis of the iridium grain-boundary chemistry of FC-345 and FC-354 showed that in mo: samples, the thorium concentration was depleted at the interior surface. Small concentrations of sulfur were detected in samples from the shield cup of FC-354. Cup QR820-2 had higher concentrations of chromium, iron, and nickel impurities than did the other cups of the primary fueled clads.

The iridium microstructures observed were similar to those of cups in SVT-3, with large interior grains occupying $20-25 \%$ of the wall thickness. The range of observed grain sizes was 18 grains $/ 640 \mu \mathrm{m}$ thickness for cup QR820-1 to 15 grains $/ 640 \mu \mathrm{m}$ thickness for cup QR820-6.

Examination of vent-assembly cross sections indicated similar conditions for both FC-343 and FC-350. The vent orifices were free of vapor-transporied deposits, a small quantity of plutonia was deposited at the entrances to the vent assemblies, and the decontamination cover and vent-assembly welds were free of defects. 


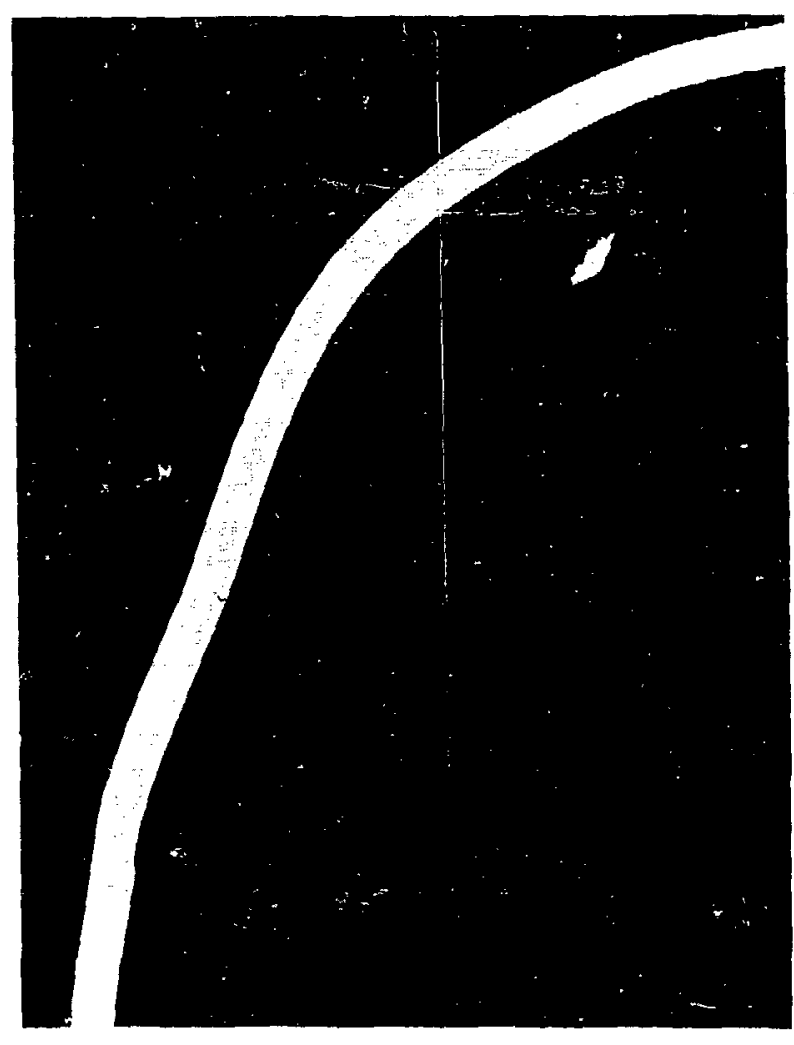

(a)

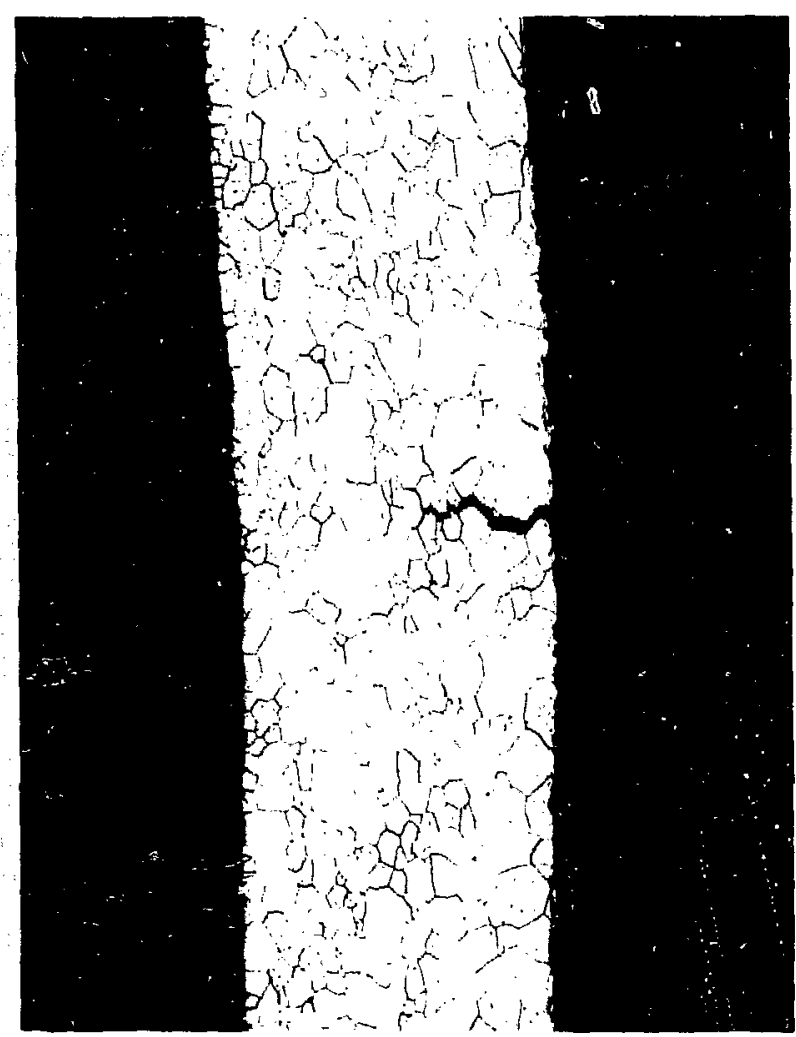

(b)

Fig. 26. A crack observed in FC-354 traversed about $40 \%$ of the wall thickness from the interior at a location of mild icverse bending. (a) $7 \times$, (b) $50 \times$.

Axial cross sections through the capsule closure welds showed that these welds were of high quality. There was no porosity, the weld penetrated completely, and the microstructure did not contain any undesirable characteristics.

All impurity elements in the plutonia pellets were well below SRP guidelines. The microstructures were typical. though HF-354 had a somewhat smaller grain size.

\section{E. SVT-5}

This test module was designated for impact testing in the orbital-decay rcentry mode with impact against a steel target on the narrow, nonclosure face of the aeroshell $\left(\alpha=90^{\circ}, \gamma=0^{\circ}\right)$. The impact temperature was $975^{\circ} \mathrm{C}$ and the impact velocity was $54.0 \mathrm{~m} / \mathrm{s}$.

Figure 27 shows the module in the catch tube and the aeroshell after the impact assemblies have been removed. The impact face of the aeroshell was separated from the body along fractures parallel to the axis of the lead impact assembly. The aeroshell closure cap of the lead impact assembly was not retained and a circular disk was torn from the opposite end, leaving the lead impact assembly free to be ejected from the aeroshell. The closure cap of the lead impact shell was not retained in the body, and one of the fueled clads was partially out of the impact shell. Damage to the lead impact shell was greater than that sustained in the $\alpha=\beta=0^{\circ}$ orientation. In addition to a crack on the impact-face centerline that was wider than is usually observed. there were cracks on each side about midway between the centerline and edge of the impact face. The trailing impact shcll had a typical irregular crack on the impact face and a transverse crack on the back side about $8 \mathrm{~mm}$ from the closure end.

No failures were observed in any of the fueled clads. As expected, the gross deformations of the fueled clads in the lead impact assembly were greater than (about twice) those of the clads in the trailing impact assembly. 


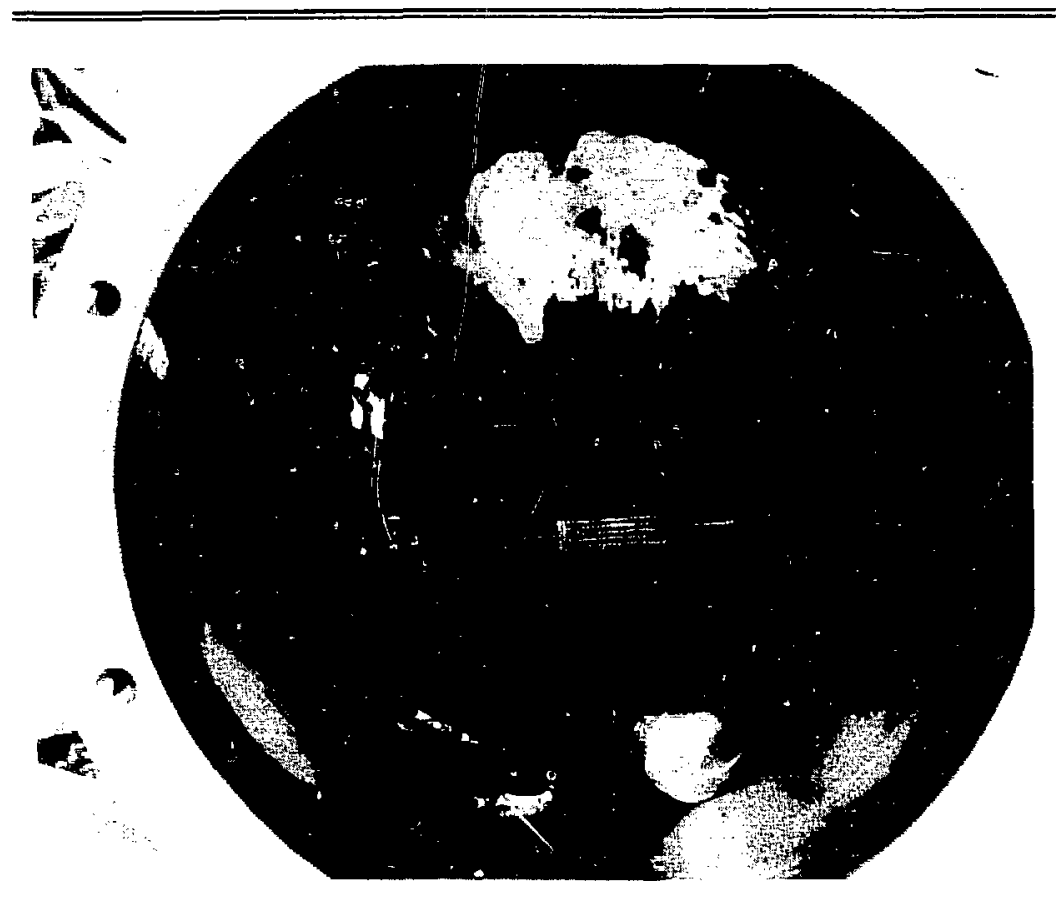

(a)
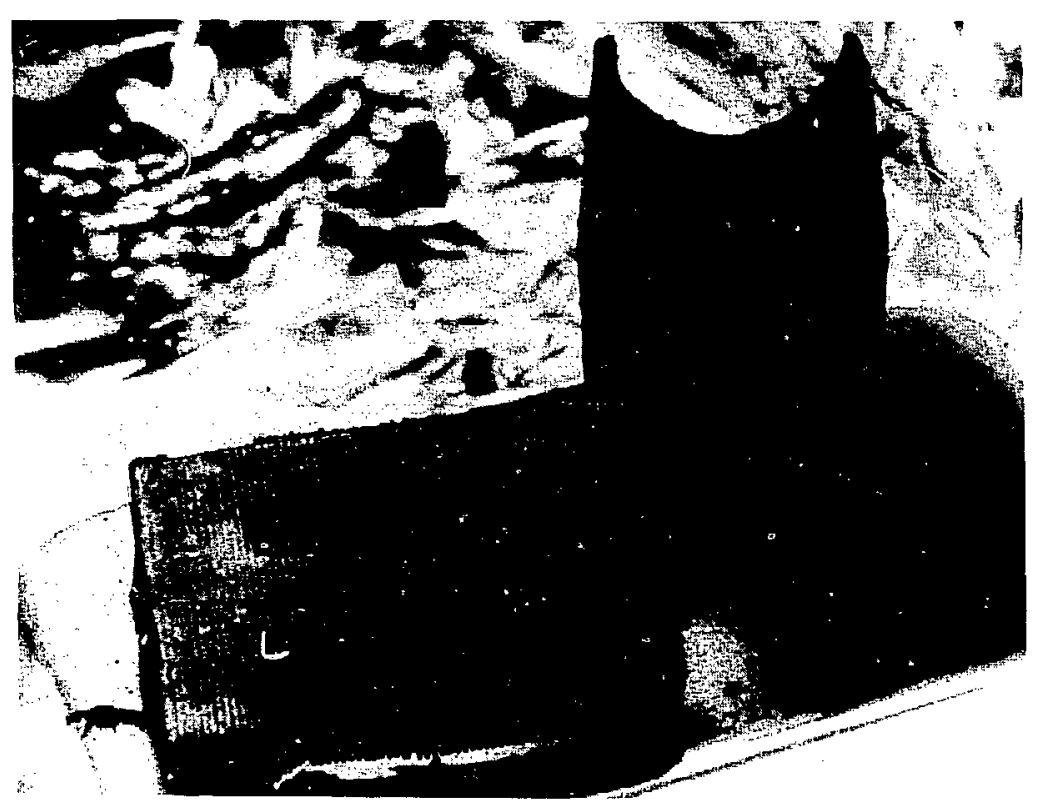

(b)

Fig. 27. The narrow impact face was torn from the acroshell. permitting the lead IA to be ejected in SVT-5. A crack was present on the impact tace. 


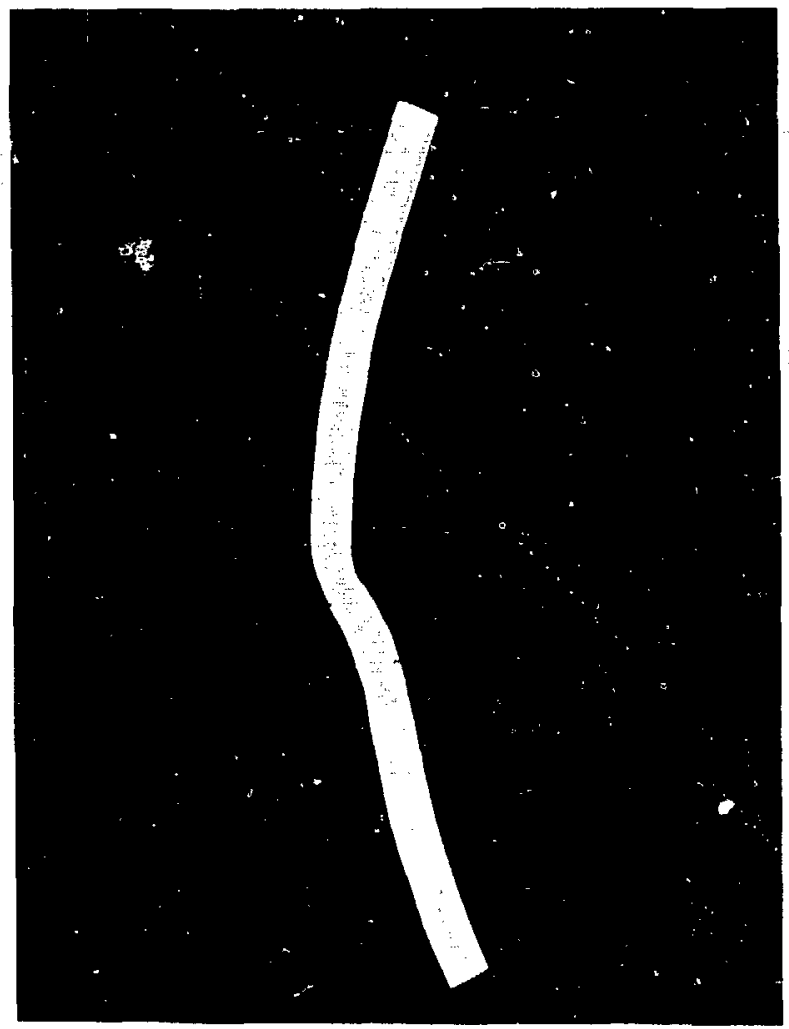

(a)

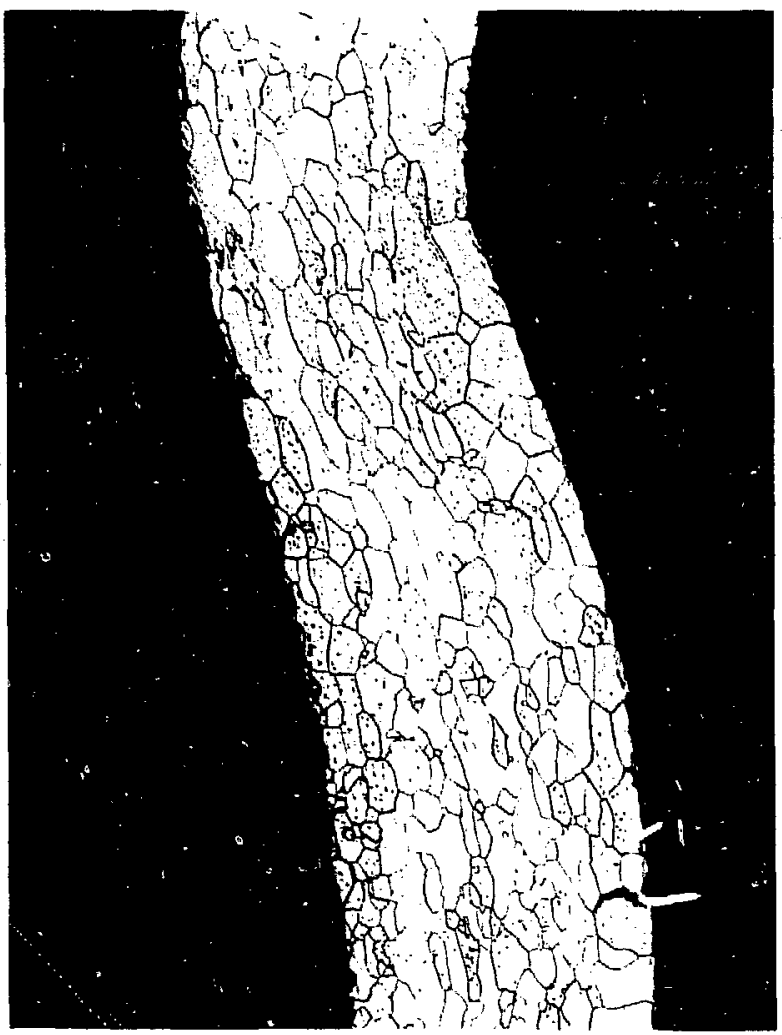

(b)

Fig. 28. Fuel-fragment push-through deformation occurred on the back of the shield cup of FC-267. The crack in the reversebend location progressed only three grains.

Localized iridium deformaticn of the clads was moderate, occurring principally on the center of the FC-260 and FC-267 impact faces. Figure 28 illustrates the most severe localized iridium deformation. which occurred on the back side of the FC-267 shield cup. A small crack was initiated at the interior surface, but it progressed only three grains into the wall.

AES analyses showed that thorium concentrations at the iridium grain boundaries were lower at the interior than at the center and exterior. Low levels of sulfur were found in one sample of the shield cup of FC-267. Emission spectroscopy analysis showed iron to be the prineipal impurity element in the iridium clads.

The microstructure of the iridium clads was nonuniform across the thickness. Large interior grains occurred to a depth of $20-25 \%$ of the thickness. The average grain-size range was narrow at 14 grains $/ 640 \mu \mathrm{m}$ thickness for cup P701-5 to 16 grains/640 $\mu$ m thickness for cups P708-5 and PR717-4.

Axial cross sections through the welds of FC-260 and FC-267 showed that the weld beads had a desirable microstructure, no porosity, and full penetration.
Emission spectrographic analysis of samples of the plutonia pellets showed that pellet HF-260 had an aluminum content of $320 \mathrm{ppm}$, which exceeds the SRP guideline. Colorimetric phosphorus analysis for samples of HF-260 and HF-267 showed 40 to $55 \mathrm{ppm}$. respectively. Subsequent $\gamma$-scan analysis of these two pellets indicated that phosphorus content was below the detcetion limit (20 ppm). The chenical samples were possibly contaminated inadvertently. The absence of phosphorus in the grain boundaries of the iridium would support this hypothesis.

The microstructure of the plutonia pellets HF-260 and HF-267 was typical of SRP material.

\section{F. SVT-6}

The SVT-6 test assembly was aged for 90 days at $1287^{\circ} \mathrm{C}$; monitoring of the helium release revealed no evidence of vent plugging. Following the aging heat treatment, the module was given a simulated reentry at $1375^{\circ} \mathrm{C}$. Post-reentry radiography indicated that all four fuel pellets were badly cracked. 
The test module impacted "side-on" at $54.6 \mathrm{~m} / \mathrm{s}$ and $975^{\circ} \mathrm{C}$ against a hardened 4340 steel plate (Fig. 29). The aeroshell walls fractired along the axial contact lines of the prime GIS, $90^{\circ}$ to the impact face (Fig. 30). Damage to the impact shells was mojerate. Both GISs had a bowed profile and were partially fractured on the impact face.

The primary clads (HF-36I and HF-373) deformed, and capsule HF-373 breaci.ed (Fig. 31). The impact face of HF-373 contained a large axial crack $(22.5 \mathrm{~mm} \times 1.7$ $\mathrm{mm})$ and a smaller parallel crack $(3.7 \mathrm{~mm} \times 0.3 \mathrm{~mm})$ on ths v'ent-cup radius. Both cracks apparently result ed from the differential displacement of a large fucl tragment.

Metallographic examination of sections removed from the primary clads revealed localized excessive grain growth. Although the average grain sizes were acceptable (see Table A-IV). areas in both vent cups contained as few as 2 grains/thickness. The largest grains were observed on the vent-cup radii (Figs. 32 and
33) and adjacent to the vent-cover welds (Figs. 34 and 35). Although the breach in HF-373 did not occur in a coarse-grained region, cracks on the vent-cup radii were associated with excessively large grains (Fig. 36).

The plutonia in the primary clads was broken into massive chunks that were held tightly by the deformed iridium. Fuel in the trailing capsules fractured into numerous small fragments. Particle-size analyses of the fuel in capsule HF-36l is given in Fig. A-1 and Table AIII, and the fines released by HF- 373 are given in Tablc A-II.

\section{DISCUSSION OF RESULTS}

In the four modules tested in the $\alpha=\beta=0^{\circ}$ orientation, failures were observed in five fueled clads for an overall failure rate of $31 \%$. One failure of a PIA fueled clad occurred for a failure rate of $12.5 \%$, and four failures occurred in a SIA fueled clad for a failure rate of

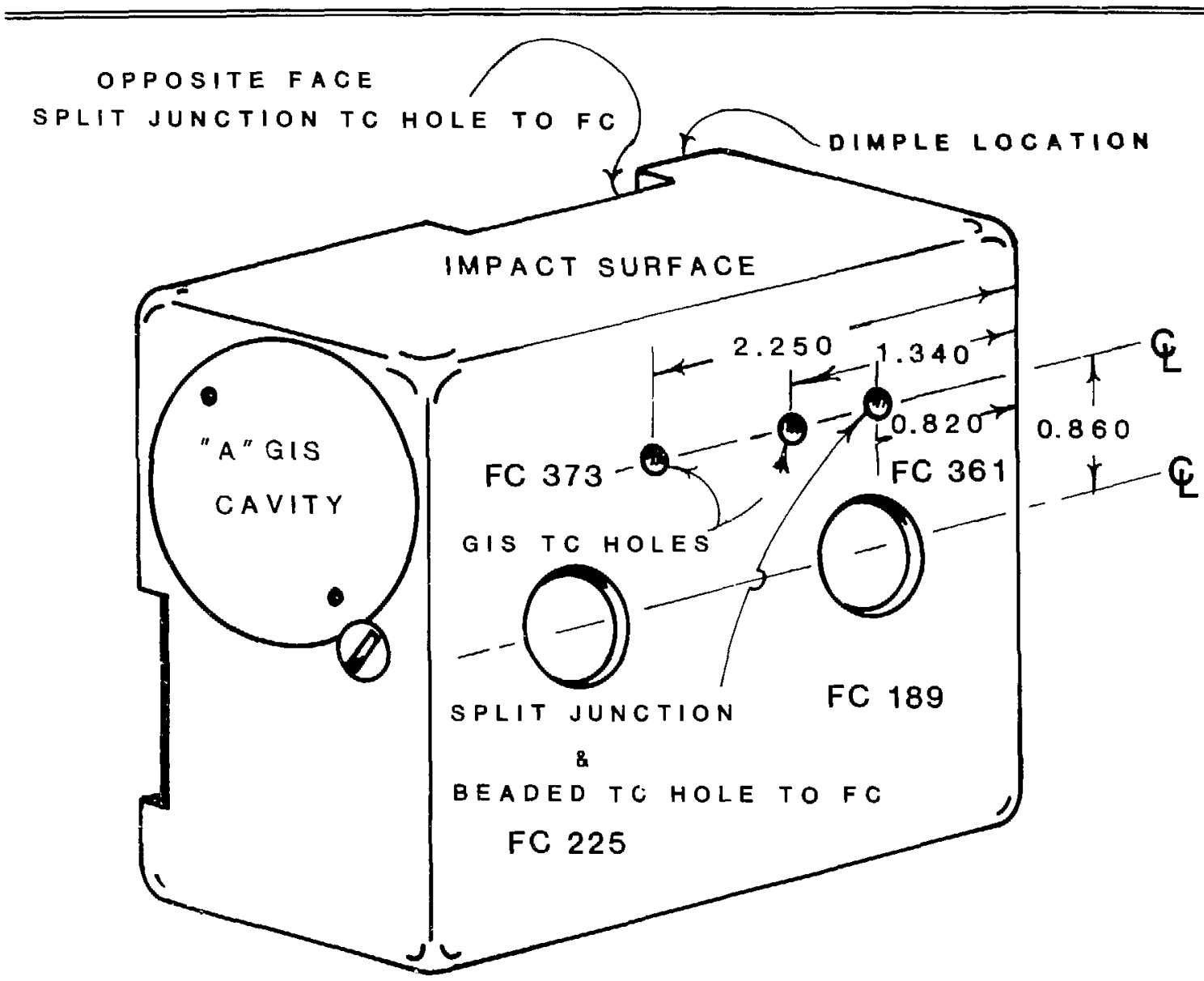

Fig. 29. SVT-6 impact orientation. 


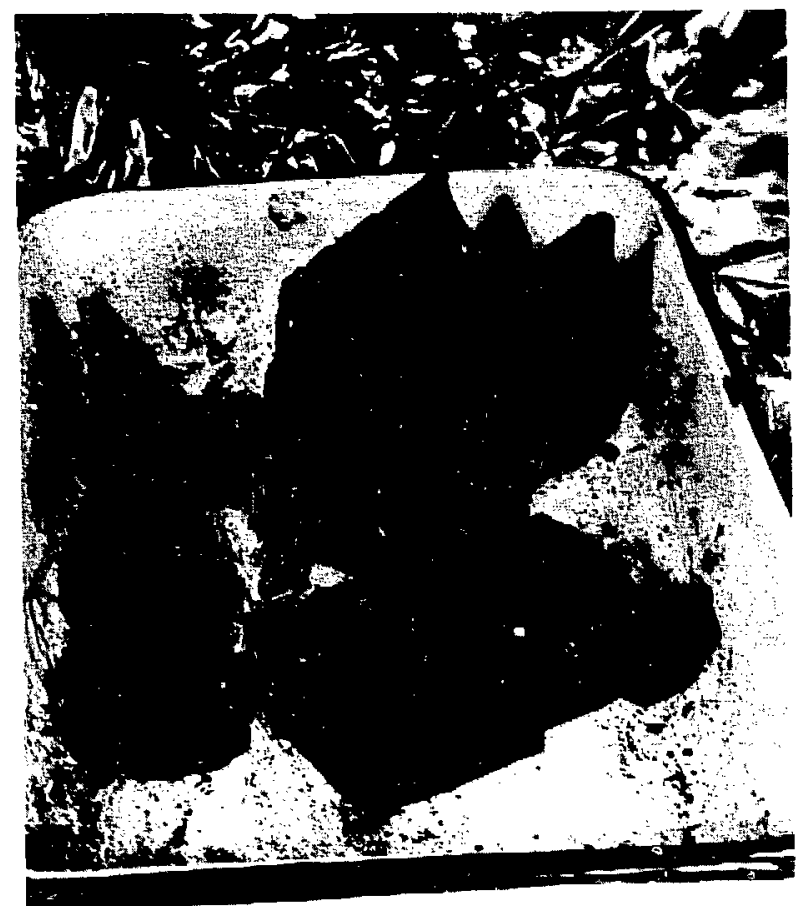

Fig. 30. The SVT-6 aeroshell fractured along the axial contact lines of the prime GIS.

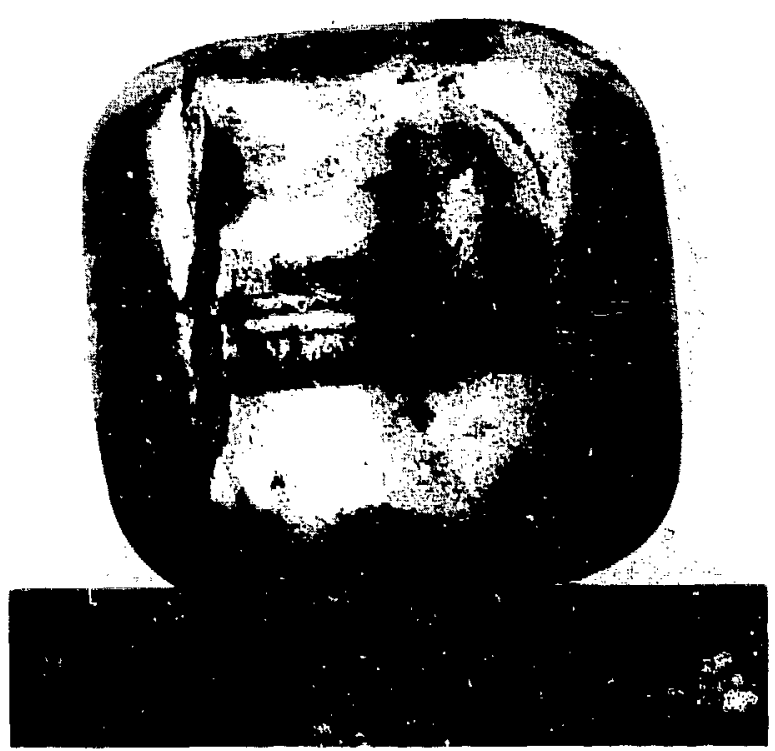

Fig. 31. A wide axial crack was present on the impact face of capsule FC-373; $2 x$

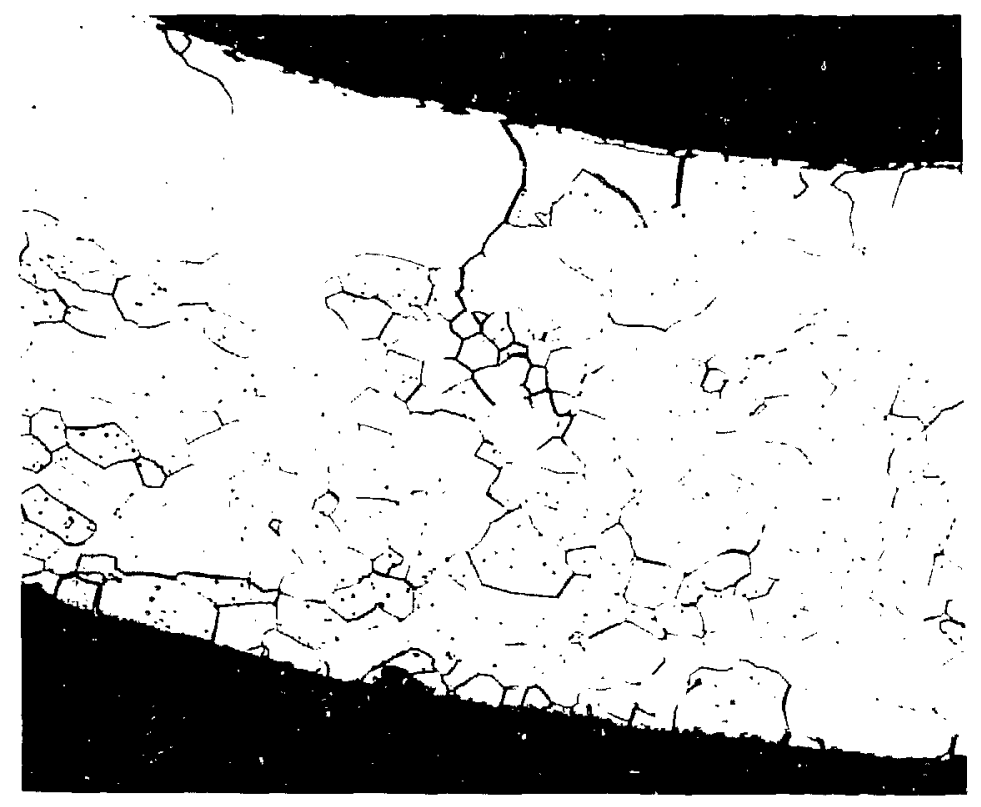

Fig. 32. Abnormal grain growth was observed on the FC-36I vent-cup radius; $100 \times$. 


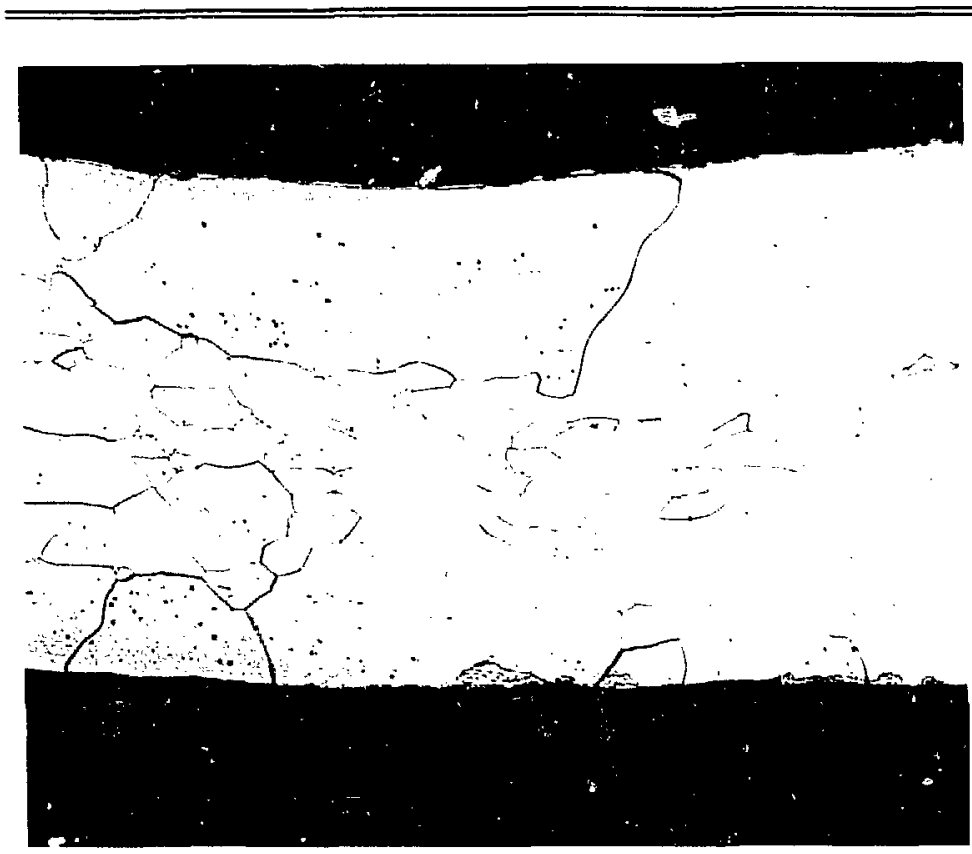

Fig. 33. Grain coarsening also occurred on the FC-373 vent-cup radius: $100 \times$.

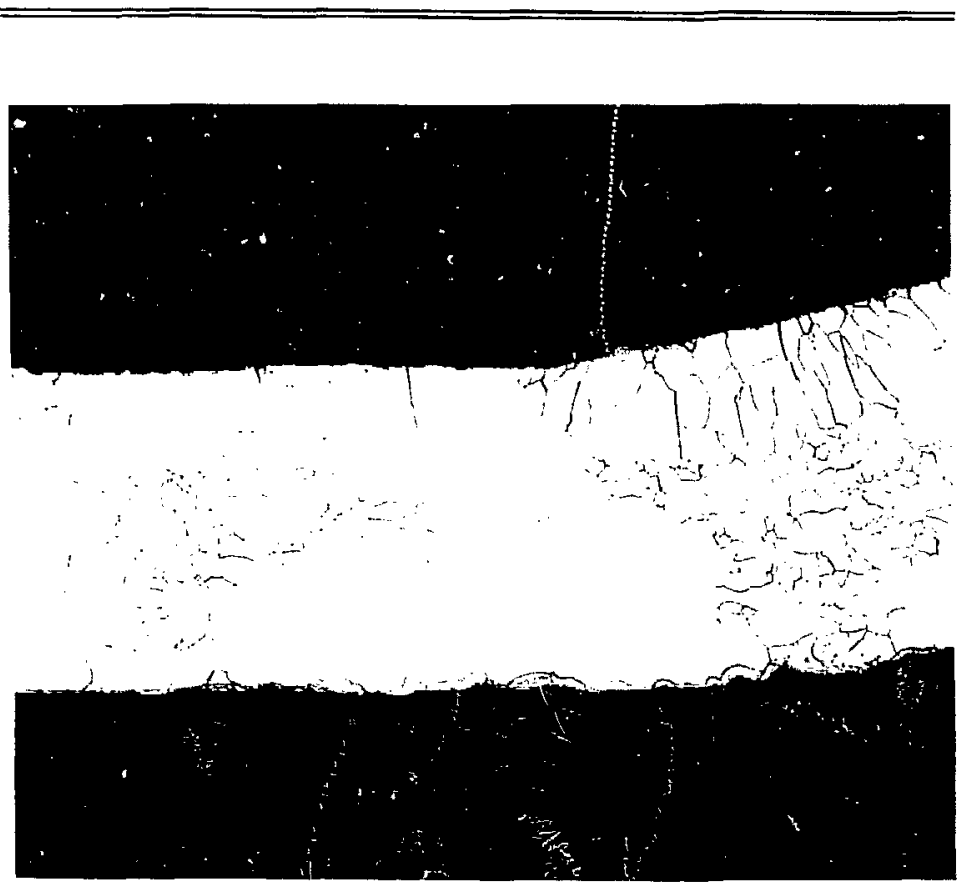

Fig. 34. Abnormal grain growth was also observed on the impact-face side of the FC -361 vent-crier weld: $40 \times$. 


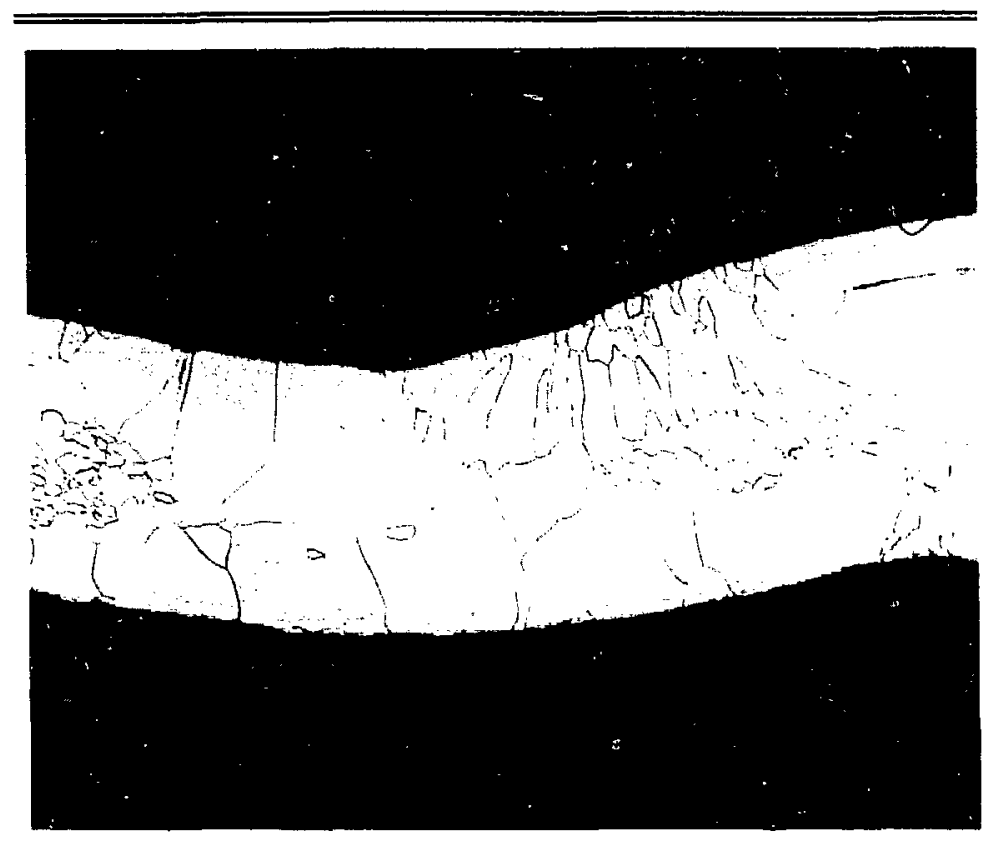

(a)

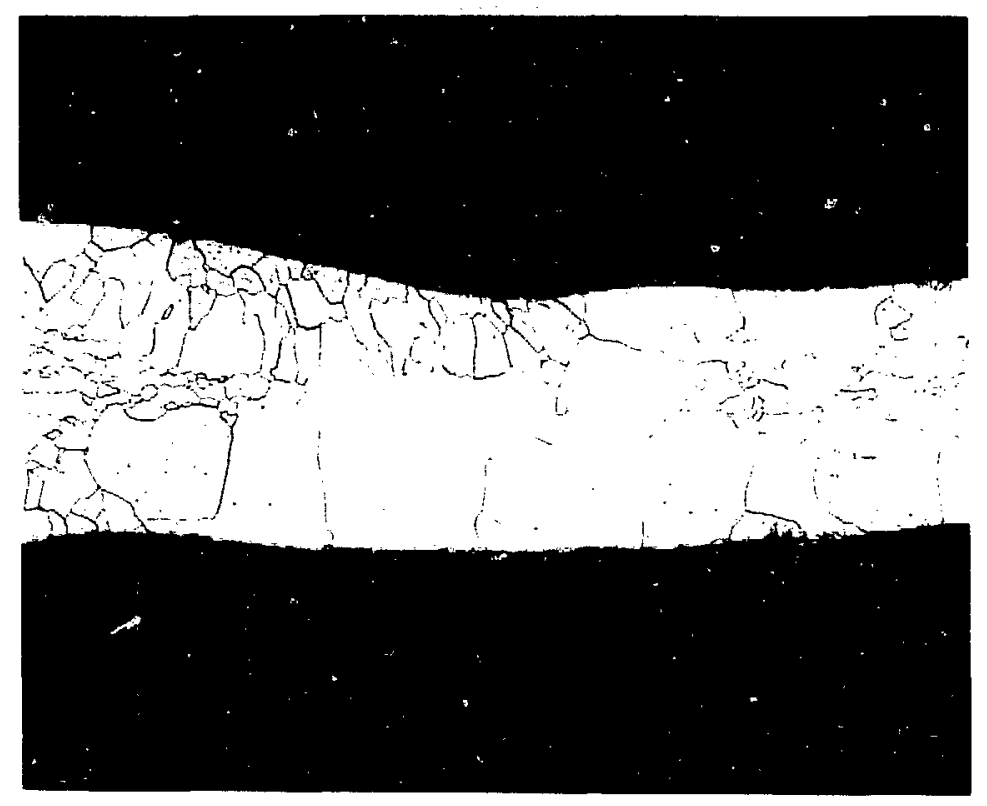

(b)

Fig. 35. Excessive grain growth was observed on the FC-273 vent-cover weld. (a) Impact-face side and (b) opposite face; both at $40 \mathrm{x}$. 


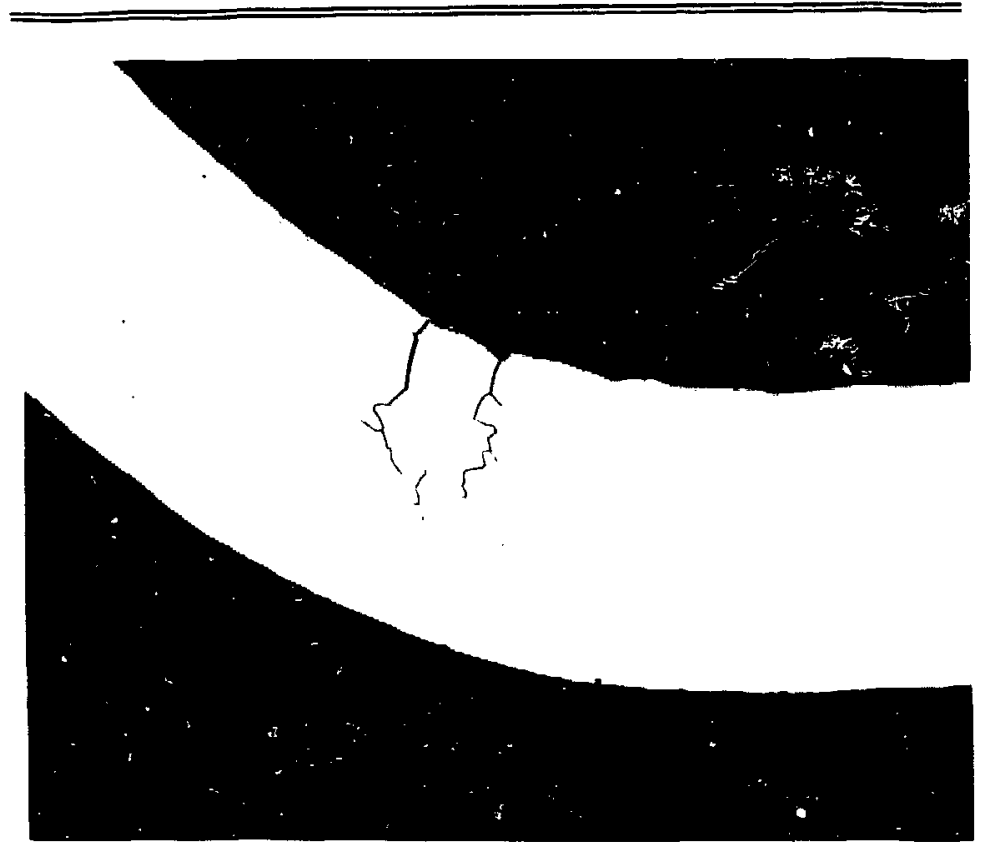

(a)

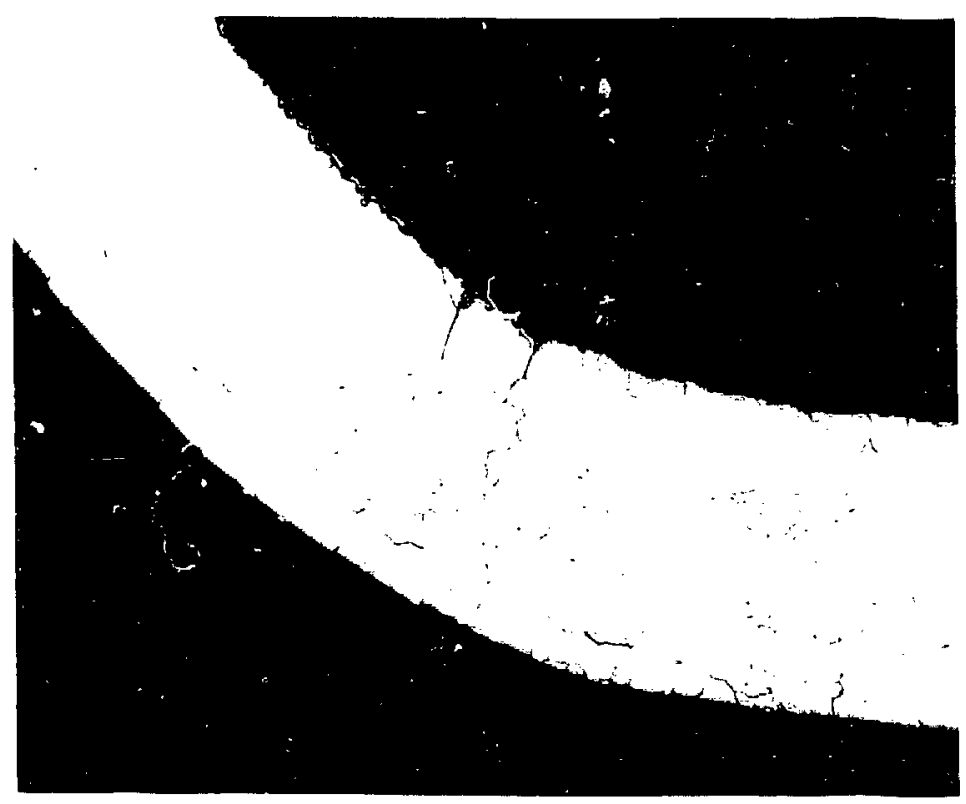

(b)

Fig. 36. Crreks on the FC-373 vent-cup radius were associated with abnormally large grains. (a) As polished and (b) etched: both at $50 x$ 
$50 \%$. The principal cause of failures was fuel-fragment push-through. For a few of the failures, a direct cause could not be identified; however, these were small fractures and did not significantly contribute to the total fracture area. Except for axial failures that traversed the girth weld, only one weld failure was observed. The failure occurred about $180^{\circ}$ from the weld-overlap region, a common site of weld cracking, and therefore fabrication defects probably were not involved in the failure. In the two modules tested in the $\alpha=90^{\circ}, \gamma=0^{\circ}$ orientation, one failure was observed for an overall failure rate of $12.5 \%$. The single failure occurred in the primary impact assembly for a failure rate of $25 \%$ in the leading impact assembly. The failure was of the fuclfragment push-through type.

Evidence of vent plugging was observed in 1 of 3 modules that were subjected to continuous monitoring of the helium release; only 1 capsule of the 12 exhibited significant vent effusate. Performance was good primarily because the impurity content of the plutonia was generally low. Positioning the vents of the two fueled clads in opposition at the center of the IA (highest temperature) probably helped avoid deposits that would plug the vent.

Iridium transport was not significant in the FCs examined (except FC-454). Processing the modules in the MRMF to slightly reduce the stoichiometry of the plutonia appears to have been beneficial in lowering the partial pressure of oxygen within the fueled clad and limited the tendency for iridium transport.

The concentration of impurity elements found in the iridium-allov capsules was, in general, low. Iron was the principal impurity found. but only at levels of a few hundred parts per million. which is not expected to significantly affect the mechanical properties. A few samples showed sulfur contamination at the grain boundaries. These instances were not consistent in all samples from a given capsule. and therefore it is difficult to account for their source. The effect of sulfur segregation to grain boundaries is not well established, but it may have contributed to the minor failure of FC-454.

The average grain size of the iridium in capsules aged for 90 days was smaller than that which would be predicted from prior MHW data $(7-8$ grains $/ 640 \mu \mathrm{m})$. Though the iridium-clad temperature during aging was slightly lower $\left(1287^{\circ} \mathrm{C}\right.$ vs $\left.1310^{\circ} \mathrm{C}\right)$, the absence of phosphorus contamination at the grain boundaries may also have helped restrict the abnormal grain growth to the clad interior where thorium depletion inevitably occurs. The excessive grain growth associated with the decontamination cover and the vent-assembly welds in some capsules suggests that this effect is a function of welding procedures and is not an inherent property of the design or the materials.

\section{ACKNOWLEDGMENT}

The authors gratefully acknowledge the cooperation and contributions of the following to the conduct of the test program rcported herein:

- G. H. Brooks and J. P. Lucero-Radiographic inspection.

- M. D. Anstey and A. R. Herrera-Impact Tests.

- L. R. Bergamo and J. I. Archuleta- rostmortem assistance and metallography.

- O. R. Simi, D. L. Gallimorc, and I. D. Montoya-Emission spectrographic analysis of irridium.

- J.D. Farr-Auger electron spectroscopy of iridium.

- W. M. Myers, C. B. Collicr, and D. Hedrick-Emission spectrographic analysis of plutonia.

- T.K. Marshall and T. R. Hahn-Colorimetric phosphorus analysis.

- T.R. Hahn. J. Bubernak, and E. M. Hodge-Analysis of plutonium in graphitic materials.

- Helen Bustos for manuscript preparation.

\section{REFERENCES}

1. "Updated Safety Analysis Report For The Galileo Mission and The International Solar-Polar Mission." General Electric document GEST-7186 (April, 1984), Section 3.4 (GPHS Reentry Response).

2. "Estimates for the Orbital Lifetime for Galileo and Solar Polar," Applied Physies Laboratory document ATD-RL-82-081/ANSP-L-662 (November 18. 1982). 
APPENDIX

Tabulation of Analytical Results for the GPHS SVT Test Series 


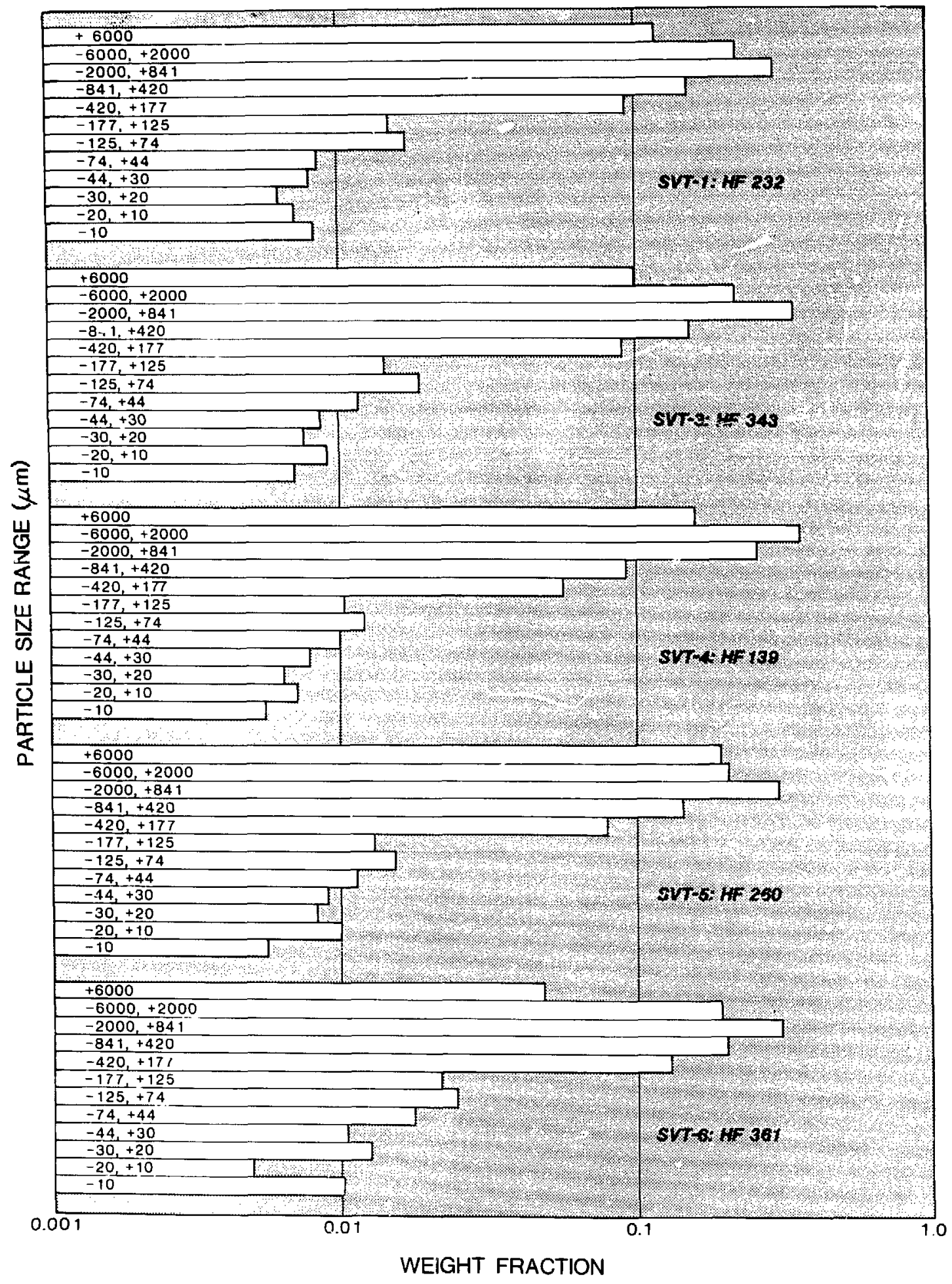


TABLE A-I. Impact Test Summary, GPHS SVT Series

\begin{tabular}{|c|c|c|c|c|c|c|c|c|}
\hline \multirow[b]{2}{*}{ Test No. } & \multirow{2}{*}{$\begin{array}{c}\text { Reentry } \\
\text { Mode } \\
\end{array}$} & \multirow{2}{*}{$\begin{array}{l}\text { Fueled } \\
\text { Clads } \\
\end{array}$} & \multirow{2}{*}{$\begin{array}{l}\text { NDE } \\
\text { Value } \\
\end{array}$} & \multicolumn{3}{|c|}{ Gross Deformation } & \multicolumn{2}{|c|}{ Failures } \\
\hline & & & & $\operatorname{Diam}(\%)$ & Height (\%) & Axial (\%) & Number & Area $\left(\mathrm{mm}^{2}\right)$ \\
\hline$\overline{\text { SVT-1 }}$ & $\begin{array}{l}\text { Min- } \gamma^{a} \\
\text { Face-on }\end{array}$ & $\begin{array}{l}\text { FC-232 } \\
\text { FC-238 } \\
\text { FC-261 } \\
\text { FC-410 }\end{array}$ & $\begin{array}{r}3.0 \\
5.0 \\
8.7 \\
12.6\end{array}$ & $\begin{array}{r}+13.5 \\
+9.6 \\
+11.7 \\
+9.8\end{array}$ & $\begin{array}{r}-11.1 \\
-7.3 \\
-11.1 \\
-9.6\end{array}$ & $\begin{array}{l}+5.8 \\
+3.8 \\
+5.6 \\
+1.4\end{array}$ & $\begin{array}{l}\mathbf{0} \\
\mathbf{0} \\
2 \\
1\end{array}$ & 25.4 \\
\hline SVT-2 & $\begin{array}{l}\text { Min- } \boldsymbol{y}^{\mathbf{a}} \\
\text { Face-on }\end{array}$ & $\begin{array}{l}\text { FC-355 } \\
\text { FC }-369 \\
\text { FC }-449 \\
\text { FC }-273\end{array}$ & $\begin{array}{r}6.8 \\
6.0 \\
13.7 \\
10.7\end{array}$ & $\begin{array}{r}+10.0 \\
+9.1 \\
+12.5 \\
+10.3\end{array}$ & $\begin{array}{r}-10.4 \\
-9.3 \\
-10.3 \\
-10.5\end{array}$ & $\begin{array}{l}+4.1 \\
+4.1 \\
+5.6 \\
+4.4\end{array}$ & $\begin{array}{l}\mathbf{0} \\
\mathbf{0} \\
\mathbf{3} \\
\mathbf{0}\end{array}$ & 8.4 \\
\hline SVT-3 & $\begin{array}{l}\text { Orbital } \\
\text { Decay }^{b} \\
\text { Face-on }\end{array}$ & $\begin{array}{l}\text { FC }-343 \\
\text { FC }-350 \\
\text { FC-457 } \\
\text { FC }-454\end{array}$ & $\begin{array}{r}2.9 \\
1.1 \\
9.8 \\
12.8\end{array}$ & $\begin{array}{r}+12.3 \\
+10.0 \\
+10.8 \\
+9.5\end{array}$ & $\begin{array}{l}-9.0 \\
-8.5 \\
-7.2 \\
-6.4\end{array}$ & $\begin{array}{l}+5.7 \\
+2.6 \\
+5.6 \\
+2.9\end{array}$ & $\begin{array}{l}0 \\
0 \\
0 \\
1\end{array}$ & 0.4 \\
\hline SVT-4 & $\begin{array}{l}\text { Orbital } \\
\text { Decay }^{b} \\
\text { Face-on }\end{array}$ & $\begin{array}{l}\text { FC-348 } \\
\text { FC-354 } \\
\text { FC-139 } \\
\text { FC-162 }\end{array}$ & \begin{tabular}{r|}
1.0 \\
3.2 \\
13.7 \\
10.7
\end{tabular} & $\begin{array}{r}+11.5 \\
+8.5 \\
+12.5 \\
+10.3\end{array}$ & $\begin{array}{r}-11.3 \\
-8.2 \\
-8.5 \\
-9.3\end{array}$ & $\begin{array}{l}+6.4 \\
+4.0 \\
+5.1 \\
+3.4\end{array}$ & $\begin{array}{l}1 \\
0 \\
0 \\
0\end{array}$ & 1.8 \\
\hline SVT-5 & $\begin{array}{l}\text { Orbital } \\
\text { Decay }^{b} \\
\text { Side-on }\end{array}$ & $\begin{array}{l}\text { FC-267 } \\
\text { FC-260 } \\
\text { FC-415 } \\
\text { FC-426 }\end{array}$ & $\begin{array}{l}3.0 \\
4.0 \\
9.4 \\
9.6\end{array}$ & $\begin{array}{r}+10.4 \\
+10.9 \\
+5.5 \\
+5.0\end{array}$ & $\begin{array}{r}-9.1 \\
-13.7 \\
-4.5 \\
-6.9\end{array}$ & $\begin{array}{c}+5.5 \\
+4.1 \\
+1.2 \\
\text { nil }\end{array}$ & $\begin{array}{l}\mathbf{0} \\
\mathbf{0} \\
\mathbf{0} \\
\mathbf{0}\end{array}$ & $\mathbf{0}$ \\
\hline SVT-6 & $\begin{array}{l}\text { Orbital } \\
\text { Decay }^{\mathrm{b}} \\
\text { Side-on }\end{array}$ & $\begin{array}{l}\text { FC-373 } \\
\text { FC-361 } \\
\text { FC-225 } \\
\text { FC-189 }\end{array}$ & $\begin{array}{r}4.1 \\
4.4 \\
13: 2 \\
13.3\end{array}$ & $\begin{array}{r}+11.2 \\
+12.3 \\
+7.8 \\
+6.4\end{array}$ & $\begin{array}{r}-14.9 \\
-17.6 \\
-8.8 \\
-7.2\end{array}$ & $\begin{array}{l}+6.2 \\
+8.8 \\
-r 3.7 \\
+2.9\end{array}$ & $\begin{array}{l}2 \\
0 \\
0 \\
0\end{array}$ & 24.1 \\
\hline
\end{tabular}


Table A-II. GPHS SVT Fuel Release

\begin{tabular}{|c|c|c|c|c|}
\hline \multirow[b]{2}{*}{ Module } & \multirow{2}{*}{$\begin{array}{l}\text { Reentry } \\
\text { Mode }\end{array}$} & \multicolumn{3}{|c|}{ Pu Content (g) } \\
\hline & & $<10 \mu \mathrm{m}$ & $>10 \mu \mathrm{m}$ & Total \\
\hline SVT-1 & $\operatorname{Min}-\gamma$ & 0.0128 & 0.0972 & 0.1100 \\
\hline SVT-2 & Min- $\gamma$ & 0.0041 & 0.0248 & 0.0289 \\
\hline SVT-3 & U-Decay & 0.0051 & 0.0126 & 0.0177 \\
\hline SVT-4 & 0-Decay & 0.0076 & 0.0181 & 0.0257 \\
\hline SVT-5 & 0-Decay & 0.0020 & 0 & 0.0020 \\
\hline SVT-6 & 0-Decay & 0.0091 & 0.0056 & 0.0147 \\
\hline
\end{tabular}

aSVT-1 to -5: Combust graphitics ai $850-900^{\circ} \mathrm{C}$, sieve ash, and analyze.

SVT-6: : Iltrasonic wash of $\mathrm{A} / \mathrm{S}$ and GIS, plasma-assisted combustion of small fragments and fines, sieve a $h$. and analyze.

\begin{tabular}{|c|c|c|c|c|c|}
\hline \multirow[b]{2}{*}{$\begin{array}{c}\text { Max. Size } \\
(\mu \mathrm{m})\end{array}$} & \multicolumn{5}{|c|}{ Weight Fraction } \\
\hline & $\begin{array}{l}\text { SVT-1 } \\
\text { HF-232 }\end{array}$ & $\begin{array}{c}\text { SVT-3 } \\
\text { HF-343 }\end{array}$ & $\begin{array}{c}\text { SVT-4 } \\
\text { HF-139 }\end{array}$ & $\begin{array}{c}\text { SVT-5 } \\
\text { HF-260 }\end{array}$ & $\begin{array}{l}\text { SVT-6 } \\
\text { HF-361 }\end{array}$ \\
\hline 1.00 & 0.001593 & 0.000511 & 0.000309 & 0.000417 & $0.00 \cup 846$ \\
\hline 2.00 & 0.000398 & 0.000260 & 0.000387 & 0.000243 & 0.000492 \\
\hline 3.00 & 0.000579 & 0.000235 & 0.000336 & 0.000253 & 0.000635 \\
\hline 4.00 & 0.000441 & 0.000341 & 0.000344 & 0.000313 & 0.000800 \\
\hline 5.00 & $0.00038 ?$ & 0.000315 & 0.000428 & 0.000229 & $0.00100 u$ \\
\hline 6.00 & 0.000992 & 0.004242 & 0.000422 & 0.000308 & 0.000972 \\
\hline 7.00 & 0.000263 & 0.000132 & 0.000419 & 0.000140 & 0.000172 \\
\hline 8.00 & 0.000784 & 0.000861 & 0.000375 & 0.000417 & 0.000768 \\
\hline 9.00 & 0.001116 & 0.001430 & 0.000534 & 0.000594 & 0.001094 \\
\hline 10.00 & 0.001531 & 0.002523 & 0.001955 & 0.001834 & 0.003001 \\
\hline $\begin{array}{c}\text { Acc. Wt. Frac. } \\
<10 \mu \mathrm{m}\end{array}$ & 0.00808 & 0.00691 & 0.00551 & 0.00475 & 0.00978 \\
\hline
\end{tabular}




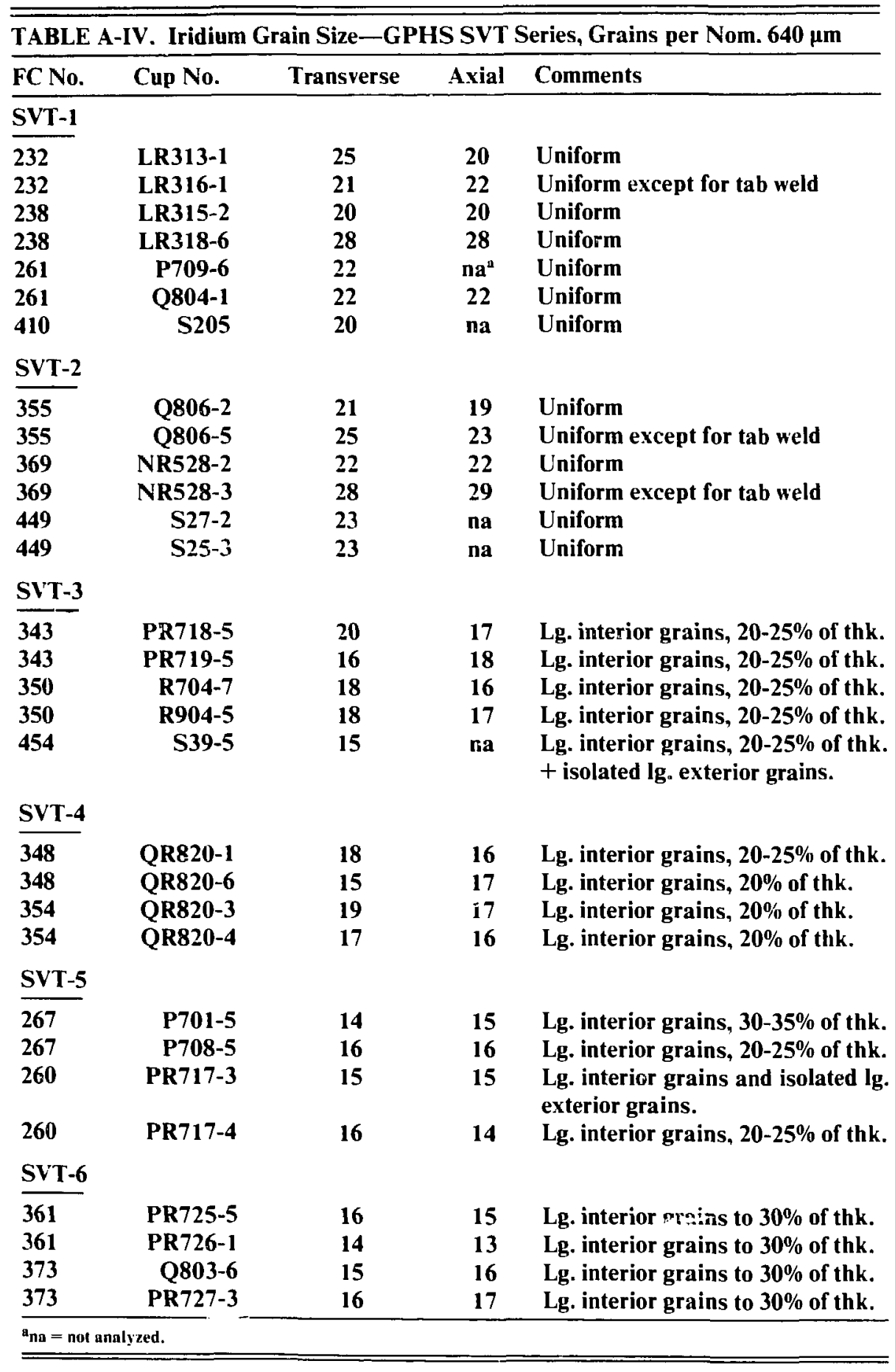


TABLE A-V. Summary of AES Analyses of GPHS SVT Iridium

\begin{tabular}{|c|c|c|c|c|c|}
\hline$T_{h_{65}} / \mathbf{I r}_{229}$ & & $\mathrm{C}_{270} / \mathbf{I} \mathbf{r}_{229}$ & $\mathbf{O}_{510} / \mathbf{I r}_{229}$ & $\mathbf{S}_{150} / \mathbf{I r}_{229}$ & $\mathrm{Cl}_{180} / \mathbf{L r}_{229}$ \\
\hline enter Ext. & & Ave. & Ave. & Ave. & Ave. \\
\hline
\end{tabular}

Specimen

Int. Center Ext. Ave.

Ave.

SVT-1

FC-232:

\begin{tabular}{|lllll} 
Vent cup-2 & $\mathbf{0 . 4 6}$ & $\mathbf{0 . 5 6}$ & $\mathbf{0 . 6 1}$ & $\mathbf{0 . 5 4}$ \\
Shield cup-1 & $\mathbf{0 . 3 6}$ & $\mathbf{0 . 6 5}$ & $\mathbf{0 . 5 7}$ & $\mathbf{0 . 5 3}$ \\
Shield cup-2 & $\mathbf{0 . 7 1}$ & $\mathbf{0 . 7 5}$ & $\mathbf{0 . 6 0}$ & $\mathbf{0 . 6 9}$ \\
& & & & \\
& $\mathbf{0 . 4 5}$ & $\mathbf{0 . 7 6}$ & $\mathbf{0 . 4 4}$ & $\mathbf{0 . 5 5}$ \\
Vent cup-1 & $\mathbf{0 . 5 5}$ & $\mathbf{0 . 6 5}$ & $\mathbf{0 . 4 1}$ & $\mathbf{0 . 5 6}$ \\
Shield cup-2 & $\mathbf{0 . 4 1}$ & $\mathbf{0 . 5 0}$ & $\mathbf{0 . 4 3}$ & $\mathbf{0 . 4 5}$ \\
Shield cup-2 & $\mathbf{0 . 8 0}$ & $\mathbf{0 . 8 8}$ & $\mathbf{0 . 8 0}$ & $\mathbf{0 . 8 3}$
\end{tabular}

$\mathrm{nd}^{\mathrm{a}}$

0.47

0.65

nd $\quad 0.35$

0.76

nd 0.17

0.43

nd

0.12

0.20

nd 0.44

0.69

FC-238: Vent cup-1

Shield cup-1

nd

0.30

0.59

1.45

1.17

0.17

nd

$\begin{array}{cc}\text { nd } & \text { nd } \\ \text { nd } & \text { nd } \\ \text { nd } & \text { nd } \\ \text { nd } & \text { nd } \\ \text { nd } & \text { nd } \\ \text { nd } & \text { nd } \\ \text { 0.04 } & \text { 0.04 } \\ \text { nd } & \text { nd }\end{array}$

SVT-2

FC-449:

Vent cup-1

$\begin{array}{lllll}0.60 & 0.69 & 0.64 & 0.61\end{array}$

nd

0.16

0.47

nd

Vent cup-2

0.82

Shield cup-1

0.43

$\begin{array}{llll}0.97 & 0.66 & 0.82\end{array}$

nd

0.09

0.08

nd

0.59

1.01

0.32

0.57

Shield cup-2

$\begin{array}{lllll}0.45 & 0.68 & 0.65 & 0.59\end{array}$

Weld VC side $\quad-\quad-\quad-\quad 0.62$

Weld SC side

nd

0.19

0.49

nd

0.92

0.88

0.05

0.10

0.31

0.08

Vent cup-2

$\begin{array}{lllll}0.82 & 0.93 & 0.76 & 0.84\end{array}$

$\begin{array}{llll}0.65 & 0.85 & 0.63 & 0.71\end{array}$

0.11

0.11

0.12

0.36

0.04

0.24

0.54

0.03

$\begin{array}{llll}0.48 & 0.63 & 0.40 & 0.50\end{array}$

FC-369: Vent cup-1

Vent cup-2

$\begin{array}{lllll}0.46 & 0.53 & 0.46 & 0.48\end{array}$

0.31

0.74

0.05

0.39

0.79

nd

nd

nd

nd

nd

nd

nd

nd

nd

nd

nd

nd

nd

nd

nd

nd

nd

SVT-3

FC-343:

cup-1

$\begin{array}{llll}0.38 & 0.68 & 0.41 & 0.49\end{array}$

nd

0.23

0.46

nd

nd

nd

nd

Vent cup-2

$\begin{array}{ll}0.17 & 0.48\end{array}$

\begin{tabular}{ll}
\hline 0.39 & 0.35 \\
\hline
\end{tabular}

nd

0.48

$\mathbf{0 . 7 0}$

0.33

0.85

0.35

0.01

$\begin{array}{cc}\text { nd } & 0.87 \\ \text { nd } & \text { nd }\end{array}$

0.70

1.54

nd

0.96

0.09

nd

Shield cup-1

$\begin{array}{lllll}0.46 & \mathbf{0 . 7 4} & 0.84 & \mathbf{0 . 6 8} \\ \mathbf{0 . 2 0} & \mathbf{0 . 4 4} & \mathbf{0 . 4 1} & \mathbf{0 . 3 5}\end{array}$

Shield cup-2

$\begin{array}{llll}0.14 & 0.75 & 0.65 & 0.51\end{array}$

0.06

0.81

0.98

$\begin{array}{lllll}0.32 & 0.48 & 0.59 & 0.46\end{array}$

nd

0.72

0.95

nd

nd

nd

Shield' cup-2

0.16

$\begin{array}{lll}0.28 & 0.36 & 0.24\end{array}$

SVT-4

FC-348: Vent cup-1

Vent cup-2

$\begin{array}{llll}0.19 & 0.49 & 0.42 & 0.40\end{array}$

$\begin{array}{lllll}0.35 & 0.56 & 0.24 & 0.38\end{array}$

Shield cup-1

0.63

$\begin{array}{lll}0.76 & 0.63 & 0.67\end{array}$

Shield cup-2

FC-354: Yent cup-1

Vent cup-2

0.44

$\begin{array}{llll}0.49 & 0.39 & 0.44\end{array}$

$\begin{array}{lllll}0.11 & 0.52 & 0.71 & 0.45\end{array}$

$\begin{array}{lllll}0.27 & 0.36 & 0.47 & 0.37\end{array}$

Shield cup-1

0.34

$\begin{array}{lll}0.46 & 0.52 & 0.44\end{array}$

$\begin{array}{lllll}0.37 & 0.68 & 0.43 & 0.49\end{array}$

$\begin{array}{lc}\text { nd } & 0.95 \\ \text { nd } & 0.13 \\ \text { nd } & \text { nd } \\ \text { nd } & 0.37 \\ \text { nd } & 0.46 \\ \text { nd } & 0.46 \\ \text { nd } & 0.31 \\ \text { nd } & 1.91\end{array}$

\subsection{9}

0.53

nd

0.82

nd

0.94

0.75

0.83

nd

nd

0.01

nd

0.15

$\mathbf{v s}^{\mathrm{b}}$

nd

Shield c'p-2

${ }^{a}$ nd-not detected.

$h_{45}$ - very strong 


\begin{tabular}{|c|c|c|c|c|c|c|c|c|c|}
\hline \multirow[b]{2}{*}{ Specimen } & \multicolumn{4}{|c|}{$\mathbf{T h}_{\mathbf{6 5}} / \mathbf{I r}_{229}$} & \multirow{2}{*}{$\begin{array}{c}\mathbf{P}_{120} / \mathbf{I r}_{229} \\
\text { Ave. }\end{array}$} & \multirow{2}{*}{$\frac{C_{270} / \mathbf{I}_{\mathbf{2 2 9}}}{\text { Ave. }}$} & \multirow{2}{*}{$\frac{\mathbf{O}_{\mathbf{5 1 0}} / \mathbf{I}_{\mathbf{2 2 9}}}{\text { Ave. }}$} & \multirow{2}{*}{$\frac{\mathbf{S}_{\mathbf{1 5 0}} / \mathbf{I r}_{\mathbf{2 2 9}}}{\text { Ave. }}$} & \multirow{2}{*}{$\frac{\mathbf{C l}_{\mathbf{1 8 0}} / \mathbf{I r}_{\mathbf{2 2 9}}}{\text { Ave. }}$} \\
\hline & Int. & Center & Ext. & Ave. & & & & & \\
\hline \multicolumn{10}{|l|}{ SVT-5 } \\
\hline $\begin{array}{r}\text { FC-260: Vent cup-1 } \\
\text { Vent cup-2 } \\
\text { Shield cup-1 } \\
\text { Shield cup-2 }\end{array}$ & $\begin{array}{l}0.20 \\
0.36 \\
0.35 \\
0.05\end{array}$ & $\begin{array}{l}0.56 \\
0.77 \\
0.36 \\
0.37\end{array}$ & $\begin{array}{l}0.38 \\
0.49 \\
0.52 \\
0.42\end{array}$ & $\begin{array}{l}0.39 \\
0.54 \\
0.43 \\
0.28\end{array}$ & $\begin{array}{l}\text { nd } \\
\text { nd } \\
\text { nd } \\
\text { nd }\end{array}$ & $\begin{array}{l}0.46 \\
0.12 \\
0.21 \\
0.79\end{array}$ & $\begin{array}{l}0.17 \\
0.25 \\
0.43 \\
1.07\end{array}$ & $\begin{array}{l}\text { nd } \\
0.02 \\
\text { nd } \\
\text { nd }\end{array}$ & $\begin{array}{l}\text { n: } 1 \\
\text { nd } \\
\text { nd } \\
\text { nd }\end{array}$ \\
\hline $\begin{aligned} \text { FC-267: } & \text { Vent cup-1 } \\
& \text { Vent cup-2 } \\
& \text { Shield cup-1 } \\
& \text { Shield cup-2 }\end{aligned}$ & $\begin{array}{l}0.21 \\
0.38 \\
0.34 \\
0.19\end{array}$ & $\begin{array}{l}0.76 \\
0.97 \\
0.35 \\
0.22\end{array}$ & $\begin{array}{l}0.81 \\
0.96 \\
0.53 \\
0.46\end{array}$ & $\begin{array}{l}0.59 \\
0.77 \\
0.41 \\
0.29\end{array}$ & $\begin{array}{l}\text { nd } \\
\text { nd } \\
\text { nd } \\
\text { nd }\end{array}$ & $\begin{array}{l}\text { nd } \\
\text { nd } \\
0.74 \\
0.91\end{array}$ & $\begin{array}{c}0.22 \\
\text { nd } \\
1.08 \\
1.10\end{array}$ & $\begin{array}{l}\text { nd } \\
\text { nd } \\
0.05 \\
0.29\end{array}$ & $\begin{array}{l}\text { nd } \\
\text { nd } \\
\text { nd } \\
0.05\end{array}$ \\
\hline \multicolumn{10}{|l|}{ SVT-6 } \\
\hline $\begin{aligned} & \text { FC-361: } \text { Vent cup-1 } \\
& \text { Vent cup-2 } \\
& \text { Shield cup-1 } \\
& \text { Shield cup-2 }\end{aligned}$ & $\begin{array}{l}0.33 \\
0.19 \\
0.38 \\
0.14\end{array}$ & $\begin{array}{l}0.52 \\
0.44 \\
0.49 \\
0.42\end{array}$ & $\begin{array}{l}0.63 \\
0.53 \\
0.56 \\
0.31\end{array}$ & $\begin{array}{l}0.49 \\
0.39 \\
0.48 \\
0.29\end{array}$ & $\begin{array}{l}\text { nd } \\
\text { nd } \\
\text { nd } \\
\text { nd }\end{array}$ & $\begin{array}{l}0.09 \\
0.11 \\
0.09 \\
0.78\end{array}$ & $\begin{array}{l}0.52 \\
0.98 \\
0.68 \\
0.86\end{array}$ & $\begin{array}{l}\text { nd } \\
\text { o.08 } \\
\text { nd } \\
\text { nd }\end{array}$ & $\begin{array}{l}\text { nit } \\
\text { nd } \\
\text { nd } \\
0.11\end{array}$ \\
\hline $\begin{array}{r}\text { FC-373: Vent cup-1 } \\
\text { Vent cup-2 } \\
\text { Shield cup-1 } \\
\text { Shield cup-2 }\end{array}$ & $\begin{array}{l}0.07 \\
0.02 \\
0.15 \\
0.40\end{array}$ & $\begin{array}{l}0.78 \\
0.54 \\
0.64 \\
0.42\end{array}$ & $\begin{array}{l}0.54 \\
0.58 \\
0.36 \\
0.40\end{array}$ & $\begin{array}{l}0.46 \\
0.38 \\
0.38 \\
0.41\end{array}$ & $\begin{array}{l}\text { nd } \\
\text { nd } \\
\text { nd } \\
\text { nd }\end{array}$ & $\begin{array}{l}0.18 \\
0.12 \\
0.23 \\
1.25\end{array}$ & $\begin{array}{l}0.56 \\
0.57 \\
0.63 \\
0.60\end{array}$ & $\begin{array}{l}\text { nd } \\
\text { nd } \\
\text { nd } \\
0.30\end{array}$ & $\begin{array}{l}\text { nd } \\
\text { nd } \\
\text { nd } \\
\text { nd }\end{array}$ \\
\hline
\end{tabular}


TABLE A-VI. Results of Spectrographic Analysis of GPHS SVT Iridium

Selected Elements" (ppm)

\begin{tabular}{|c|c|c|c|c|c|c|c|c|c|c|}
\hline FC No. & Cup No. & $\mathrm{Cu}$ & $\mathbf{M g}$ & $\mathrm{Ca}$ & Al & $\mathbf{S i}$ & $\mathrm{Cr}$ & $\mathrm{Fe}$ & $\mathbf{N i}$ & Pt \\
\hline \multicolumn{11}{|l|}{ SVT-1 } \\
\hline \multirow[t]{2}{*}{232} & LR313-1 & 3 & nd $^{b}$ & nd & 40 & nd & nd & 80 & 10 & nd \\
\hline & LR316-1 & 20 & 7 & 5 & 50 & 25 & 30 & 150 & 40 & nd \\
\hline \multirow[t]{2}{*}{238} & LR315-2 & 15 & 10 & 20 & 50 & 25 & nd & 120 & 40 & nd \\
\hline & LR318-6 & 15 & 7 & 15 & 50 & 10 & 10 & 120 & 45 & nd \\
\hline \multirow[t]{2}{*}{261} & P709-6 & 15 & 15 & 20 & 50 & 50 & nd & 150 & 45 & 50 \\
\hline & Q804-1 & 15 & 15 & 25 & 50 & 30 & nd & 150 & 35 & 150 \\
\hline \multirow[t]{2}{*}{410} & S2-4 & 3 & 15 & 20 & 50 & 100 & nd & 150 & 50 & nd \\
\hline & S2-5 & 5 & 20 & 30 & 50 & 140 & nd & 120 & 20 & 100 \\
\hline
\end{tabular}

SVT-2

\begin{tabular}{lrrrrrrrrrr}
\hline 355 & Q806-2 & nd & 3 & nd & $\mathbf{5 0}$ & nd & nd & $\mathbf{2 0 0}$ & $\mathbf{3 0}$ & nd \\
& $\mathbf{Q 8 0 6 - 5}$ & 10 & $\mathbf{5}$ & $\mathbf{3}$ & $\mathbf{6 0}$ & $\mathbf{1 5 0}$ & $\mathbf{1 5}$ & $\mathbf{2 0 0}$ & $\mathbf{4 0}$ & nd \\
$\mathbf{3 6 9}$ & NR528-2 & $\mathbf{3}$ & nd & nd & $\mathbf{4 0}$ & nd & nd & $\mathbf{1 0 0}$ & nd & nd \\
& NR528-3 & nd & nd & nd & $\mathbf{5 0}$ & nd & nd & $\mathbf{1 5 0}$ & $\mathbf{1 0}$ & nd \\
449 & S27-2 & $\mathbf{2 0}$ & nd & nd & $\mathbf{4 0}$ & nd & 10 & $\mathbf{2 0 0}$ & $\mathbf{3 0}$ & nd \\
& S25-2 & 10 & nd & nd & $\mathbf{5 0}$ & nd & 15 & $\mathbf{2 0 0}$ & $\mathbf{3 0}$ & nd
\end{tabular}

SVT-3

$\begin{array}{lrrrrrrrrrr}343 & \text { PR718-5 } & 40 & \text { nd } & \text { nd } & 40 & \text { nd } & \text { nd } & 150 & 30 & \text { nd } \\ & \text { PR719-5 } & 20 & \text { nd } & \text { nd } & \mathbf{5 0} & \text { nd } & 15 & \mathbf{2 0 0} & \mathbf{6 0} & \text { nd } \\ 350 & \text { R904-7 } & 6 & \text { nd } & \text { nd } & \mathbf{6 0} & \text { nd } & 15 & \mathbf{3 0 0} & \mathbf{5 0} & \text { nd } \\ & \text { R904-5 } & 6 & \text { nd } & \text { nd } & \mathbf{6 0} & \text { nd } & \mathbf{1 5} & \mathbf{3 0 0} & \mathbf{4 0} & \text { nd }\end{array}$

$\begin{array}{llrllllllll}\text { SVT-4 } & & & & & & & & & & \\ 348 & \text { QR820-1 } & 5 & \text { nd } & \text { nd } & \mathbf{5 0} & \text { nd } & \mathbf{1 0} & \mathbf{2 0 0} & \mathbf{4 0} & \text { nd } \\ & \text { QR820-6 } & \text { nd } & \text { nd } & \text { nd } & \mathbf{5 0} & \text { nd } & \mathbf{1 0} & \mathbf{2 0 0} & \mathbf{3 0} & \text { nd } \\ 354 & \text { QR820-3 } & 15 & \text { nd } & \text { nd } & \mathbf{4 0} & \mathbf{1 0} & \mathbf{1 5} & \mathbf{1 5 0} & \mathbf{3 0} & \text { nd } \\ & \text { QR820-2 } & \mathbf{4 0} & \text { nd } & \mathbf{3} & \mathbf{6 0} & \mathbf{1 0} & \mathbf{5 0} & \mathbf{4 0 0} & \mathbf{8 0} & \mathbf{3 0}\end{array}$

$\underline{\text { SVT-5 }}$

$\begin{array}{lrrrrrrrrrr}267 & \text { P701-5 } & 15 & 7 & 4 & 50 & 50 & \text { nd } & 150 & 60 & \text { nd } \\ & \text { P708-5 } & 15 & \text { nd } & \mathbf{3} & \mathbf{6 0} & \text { nd } & \mathbf{1 0} & \mathbf{1 5 0} & \mathbf{5 0} & \text { nd } \\ 260 & \text { PR717-3 } & 20 & \text { nd } & \text { nd } & \mathbf{6 0} & \text { nd } & 10 & 120 & \mathbf{5 0} & \text { nd } \\ & \text { PR717-4 } & 20 & \text { nd } & \text { nd } & 70 & \text { nd } & \text { nd } & 120 & \mathbf{5 0} & \text { nd }\end{array}$

SVT-6

\begin{tabular}{rrrrrrrrrrr}
361 & PR725-5 & $\mathbf{1 5}$ & nd & nd & $\mathbf{6 0}$ & $\mathbf{1 0}$ & $\mathbf{3 0}$ & $\mathbf{1 5 0}$ & $\mathbf{4 0}$ & 30 \\
& PR726-1 & $\mathbf{5}$ & nd & nd & $\mathbf{5 0}$ & nd & $\mathbf{1 5}$ & $\mathbf{2 0 0}$ & $\mathbf{4 0}$ & nd \\
373 & Q803-6 & $\mathbf{3}$ & nd & nd & $\mathbf{5 0}$ & nd & $\mathbf{4 0}$ & $\mathbf{2 0 0}$ & $\mathbf{4 0}$ & nd \\
& PR727-3 & $\mathbf{3}$ & nd & $\mathbf{3}$ & $\mathbf{5 0}$ & $\mathbf{3 0}$ & $\mathbf{3 0}$ & $\mathbf{2 0 0}$ & $\mathbf{4 0}$ & nd \\
\hline
\end{tabular}

a Elements present in excess of the detection limit.

bnd-not defected. 
TABLE A-VII. Plutonia Analyses, GPHS SVT Series

Selected Elements (ppm)

\begin{tabular}{|c|c|c|c|c|c|c|c|c|c|}
\hline Pellet No. & $\mathbf{P}^{i}$ & Mg & $\mathrm{Ca}$ & Al & $\mathbf{S i}$ & Fe & $\mathrm{Cr}$ & $\mathrm{Ni}$ & $\mathbf{T i}$ \\
\hline SVT-1 & & & & & & & & & \\
\hline HF-232 & 5 & 直 & 130 & 20 & 15 & 60 & 15 & nd & 5 \\
\hline HF-238 & 5 & 1 & 200 & 25 & 70 & 70 & 15 & 5 & \\
\hline HF-261 & 5 & nd & 200 & 20 & 25 & 85 & 40 & nd & 7 \\
\hline $\mathrm{HF}-410$ & 2 & 3 & 400 & 25 & 45 & 110 & 35 & 5 & 7 \\
\hline
\end{tabular}

SVT-2

HF-355

HF-369

HF-273

HF-449

$\begin{array}{rrrrrrrrr}4 & \mathbf{2} & \mathbf{4 0} & \mathbf{2 5} & \mathbf{3 0} & \mathbf{6 5} & \mathbf{3 0} & \text { nd } & \mathbf{1 0} \\ 3 & \mathbf{2} & \mathbf{3 0} & \mathbf{1 5} & \mathbf{1 5} & \mathbf{4 5} & \mathbf{1 0} & \text { nd } & \mathbf{5} \\ 3 & 2 & \mathbf{4 0} & \mathbf{2 5} & \mathbf{7 0} & \mathbf{5 5} & \mathbf{2 5} & 7 & \mathbf{5} \\ 2 & 2 & \mathbf{4 0} & \mathbf{3 5} & \mathbf{5 0} & \mathbf{8 0} & \mathbf{3 0} & \mathbf{n d} & \mathbf{1 0}\end{array}$

SVT-3

$\begin{array}{rrlllllllr}\text { HF-350 } & \mathbf{3} & \text { nd } & \mathbf{2 0 0} & \mathbf{3 5} & \mathbf{2 0} & \mathbf{3 5} & \mathbf{1 0} & \text { nd } & \mathbf{2 0} \\ \text { HF-343 } & \mathbf{5} & \mathbf{1 0} & \mathbf{1 0 0} & \mathbf{3 5} & \mathbf{3 0} & \mathbf{2 0} & \mathbf{1 0} & \text { nd } & \mathbf{1 5} \\ \text { HF-454 } & \mathbf{2} & \text { nd } & \mathbf{2 0 0} & \mathbf{6 0} & \mathbf{5 0} & \mathbf{7 0} & \mathbf{6 0} & \text { nd } & \mathbf{2 0} \\ \text { HF-457 } & \mathbf{3} & \text { nd } & \mathbf{1 5 0} & \mathbf{3 5} & \mathbf{1 0} & \mathbf{2 0} & \mathbf{1 5} & \text { nd } & \mathbf{3}\end{array}$

SVT-4

HF-348

HF-354

HF-139

HF-162

$\begin{array}{rrrrrrrrr}4 & 3 & \mathbf{4 0} & \mathbf{4 0} & \mathbf{1 0} & \mathbf{3 0} & \mathbf{1 5} & \text { nd } & 7 \\ 3 & \mathbf{3} & \mathbf{5 0} & \mathbf{4 0} & \mathbf{1 5} & \mathbf{3 5} & \mathbf{2 5} & \text { nd } & 7 \\ 3 & 2 & \mathbf{3 0} & \mathbf{2 5} & \mathbf{8} & \mathbf{2 0} & \mathbf{2 5} & \text { nd } & 10 \\ 2 & 2 & 30 & \mathbf{2 0} & \mathbf{8} & \mathbf{2 5} & \mathbf{9} & \text { nd } & \mathbf{5}\end{array}$

SVT-5

$\begin{array}{lrrrrrrrrr}\text { HF-260 } & \mathbf{4 0}^{\text {b }} & \text { nd } & 30 & 320 & 15 & 20 & 5 & \text { nd } & 15 \\ \text { HF-267 } & 55^{\text {b }} & 2 & \mathbf{4 0} & 75 & 35 & 30 & 6 & \text { nd } & 15 \\ \text { HF-415 } & 6 & \text { nd } & 20 & \mathbf{4 0} & \mathbf{8} & 7 & \text { nd } & \text { nd } & 15 \\ \text { HF-426 } & 6 & \text { nd } & \mathbf{3 0} & \mathbf{6 0} & \mathbf{1 0} & 10 & \mathbf{1 5} & \text { nd } & \mathbf{2 0}\end{array}$

SVT-6

\begin{tabular}{lrrrrrrrrr} 
HF-189 & 3 & 3 & nd & 65 & 25 & 20 & nd & nd & 20 \\
HF-225 & 9 & 10 & 60 & 45 & 30 & 15 & nd & nd & 10 \\
HF-361 & $\mathbf{8}$ & 20 & 150 & 30 & 35 & 10 & 15 & nd & 20 \\
HF-373 & 2 & 4 & 130 & 15 & $\mathbf{4 5}$ & 20 & nd & nd & 20 \\
\hline
\end{tabular}

${ }^{a}$ Colorimetric Analysis.

${ }^{b} y$-Scan indicates $<20 \mathrm{ppm}$ for HF-260 and HF-267. 